\title{
Unsaturated Flow Modeling of a Retorted Oil Shale Pile
}

F. W. Bond

M. D. Freshley

G. W. Gee

October 1982

Prepared for the U.S. Department of Energy under Contract DE-AC06-76RLO 1830

Pacific Northwest Laboratory Operated for the U.S. Department of Energy by Battelle Memorial Institute 


\title{
DISCLAIMER
}

This report was prepared as an account of work sponsored by an agency of the United States Government. Neither the United States Government nor any agency thereof, nor any of their employees, makes any warranty, express or implied, or assumes any legal liability or responsibility for the accuracy, completeness, or usefulness of any information, apparatus, product, or process disclosed, or represents that its use would not infringe privately owned rights. Reference herein to any specific commercial product, process, or service by trade name, trademark, manufacturer, or otherwise, does not necessarily constitute or imply its endorsement, recommendation, or favoring by the United States Government or any agency thereof. The views and opinions of authors expressed herein do not necessarily state or reflect those of the United States Government or any agency thereof.

\author{
PACIFIC NORTHWEST LABORATORY \\ operated by \\ BATTELLE \\ for the \\ UNITED STATES DEPARTMENT OF ENERGY \\ under Contract DE-AC06-76RLO 1830
}

\begin{tabular}{|c|c|}
\hline \multicolumn{2}{|c|}{$\begin{array}{c}\text { Printed in the United States of America } \\
\text { Available from } \\
\text { National Technical Information Service } \\
\text { United States Department of Commerce } \\
5285 \text { Port Royal Road } \\
\text { Springfield, Virginia } 22151\end{array}$} \\
\hline \multicolumn{2}{|c|}{$\begin{array}{l}\text { NTIS Price Codes } \\
\text { Microfiche A01 }\end{array}$} \\
\hline \multicolumn{2}{|c|}{ Printed Copy } \\
\hline Pages & $\begin{array}{l}\text { Price } \\
\text { Codes }\end{array}$ \\
\hline $001-025$ & $\mathrm{~A} 02$ \\
\hline $026-050$ & $\mathrm{~A} 03$ \\
\hline $051-075$ & A04 \\
\hline $076-100$ & A05 \\
\hline $10:-125$ & A06 \\
\hline $126-150$ & A07 \\
\hline $151-175$ & $A 08$ \\
\hline $176-200$ & A09 \\
\hline $201-225$ & A010 \\
\hline $226-250$ & A011 \\
\hline $251-275$ & A012 \\
\hline $276 \cdot 300$ & A013 \\
\hline
\end{tabular}




\section{9}

PNL-4284

UC-91

UNSATURATED FLOW MODELING OF A RETORTED OIL SHALE PILE

F. W. Bond

M. D. Freshley

G. W. Gee

October 1982

Prepared for

the U.S. Department of Energy

under Contract DE-ACO6-76RLO 1830

Pacific Northwest Laboratory

Richland, Washington 99352 
SUMMARY

In recent years there has been a renewed interest in the recovery of crude oil from oil shale; however, there is much concern as to how to dispose of the huge quantities of spent shale that would be generated. The spent shales contain a large percentage of soluble salts and other constituents that may exceed permissible levels if they enter local surface and ground-water systems. The objective of this study was to demonstrate the capabilities of the UNSAT1D model for assessing this potential threat to the environment by understanding water movement through spent shale piles.

Infiltration, redistribution, and drainage of water in a spent shale pile were simulated with the UNSAT1D model for two test cases: 1) an existing $35 \mathrm{~m}$ pile, and 2) a transient pile growing at a rate of $10 \mathrm{~m} /$ year for 5 years. The first test case simulated three different layering scenarios with each one being run for 1 year. The second test case simulated two different initial moisture contents in the pile with each simulation being run for 30 years. Grand Junction and Rifle, Colorado climatological data were used to provide precipitation and potential evapotranspiration for a wet (1979) and dry (1976) year, respectively. Hydraulic properties obtained from the literature on Paraho process spent shale $\left[1.2 \mathrm{Mg} / \mathrm{m}^{3}\left(751 \mathrm{~b} / \mathrm{ft}^{3}\right)\right.$ and $\left.1.5 \mathrm{Mg} / \mathrm{m}^{3}\left(951 \mathrm{~b} / \mathrm{ft}^{3}\right)\right]$, soil, and clay were used as model input parameters to describe water retention and hydraulic conductivity characteristics. Plant water uptake was not simulated in either test case. The two test cases only consider the evaporation component of evapotranspiration, thereby maximizing the amount of water infiltrating into the pile.

The results of the two test cases demonstrated that the UNSAT1D model can adequately simulate flow in a spent shale pile for a variety of initial and boundary conditions, hydraulic properties, and pile configurations. The test cases provided a preliminary sensitivity analysis in which it was shown that the material hydraulic properties, material layering, and initial moisture content are the principal parameters influencing drainage from the base of a pile. Pile design, to minimize drainage, can be improved significantly by use of detailed hydrologic modeling similar to that described in this report. 


\section{ACKNOWLEDGMENTS}

This work was performed for the Department of Energy (Contract Number DE-AC06-76RLO 1830) under the guidance of Dr. R. E. Franklin. Support and encouragement for this work has been given by Dr. R. E. Wildung and Mr. J. M. Zachara of the Environmental Sciences Department of PNL and is appreciated. We also acknowledge the efforts of Dr. G. Bloomsburg of the University of Idaho who supplied most of the hydrologic properties data for Paraho shale, and M. E. Dodson and W. Wakamiya of the Water and Land Resources Department of PNL who helped in determining the effect of compaction on water permeability of Paraho shale. 
,

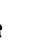

. 


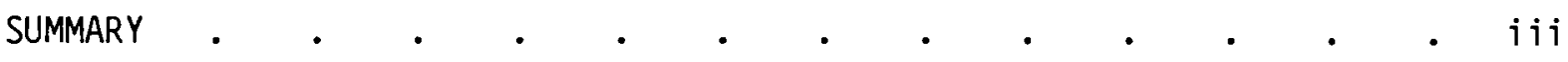

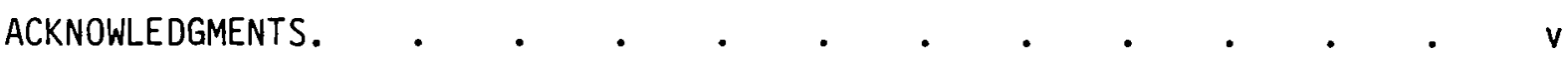

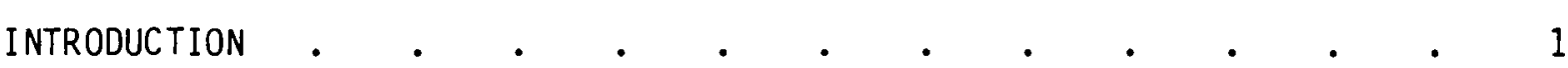

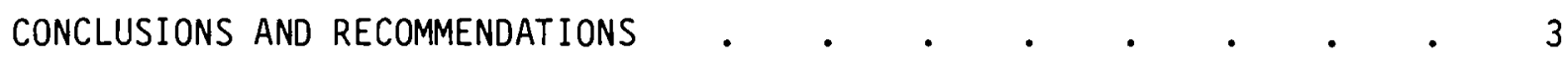

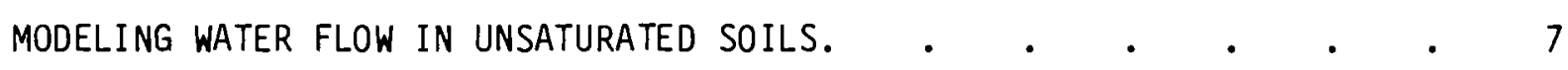

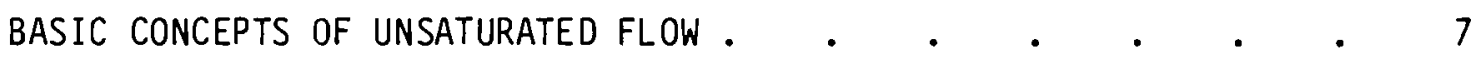

UNSATURATED FLOW MODEL UNSATID.

Input Data Requi rements . $\quad . \quad$. $\quad . \quad$. $\quad . \quad$. 10

Unsaturated Flow Simulation Technique . • . . . 12

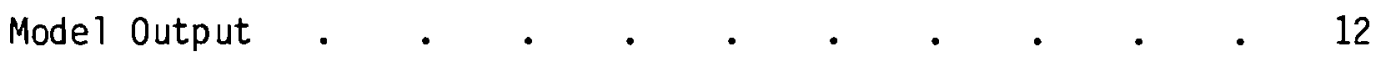

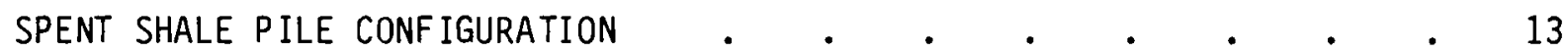

APPLICATION OF THE UNSATID MODEL TO SPENT OIL SHALE TEST CASES • • 17

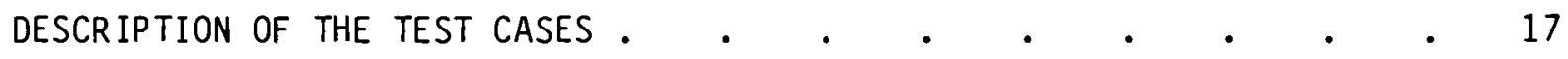

Existing Pile Test Case . . . . . . . . . . . 17

Transient Pile Test Case . . . . . . . . . . 18

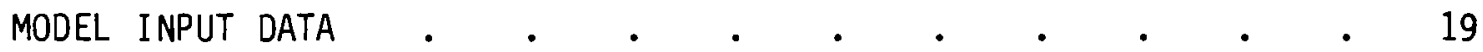

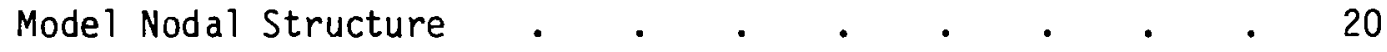

Material Properties . $\quad . \quad$. $\quad$. . . . 20

Initial Conditions . $\quad$. . . . . . . . 22

Boundary Conditions . . . . . . . . . . 24

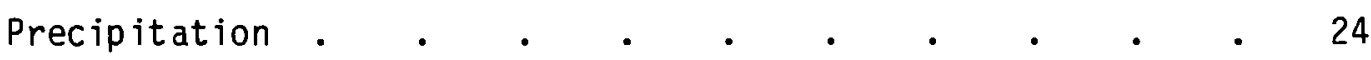

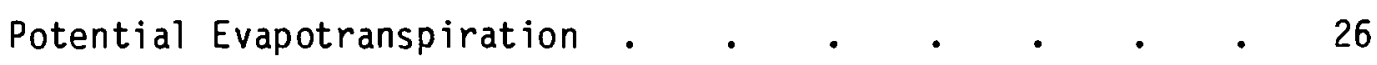

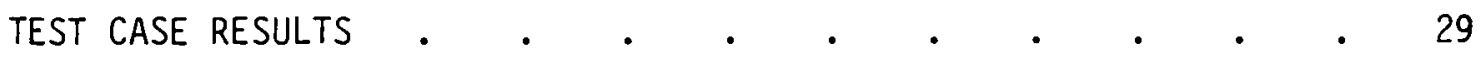

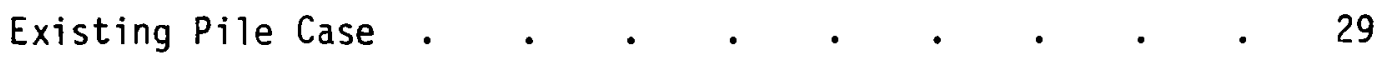




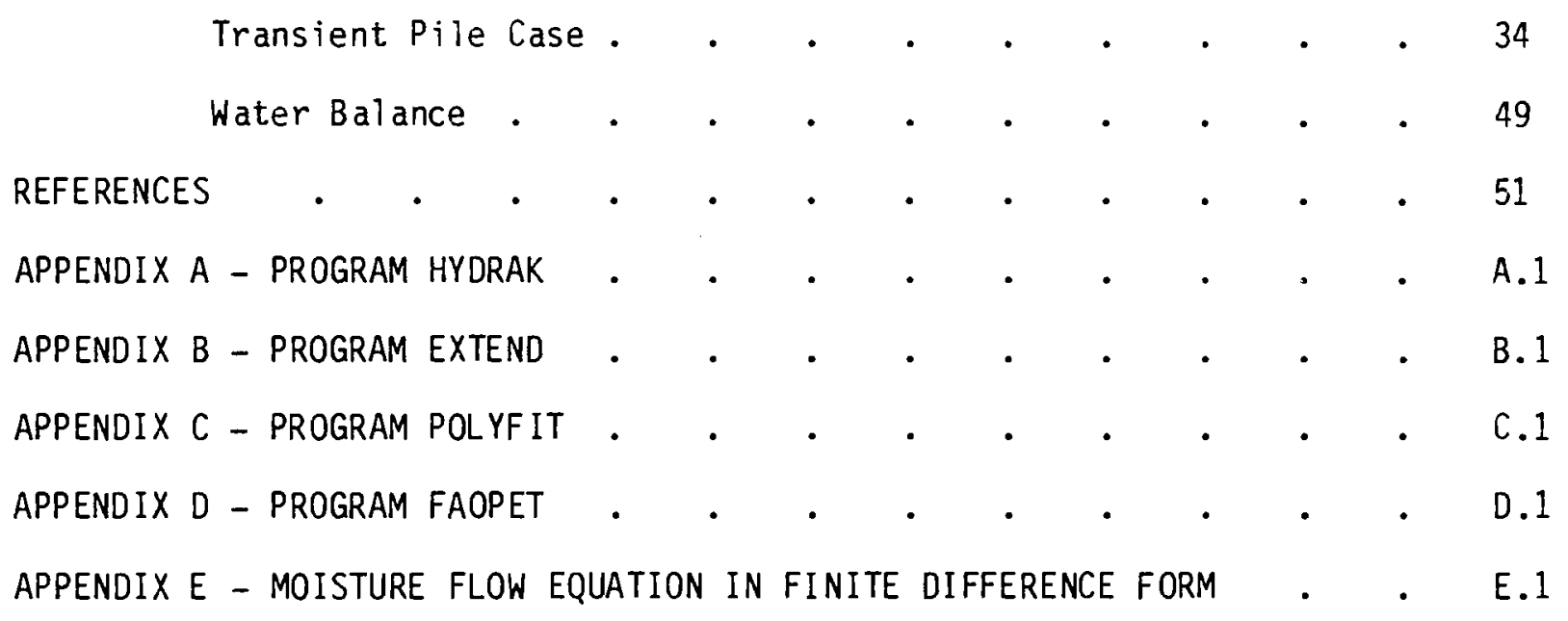




\section{FIGURES}

1 A Conceptual Head of Canyon Spent Shale Disposal Site . . . 14

2 Schematic of the Existing Spent Shale Pile . . . . . . 18

3 Schematic of the Transient Spent Shale Pile . . . . . . 19

4 Soil Moişture Characteristic Curves for Soil, 1.2 and $1.5 \mathrm{Mg} / \mathrm{m}^{3}$ Shale, and Clay . . . . . . . . 23

5 Hydraulif Conductivity Relationship for Soil, 1.2 and $1.5 \mathrm{Mg} / \mathrm{m}^{3}$ Shale, Topsoil and Clay . . . . . . 24

$6 \quad 1976$ Potential Evapotranspiration as Calculated by the by the Penman Method . . . . . . . . . . 28

$7 \quad 1979$ Potential Evapotranspiration as Calculated by the by the Penman Method . . . . . . . . . 28

8 Daily Distribution of Potential Evapotranspiration $\quad$. $\quad$. $\quad 29$

9 Water Content Versus Depth $(30.2 \mathrm{~m})$ on Days 1, 90, 180, 270, and 365 for the Three Scenarios for Existing Pile Case. . . 30

10 Water Content Versus Depth $(1.5 \mathrm{~m})$ on Days $1,90,180,270$, and 365 for the Three Scenarios for Existing Pile Case. . . 31

11 Water Content Versus Time at Depths 5, 15, $25 \mathrm{~cm}$ for the Three Scenarios for Existing Pile Case . . . . . . 33

12 Depth Versus Time Versus Moisture Content for the First Scenario of the Existing Pile Case. . . . . . . . 34

13 Transient Pile 1st Scenario - Moisture Profile on Days 1, $90,180,270$, and 365 of the 1st Year . . . . . . 36

14 Transient Pile 2nd Scenario - Moisture Profile on Days 1, $90,180,270$, and 365 of the 1st Year . . . . . . . 36

15 Transient Pile 1st Scenario - Moisture Profile on Days 1, $90,180,270$, and 365 of the 6 th Year . . . . . . 37

16 Transient Pile 2nd Scenario - Moisture Profile on Days 1, $90,180,270$, and 365 of the 6 th Year . . . . . 37

17 Transient Pile 1st Scenario - Moisture Profile on Days 1, $90,180,270$, and 365 of the 10th Year. . . . . . 38 
18 Transient Pile 2nd Scenario - Moisture Profile on Days 1, $90,180,270$, and 365 of the 10th Year. . . . . . 38

19 Transient Pile 2nd Scenario - Moisture Profile on Days 1, $90,180,270$, and 365 of the 12th Year . . . . . . 40

20 Transient Pile 2nd Scenario - Moisture Profile on Days 1, $90,180,270$, and 365 of the 13 th Year . . . . . 40

21 Transient Pile 2nd Scenario - Moisture Profile on Days 1, $90,180,270$, and 365 of the 15th Year

22 Transient Pile 1st Scenario - Moisture Profile on Days 1, $90,180,270$, and 365 of the 20th Year. . . .

23 Transient Pile 1st Scenario - Moisture Profile on Days 1, $90,180,270$, and 365 of the 30 th Year . . . .

24 Transient Pile 2nd Scenario - Moisture Profile on Days 1,

25 Transient Pile 2nd Scenario - Moisture Profile on Days 1, $90,180,270$, and 365 of the 30th Year.

25 Transient Pile 1st Scenario - Moisture Content Versus Time at Depths $0.0,0.05,0.1,0.2,0.5$, and $6.0 \mathrm{~m} .$.

27 Transient Pile 2nd Scenario - Moisture Content Versus Time at Depths $0.0,0.05,0.1,0.2,0.5$, and $6.0 \mathrm{~m}$.

28 Transient Pile 1st Scenario - Cumulative Water Flux Versus Time at Depths 10, 20,30, 40, and 55 m After 10 Years . . 46

29 Transient Pile 2nd Scenario - Cumulative Water Flux Versus Time at Depths 10, 20,30, 40, and $55 \mathrm{~m}$ After 10 Years

30 Transient Pile 1st Scenario - Cumulative Water Flux Versus

Time at Depths 10, 20,30, 40, and $55 \mathrm{~m}$ After 20 Years

31 Transient Pile 1st Scenario - Cumulative Water Flux Versus

Time at Depths 10, 20,30,40, and 55 m After 30 Years . .

32 Transient Pile 2nd Scenario - Cumulative Water Flux Versus

Time at Depths 10, 20, 30, 40, and 50 m After 20 Years

33 Transient Pile 2nd Scenario - Cumulative Water Flux Versus

Time at Depths 10, 20,30, 40, and 50 m After 30 Years

34 Transient Pile - Annual Water Flux (Drainage) Out the Base of the Spent Shale Pile Over the 30-yr Simulation Period 


\section{TABLES}

1 Match of the Particle Size Distributions for the Nihill

Channery Loam and the Gilat Loam from Mualem . . . . . 21

2 Sumnary of Material Properties and Initial Moisture

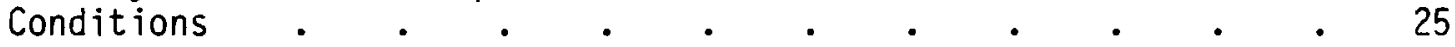

3 Polynomial Coefficients for the Soil Moisture Characteristic

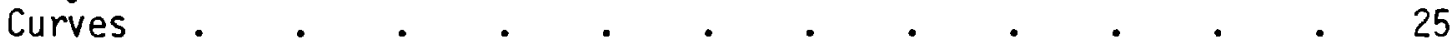

4 Polynomial Coefficients for the Hydraulic Conductivity Curves 
$:$

.

. 


\section{INTRODUCTION}

Worldwide depletion of petroleum resources has sparked an interest in the recovery of crude oil from oil shale. One of the primary concerns in determining the feasibility of the process is how to dispose of the huge quantities of spent shale that would be generated. A primary reason for concern is that oil shales were formed in a saline environment, so the spent shales contain a large percentage of soluble salts. In addition, processing shale at high temperature can release both inorganic and organic constituents that may exceed permissible concentration levels established by federal and state regulatory agencies. Leaching of these salts into local surface and ground-water systems poses a potential threat to the environment.

The ultimate objective of the project for which this work was conducted is to assess current spent shale disposal plans and to determine if they are environmentally safe. In order to make this assessment, models will be used to predict water and leachate movement in spent shale piles. The first step in understanding leachate movement in spent shale materials is to understand the water movement. The specific objective of this study was to demonstrate the capabilities of the UNSATID flow model for simulating one-dimensional vertical flow in spent shale piles.

To demonstrate its capabilities with regard to spent shale disposal, the UNSAT1D model was used to simulate two test cases: 1) an existing pile $35 \mathrm{~m}$ in height, and 2) a transient pile growing at a rate of $10 \mathrm{~m} / \mathrm{yr}$ for $5 \mathrm{yr}$. The test cases were designed to utilize and demonstrate as many of the UNSATID capabilities as possible. The existing pile was simulated for 3 scenarios using different densities of shale. Each scenario was run for $1 \mathrm{yr}$. The transient pile was simulated with two different initial moisture contents and each scenario was run for $30 \mathrm{yr}$. Grand Junction and Rifle, Colorado climatological data were used to provide precipitation and calculate potential evapotranspiration data for a wet (1979) and dry (1976) year, respectively. Hydraulic properties obtained from the literature for Paraho process spent shale $\left[1.2 \mathrm{Mg} / \mathrm{m}^{3}\left(751 \mathrm{~b} / \mathrm{ft}^{3}\right)\right.$ and $\left.1.5 \mathrm{Mg} / \mathrm{m}^{3}\left(951 \mathrm{~b} / \mathrm{ft}^{3}\right)\right]$, soil, and clay were used in the modeled cases to describe water retention and hydraulic conductivity characteristics. 
In the process of demonstrating the model capabilities, this study provides a preliminary sensitivity analysis regarding water movement in spent shale piles. Because literature rather than actual field data were used in many instances, actual fluxes, storage amounts, and moisture contents could not be predicted. However, the limited sensitivity analysis did provide some insight into the relative importance of, and the relationship between, some of the model input parameters.

This report is organized into five sections. Following the introduction, conclusions and recommendations are made based on the modeling results. The third section discusses the basic concepts of unsaturated flow and describes the UNSATID model. The fourth section describes the configurations of the spent shale piles modeled in this study. The last section describes the test cases, discusses the model input data, and presents the results of the two test case simulations. 


\section{CONCLUSIONS AND RECOMMENDATIONS}

The primary objective of this study was to assess water movement in spent shale piles using the unsaturated flow model UNSAT1D. In addition to demonstrating the model capabilities for handling complex, transient, layered flow systems, a sensitivity analysis was performed which tested the relative importance of several of the model input parameters. The results of the two test cases, simulating water redistribution and drainage for periods of time up to 30 years, show that key input parameters are the pile initial water content, the hydraulic properties of the spent shale and cover material, and the climatic variables including precipitation and surface evaporation.

The unsaturated flow model served to simulate precipitation and evaporation on an hourly basis and to predict infiltration rates with residence time in the environment for different embankment configurations, different material types with different initial water contents, different construction scenarios, and different climatic and boundary conditions. Potential Evapotranspiration (PET) was distributed on an hourly basis over the day, and the rate was controlled by the suction head in the surface soil layer. The difference between precipitation and PET provided a measure of the amount of water available for infiltration. The amount of infiltration with depth was calculated according to the hydraulic conductivity and the hydraulic gradient in individual layers.

The test cases provided a preliminary sensitivity analysis for water movement in retorted shale embankments although, of course, more thorough and systematic sensitivity analyses need to be performed.

The principal parameters evaluated were initial moisture content and hydraulic conductivity. Estimates of PET indicate that, although PET is far greater than precipitation, the distribution of rainfall throughout the year results in some water infiltration. Between $60 \%$ and $90 \%$ of the rainfall was lost to evaporation. If plant water uptake was simulated, evaporation and transpiration combined would further reduce the amount of infiltration. With the assumptions in this simulation, precipitation alone did not result in drainage from the base of an embankment in $30 \mathrm{yr}$ for the shale pile initially 
at $15 \%$ (dry weight basis) water content. For the test pile at this water content, significant storage capacity remained limiting the possibility of drainage for a number of years. However, surface infiltration became a significant factor when initial water content was increased, such as might occur for dust control, compaction, or disposal.

The initial moisture content of a pile influenced the amount of storage in the embankment which, in turn, influenced the water movement in and drainage from the embankment. At near saturation initial water levels, drainage occurred after the first year and continued for 30 years. After about 30 years, the pile approached an equilibrium state where the amount of drainage nearly equaled the amount of precipitation infiltrating at the surface. Water content will therefore likely be an important factor controlling leaching of solutes from a retorted shale embankment.

The permeability of shale at different compaction densities will also be an important factor influencing water movement in a retorted shale embankment. Permeability at the surface regulates the amount of infiltration whereas permeability with depth regulates redistribution and drainage. Higher permeabilities at the surface may result in increased downward flux and in certain instances increased upward flux due to evaporation. Lower permeabilities at depth may serve a useful purpose in restricting drainage but also may result in reduced storage capacity and perched water tables depending upon circumstances.

Recommendations for future work include studying additional shale pile configurations or disposal scenarios and utilizing some of the model capabilities not demonstrated in this study such as plant growth (transpiration) and snow melt modeling. The sensitivity analysis conducted in this study was only preliminary in nature, hence, a more detailed sensitivity analysis should be conducted. A more detailed analysis would look at the influence of different thicknesses of soil covers and liners, compaction densities of shale materials, layering scenarios, initial water contents, amounts of precipitation and evaporation, and lengths of simulation time periods. 
In order to provide confidence and credibility in UNSAT1D model predictions, the model results need to be validated with field measurements. Such a validation would require careful hydrologic characterization of a spent shale pile and detailed monitoring of climatic variables for an extended period of time ( 1 year or longer). It is possible that the large field lysimeter at Anvil Points, Colorado, currently managed by PNL, could be used to provide a set of detailed water balance measurements for field validation. 


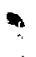

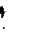

7 
MODELING WATER FLOW IN UNSATURATED SOILS

The following section provides an analysis of how water flows through unsaturated soils, as well as a general description of the unsaturated flow model (UNSAT1D) used in this study.

\section{BASIC CONCEPTS OF UNSATURATED FLOW}

The unsaturated zone is the transition region between the atmosphere and the saturated ground-water system. Passage of water through this zone is very dynamic and depends on detailed variations in the hydraulic properties of the water in the soil.

Rainfall, irrigation, and ponded water are the primary sources of water to the unsaturated zone. Redistribution or downward movement of this water through the soil occurs under the influence of gravity as long as there is a sufficient quantity present to overcome the restraining forces of capillary hydraulic potential.

Water is removed from the surface of the unsaturated zone by the processes of evaporation and/or transpiration. The rates of both processes depend directly on available solar energy and surface winds. Water also moves out the bottom of the unsaturated zone as drainage if the soil-water holding capacity is exceeded. Drained water may possibly enter the water table depending on its depth.

Water can also move within and be stored in the unsaturated zone. Water storage is characterized by a water content distribution. Water moves through and within a soil via two physical mechanisms: capillary Darcian flow (liquid phase) and vapor diffusion. Darcian flow is described by hydraulic conductivity and matric potential gradients, both of which are highly dependent on moisture content. Vapor diffusion controls actual surface evaporation and results from thermal gradients.

A soil is saturated when all void space (space not occupied by solid particles) is filled with water. An unsaturated soil contains air-filled void 
space as well as water. A measure of the quantity of water contained by a soil is called the water content which $c$ an be defined either on a volumetric basis (volume of water/total volume of soil, water and voids) or a mass basis (mass of water/mass of soil solids). Except where noted, we use the volumetric water content terminology throughout this report.

Movement of water in the unsaturated zone is always directed from areas of higher to those of lower potential energy (assuming isothermal conditions). Total soil water potential $(\psi)$ is expressed as (Feddes et al. 1978):

$$
\psi=\psi_{p}+\psi_{s}+\psi_{m}+\psi_{z}
$$

where

$$
\begin{aligned}
\psi_{\mathrm{p}}= & \text { the pneumatic potential arising from changes in external } \\
& \text { pressure } \\
\psi_{\mathrm{s}}= & \text { osmotic potential arising from the attraction forces of water } \\
& \text { to a higher solute concentration } \\
\psi_{\mathrm{m}}= & \text { the matric potential arising from capillary and adsorptive } \\
& \text { forces of the soil matrix } \\
\psi_{\mathrm{g}}= & \text { the gravitational potential expressing the potential energy of } \\
& \text { changes in relative elevation changes. }
\end{aligned}
$$

The negative of the gradient of total potential is the force causing water movement in a soil.

Water moves through different soils at different rates for the same hydraulic potential gradient as a result of their difference in hydraulic conductivity $[K(\theta)]$. The $K(\theta)$ represents the ability of a soil to transmit water from wet to dry locations. Water flux $\left(q_{L}\right)$ is described in terms of $K(\theta)$ by Darcy's law:

$$
q_{L}=-K(\theta) \frac{\partial h}{\partial z}
$$


where

$z=$ the relative elevation.

Hydraulic conductivity is a function of moisture content $(\theta)$, decreasing rapidly by several orders of magnitude from its maximum saturated values as water content decreases. Combining Equation (1) with the equation for water conservation and expressing potential in terms of suction head (h) yields the basic differential equation for unsaturated soil water flow in the vertical direction:

$$
c(h) \frac{\partial h}{\partial t}=\frac{\partial}{\partial z}\left[K(h)\left(\frac{\partial h}{\partial z}+1\right)\right]+S(z, t)
$$

where

$$
c(h)=\frac{-d \theta}{d h}
$$

is the soil-water capacity; $K(h)$ is expressed explicitly as a function of $h$ by means of the soil-water characteristic, which is usually represented by a single drying curve; and $S(z, t)$ is a plant root sink term. Depth $z$ in Equation (2) is positive downward from the surface, and soil-water flux is given by:

$$
q_{L}=K(h)\left(\frac{\partial h}{\partial z}+1\right)
$$

The review by Molz et a1. (1979) provides a summary of the current understanding of unsaturated flow.

UNSATURATED FLOW CODE UNSAT1D

The model used to simulate water movement in a spent shale pile was developed from the one-dimensional unsaturated ground-water flow code UNSAT1D. The UNSAT1D computer code was originally developed to describe water movement under typical agricultural conditions (Gupta et al. 1978). In 1981 the model and its auxiliary programs were revised and incorporated into an unsaturated flow modeling system (Bond et al. 1982). The UNSAT1D modeling 
system can be applied to any unsaturated flow problem in one-dimension. It is this modeling system which was applied to the oil shale test cases discussed in this report.

The UNSAT 10 model $c$ an be used to estimate surface infiltration, consumptive use by plants, vertical seepage (redistribution), and drainage to the saturated zone. The model is designed for use under varied field conditions. Application of water $c$ an be in the form of rain, sprinkler irrigation, or flooding. Actual evapotranspiration can be estimated as a function of moisture content and potential evapotranspiration using on-off, linear decrease, logrithmic decrease, or combination methods. The soil or solid waste profile can be homogeneous or layered and hydraulic properties can be defined as polynomials or mathematical equations. The root uptake capability incorporates root suction and root distribution, or the user can define his own mathematical model. The lower boundary conditions can be water table, flux, impermeable liner, or infinite. A simplified approach to predicting water application rates resulting from snow melt is operational as a subprogram to the model. Input Data Requirements

The input data required by UNSAT10 are dependent on the given problem. The following input information is necessary to define a model simulation of a specific site:

1. Depth of the soil profile and location of each soil layer. The maximum depth is the lower boundary condition location.

2. Type of lower boundary condition specified as a water table, no flow, or free drainage situation. Free drainage conditions are applicable if the water table is well below the simulated profile.

3. The soil hydraulic properties defined by a soil-water characteristic curve (water retention relationship) and hydraulic conductivity/ water content relationship for each soil type present in the profile.

4. The rainfall and potential evapotranspiration for each day of the simulation period, including the pattern of diurnal variation. Rainfall should be by hour and diurnal variation should be expressed as a fraction of daily amounts for each hour. 
5. The initial water content distribution over the soil profile as established by a water movement history.

6. Plant growth and water extraction behavior. This information must include a root density distribution as a function of the growth period and actual transpiration as some factor of the potential value when water is not limited.

The above list represents a considerable amount of data. The difficulty of unsaturated flow modeling is that many of the data are seldom available from direct measurements, and so must be estimated by various theoretical methods. Auxiliary programs to UNSATID have been developed which use various theoretical methods to provide the data required by the model. A list of these programs and a brief description of their function is provided below:

HYDRAK - Normally the relationship between suction head $(h)$ and water content $(\theta)$ (soil moisture characteristic curve) for a soil profile is measured in the laboratory. However, methods for direct determination of hydraulic conductivity $(K)$ as a function of $\theta$ or $h$ over the unsaturated range of interest are experimentally difficult to measure. As a result, the $K$ versus $\theta$ or $h$ relationship is normally determined by theoretical methods. Program HYDRAK was developed for estimating the $K$ versus $\theta$ or $h$ relationship which is needed by UNSAT1D. A more thorough description of HYORAK is presented in Appendix $A$.

EXTEND - Oftentimes data are not available for the high suction head/ low water content end of the soil moisture characteristic curve. Program EXTEND was develged to extrapolate additional data points at this end of the soil moisture characteristic curve. A more thorough description of EXTEND is presented in Appendix B.

POLYFIT - The soil moisture characteristic data and the hydraulic conductivity versus suction head data is normally entered into the UNSATID model in the form of polynomial expressions. Polynomial representations avoid large data storage requirements that would be associated with many soil layers and provide a convenient method for interpolation. Program POLYFIT was developed to fit these relationships on either a log-linear 
or a log-log scale and to calculate the coefficients of the polynomial expression which can be used directly in UNSATID. A more thorough description of POLYFIT is provided in Appendix $C$.

FAOPET - Oftentimes measurements of daily potential evapotranspiration (PET) for a given site, as required by the model, are not available. Program FAOPET can be used to estimate PET using the modified Blaney Criddle, Penman, Penman with correction, Radiation, and/or Pan Evaporation methods. A more thorough description of FAOPET is provided in Appendix $D$. Unsaturated Flow Simulation Technique

UNSAT1D solves the differential equation for unsaturated soil water flow (Equation 2) using a fully implicit finite difference method. By employing this method, the suction head $(h)$ is calculated over the profile at each time step (normally $1 \mathrm{hr}$ ). Mathematical details of the finite difference scheme are provided in Appendix E.

The fundamental assumption used in solving Equation (2) is that matric potential is a continuous physical quantity in the transition between soil layers. Accuracy of the finite difference solution is controlled by the mass balance error allowed over the nodal representation of the soil profile.

Model Output

The model output includes predictions of soil water potential (suction), moisture content, and soil water flux rate at each node (depth increment) for each time interval (hourly for the first day and daily for the remainder of the simulation). The results can be in the form of lineprinter listings, binary files, or Calcomp plots. 


\section{SPENT SHALE PILE CONFIGURATION}

The retorting process involves crushing high grade oil shales and heating them until economic recovery of shale oil is achieved. The primary waste products are retorted (spent) oil shale and retort water. Large volumes of spent shale, retort water and other process and mining related wastes will likely be disposed of to the ground. At the present, no large waste shale piles exist and detailed disposal plans have not yet been developed. However, two general approaches are being considered: head of canyon fill and mesa disposal.

The canyon fill approach has been proposed for a number of containment sites with markedly different dimensions and physiographic characteristics (Wildung and Zachara 1981). Despite these differences, some common features would be applicable to all sites (see Figure 1). Generally, commercial disposal site development would begin with the removal and storage of surface materials for later use in revegetation. Retaining dams of rock, earthen fi11, concrete and/or compacted spent shale would then be constructed to form a catchment basin. The basin would be lined, possibly with a layer of compacted spent shale, and filled with spent shale or other process wastes (Wildung and Zachara 1980). Impoundment dams would bypass stream flows under or around the fill material (U.S. Department of Interior 1977) and drainage systems will be constructed to retain runoff or leakage from the pile to facilitate evaporation (Wildung and Zachara 1980). The height of the pile and the area covered by the spent shale would vary greatly depending on the dimensions of the canyon being filled. Estimates of pile height range from tens of meters up to a maximum of $300 \mathrm{~m}$ with the average being around $100 \mathrm{~m}$ (DOI 1977, Cloninger 1978, Rio Blanco 1981).

The mesa disposal option is simply a disposal system where large spent shale piles would be constructed on flat terrain. Pile heights would likely not be as great as in the canyon fill approach and more attention would be paid to erosion control and slope stability problems. The modeling effort described in this report is applicable to both disposal options. 


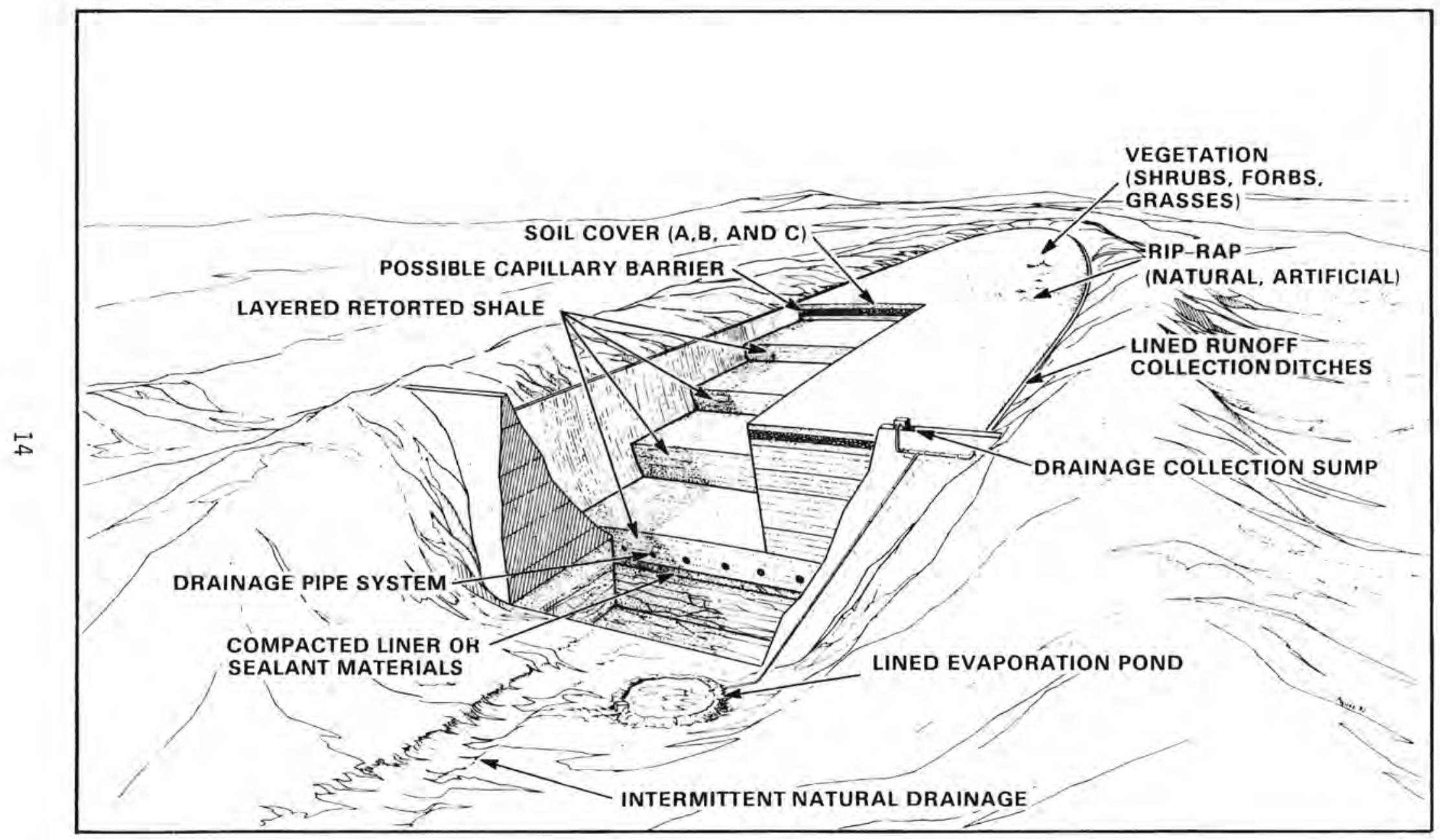

FIGURE 1. A Conceptual Head of Canyon Spent Shale Disposal Site 
Retort water may be disposed of by several different methods. The disposal methods of particular interest to this study are direct disposal (either with or without treatment) to the shale pile, and application of the water to the shale pile for dust control and/or stabilization.

The test case simulations discussed in the next section were designed to represent the current conceptualization of spent shale pile configuration. As a first attempt at simulating the flux through a retorted oil shale pile, a one-dimensional unsaturated flow code was used. This one-dimensional code simulates flow in a hypothetical vertical column in the center of the pile shown in Figure 1 .

Merino and Crookston (1977) suggest that spent shales will contain as much moisture as 15\% on a weight dry basis. The Paraho retorted shale has an optimum Proctor (compaction) moisture content in excess of $20 \%$ (dry weight basis). The initial moisture content of the spent shale will depend largely upon the amount required for pile stability (compaction). This may vary from as 10 as $5 \%$ (dry weight) to more than $20 \%$ (dry weight), depending on the material and the processing conditions. 
.

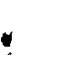

$\checkmark$ 
APPLICATION OF THE UNSAT1D MODEL TO

SPENT OIL SHALE TEST CASES

The application of the UNSAT1D model to two test cases is discussed in this section. The principal intent of simulating these test cases is to demonstrate the capabilities of the model to simulating water movement in spent shale piles. In addition to demonstrating the model, a preliminary sensitivity analysis was conducted which provided some insight into the relative importance of, and the relationship between, some of the model input parameters.

The first part of this section describes the test cases, the second part discusses the input data, and the last part presents the results of the test case simulations. In many instances actual field data were not available so values from the literature were used. The test cases described below were not intended to simulate an actual waste disposal pile, but rather they were intended to demonstrate model capabilities while at the same time establishing a basic understanding of how selected parameters effect water movement in spent shale piles.

\section{DESCRIPTION OF THE TEST CASES}

Two test cases were defined and simulated in order to demonstrate the capabilities of the UNSAT1D model. The first test case looked at the movement of water in an existing spent shale pile for three different material layering configurations. The second test case looked at water movement and redistribution during transient conditions of pile growth for two different initial moisture content scenarios. A detailed description of each test case is provided below.

Existing Pile Test Case

The existing pile test case assumed that the pile was al ready in place with a soil cap and had reached an equilibrium moisture content (Figure 2). Three UNSAT1D model runs were made for three hypothetical material layering conf igurations: 


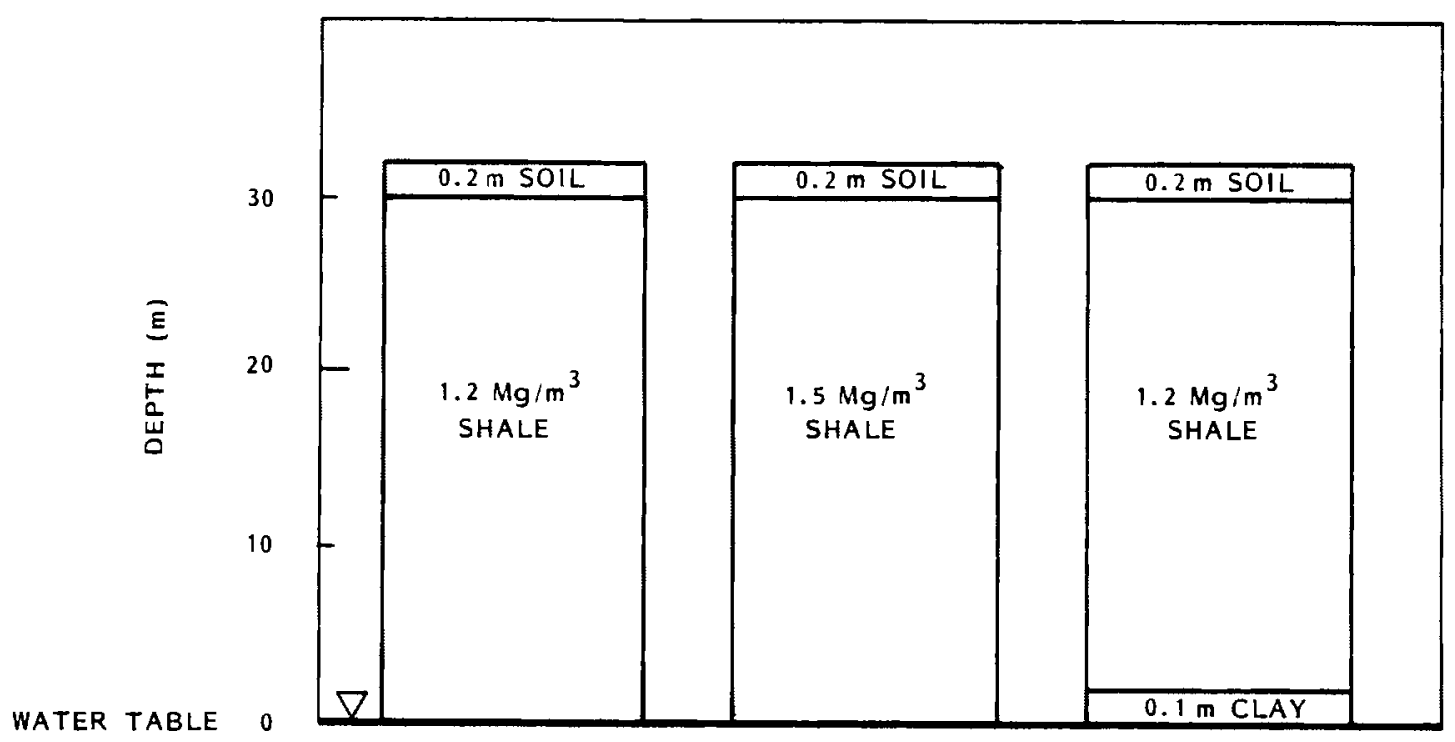

FIGURE 2. Schematic of the Existing Spent Shale Pile

1. $30 \mathrm{~m}$ of $1.2 \mathrm{Mg} / \mathrm{m}^{3}\left(75 \mathrm{lb} / \mathrm{ft}^{3}\right)$ shale covered by $0.2 \mathrm{~m}$ of soil

2. $30 \mathrm{~m}$ of $1.5 \mathrm{Mg} / \mathrm{m}^{3}\left(95 \mathrm{lb} / \mathrm{ft}^{3}\right)$ shale covered by $0.2 \mathrm{~m}$ of soil

3. A $0.1 \mathrm{~m}$ clay liner overlaid by $30 \mathrm{~m}$ of $1.2 \mathrm{Mg} / \mathrm{m}^{3}$ shale which is covered with $0.2 \mathrm{~m}$ of soil.

The change in layering was the only difference between the three scenarios. All other parameters remained constant throughout a 1 year simulation period.

\section{Transient Pile Test Case}

The transient pile growth test case is considered more realistic than the existing pile case in that it simulates water movement in the spent shale while the pile is under construction, as well as the long term movement in the resulting established spent shale pile. The test case (Figure 3 ) is based upon the construction of a $50 \mathrm{~m}$ shale pile in $10 \mathrm{~m}$ lifts over a period of 5 years. It was assumed that a $10 \mathrm{~m}$ layer of shale was added on the first day of each year and then was exposed to environmental conditions for the entire year. A $5 \mathrm{~m}$ thick layer of soil was assumed to exist between the water table and the lower layer of shale. The lowest $5 \mathrm{~m}$ of shale was assigned a compaction density of $1.5 \mathrm{Mg} / \mathrm{m}^{3}$, while the remainder of the shale $(44.5 \mathrm{~m})$ was assigned a density of $1.2 \mathrm{Mg} / \mathrm{m}^{3}$. At the end of the 5 year pile growth 


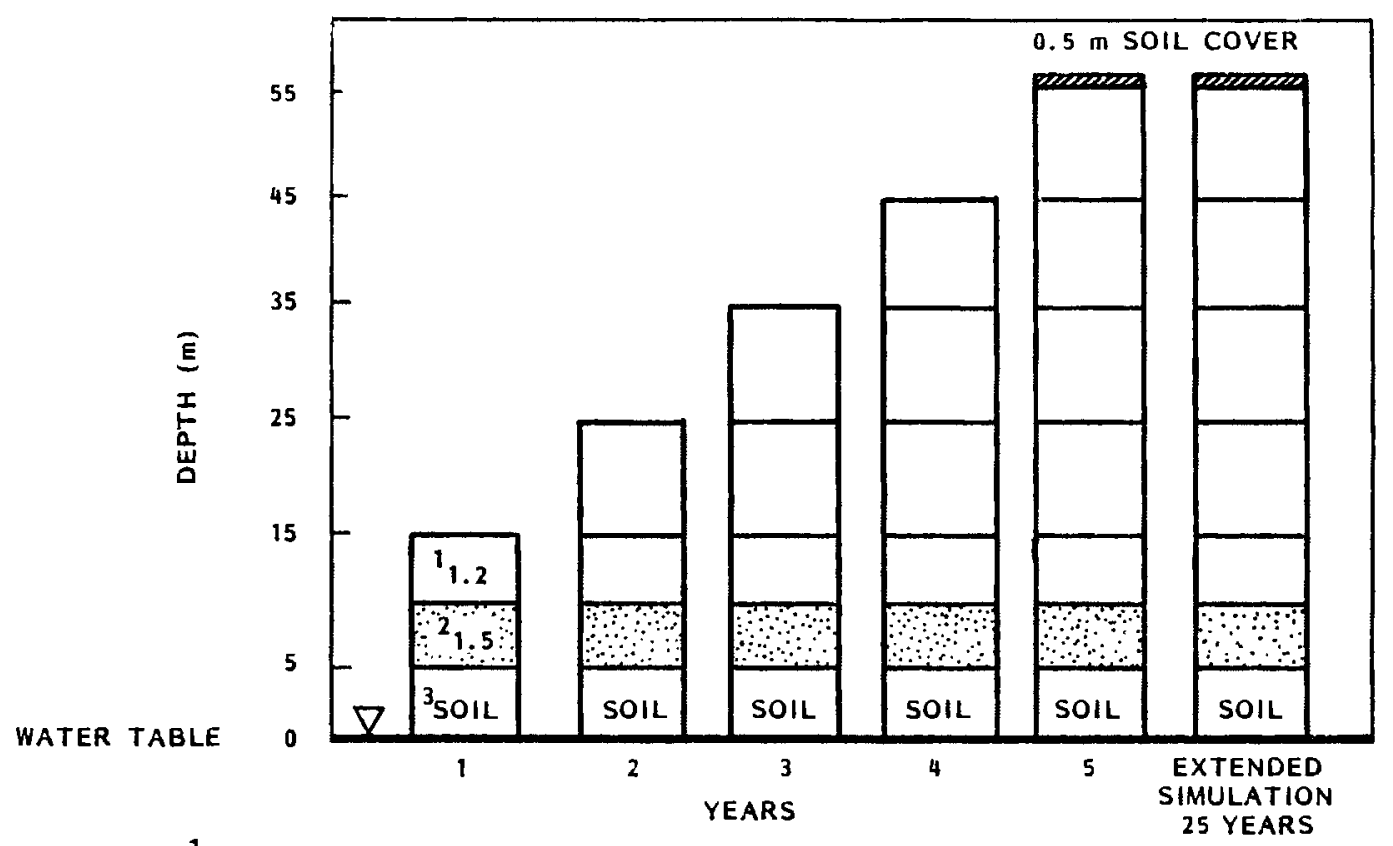

${ }^{1}$ Unless specjified, all spent shale lifts are at a density of $1.2 \mathrm{mg} / \mathrm{m}^{3}$.

$25 \mathrm{~m}$ of shale compacted to $1.5 \mathrm{mg} / \mathrm{m}^{3}$.

$35 \mathrm{~m}$ of soil between the $1.5 \mathrm{mg} / \mathrm{m}^{3}$ shale and the water table.

FIGURE 3. Schematic of the Transient Spent Shale Pile

period, the pile was capped with $0.5 \mathrm{~m}$ of soil and the model was run for 25 additional years. The total simulation time of 30 years was chosen as the preliminary period of interest.

Two different initial moisture contents in the shale were tested with the mode1. In the first case, the shale material was assigned an initial moisture content of $15 \%$ dry weight (Merino and Crookston 19.77). In the second case, the $1.2 \mathrm{Mg} / \mathrm{m}^{3}$ and $1.5 \mathrm{Mg} / \mathrm{m}^{3}$ shale were assigned initial moisture contents of $30 \%$ and $26 \%$ dry weight, respectively. The $15 \%$ dry weight moisture content is near normal while the higher moisture contents are almost at saturation.

\section{MODEL INPUT DATA}

Much of the same input data were used in the two test cases. In instances where field data were not available, data obtained from the literature or realistic approximations based on the literature were used. The actual data used in the model for the two cases are presented below. 
Model Nodal Structure

The UNSAT1D model simulates one-dimensional flow in a vertical column, where the finite difference nodal structure is simply a line of nodes. The model node structure is different for the two cases as described below.

Existing Pile - Scenarios 1 and 2 of the first test case used 29 vertical nodes and scenario 3 used 31 . Twelve nodes were placed in the surface soil layer and 17 nodes in the shale. Two additional nodes were placed in the clay layer of scenario 3 . The majority of the nodes were placed near the surface because that is where most of the water movement occurred in the 1 year simulation period.

Transient Pile - The same nodal configuration was used for the 2 scenarios of the second test case. The number of nodes changed depending on the growth stage of the pile with the total number ranging between 34 and 58. The nodes were fairly evenly spaced except for additional nodes placed at the surface and at the interface between adjacent lifts. Material Properties

The same materials were used in both test cases; soil, $1.2 \mathrm{Mg} / \mathrm{m}^{3}$ shale, $1.5 \mathrm{Mg} / \mathrm{m}^{3}$ shale, and clay. The soil moisture characteristics and the hydraulic conductivity relationships for these materials, as required by the model, were obtained from the literature (Bloomsburg and Wells 1978, Mualem 1976a). The literature values obtained were either actual measurements for material obtained from the Paraho retorting process, or they were chosen for materials that are very similar to Paraho materials.

Laboratory measurements are currently being made at PNL for materials obtained from the Paraho retorting process. These data will be used in future model runs. Preliminary results were used to influence material properties in the second test case as described below.

The UNSAT1D model requires the relationship between moisture content $(\theta)$, suction head $(h)$, and hydraulic conductivity $(K)$ for each material. The procedure for obtaining this information is to first measure the relationship 
between $\theta$ and $h$ in the laboratory, and then to compute the $\theta$ vs. K relationship by published empirical methods (Maulem 1976b). An auxiliary program to the UNSAT1D mode1, HYDRAK (Appendix $A$ ), was used to compute the $\theta$ vs. $K$ relationship by the Mualem method.

The soil covering considered in this modeling effort is the Nihill Channery Loam. The Nihill is derived from mixed Green River and Wasatch alluvium obtained near the Paraho site. Measured hydraulic properties of this soil are unavailable, so a substitution was made using an unpublished particle size analysis for Gilat loam from A Catalog of the Hydraulic Properties of Unsaturated Soils by Mualem (1976a). Mualem lists the hydraulic properties of a wide range of soils collected from the literature. Table 1 shows the match of particle size distributions.

Measured hydraulic properties for spent shale $\left(1.2\right.$ and $\left.1.5 \mathrm{Mg} / \mathrm{m}^{3}\right)$ were obtained from the Agricultural Engineering Department, University of Idaho (Bloomsburg and Wells 1978). Samples were provided to the University of Idaho by the U.S Bureau of Mines (USBM) from the Paraho Retort at the Anvil Points site. The samples were sieved to $9.5 \mathrm{~mm}$ prior to shipping. Further sieving reduced the particle size to $2 \mathrm{~mm}$ and finer to accommodate the spent shale in a small test apparatus.

The soil moisture characteristic data obtained from the University of Idaho were incomplete for high values of suction head. Values of moisture content in the high range of suction head were calculated using an auxiliary program to UNSATID called EXTEND (Appendix B).

TABLE 1. Match of the Particle Size Distributions for the Nihill Channery Loam and the Gilat Loam from Mualem (1976a)

\begin{tabular}{|c|c|c|}
\hline $\begin{array}{c}\text { Size } \\
\text { Fraction }\end{array}$ & $\begin{array}{c}\text { Nihill } \\
\text { Channery Loam } \\
\text { (a) }\end{array}$ & Gilat Loam \\
\hline sand & $48 \%$ & $48 \%$ \\
\hline silt & $29 \%$ & $32 \%$ \\
\hline clay & $23 \%$ & $20 \%$ \\
\hline
\end{tabular}

(a) Arithmetic mean of four samples 
A clay liner was used in the third scenario of the existing pile test case. The measured data on the clay liner is from a uranium mill tailings study at the Morton Ranch site in central Wyoming by Nelson et al. (1980). The sample tested was an interbedded silty claystone of the Wasatch Formation taken near the Morton Ranch.

The soil moisture characteristic curves for the four material types are shown in Figure 4. The hydraulic conductivity relationships for the four materials, as calculated by program HYDRAK, are shown in Figure 5 .

As indicated above, preliminary PNL laboratory measurements of permeability for spent shale indicated that field permeabilities of $1.2 \mathrm{Mg} / \mathrm{m}^{3}$ shale may be higher than those measured by the University of Idaho. As a result of these findings, $1.2 \mathrm{Mg} / \mathrm{m}^{3}$ shale permeabilities in the transient pile test case were increased by an order of magnitude over those used in the existing pile case.

A summary of the material properties for the two cases is presented in Table 2.

Once the soil moisture characteristics and conductivity relationships are available, it is necessary to fit them with polynomial expressions of suction head, which are then used by the UNSAT10 model. Using polynomial functions avoids large data storage requirements and provides an efficient means of interpolation between data points. An auxiliary program to the UNSAT1D model, POLYFIT (Appendix C), was used for fitting these relationships with polynomials.

The polynomial coefficients for the soil moisture characteristic and conductivity relationships for the four materials are shown in Tables 3 and 4. In most cases the curves were broken into two subsets and each subset was fit with a polynomial expression.

\section{Initial Conditions}

Initial conditions refers to the moisture content in the materials when they are initially placed in the pile. The initial conditions were different for the two cases as described below. 


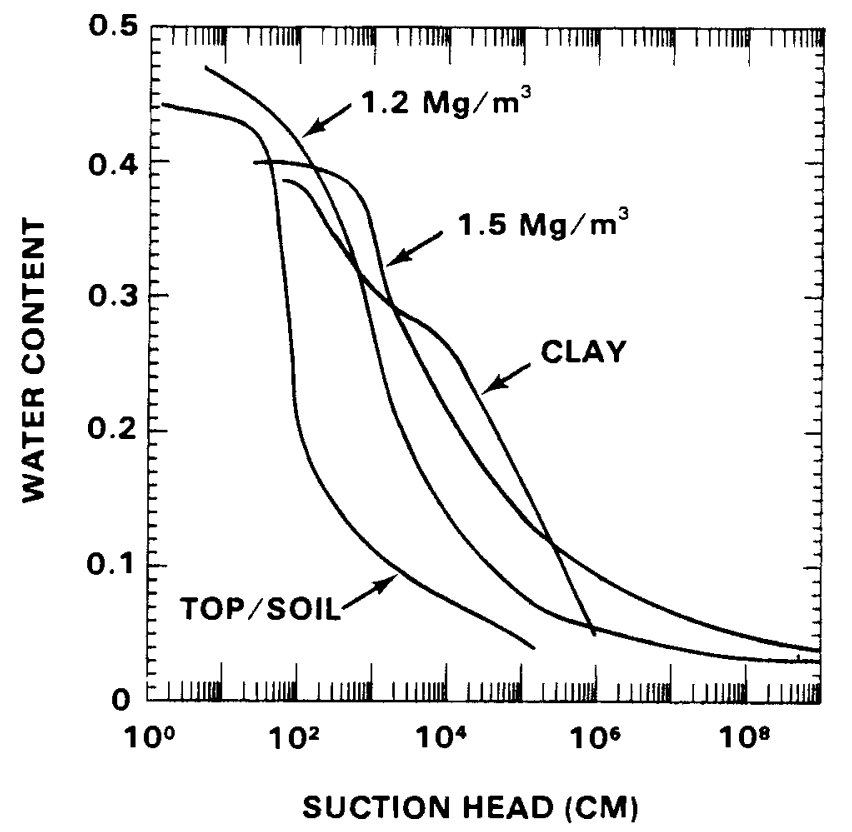

FIGURE 4. Soil Moisture Characteristic Curves for Soil, 1.2 and $1.5 \mathrm{Mg} / \mathrm{m}^{3}$ Shale, Topsoil, and Clay

Existing Pile. Equilibrium initial conditions were used in all existing pile runs. Equilibrium conditions are the moisture content distribution that would be realized if the pile was saturated and allowed to drain under normal field conditions. Values of suction head corresponding to the initial moisture content at each node are used in the model.

Transient Pile. The initial moisture conditions in the transient pile test case were different for the two scenarios simulated. In the first scenario, the pile was initially set at a moisture content of $15 \%$ dry weight. This relatively low moisture content (compared to saturation) left a significant amount of storage capacity remaining in the pile. In the second scenario the initial moisture was set near saturation, thereby decreasing the storage capacity of the pile and maximizing the potential for drainage out the bottom.

A summary of the initial conditions for the two cases is shown in Table 2. 


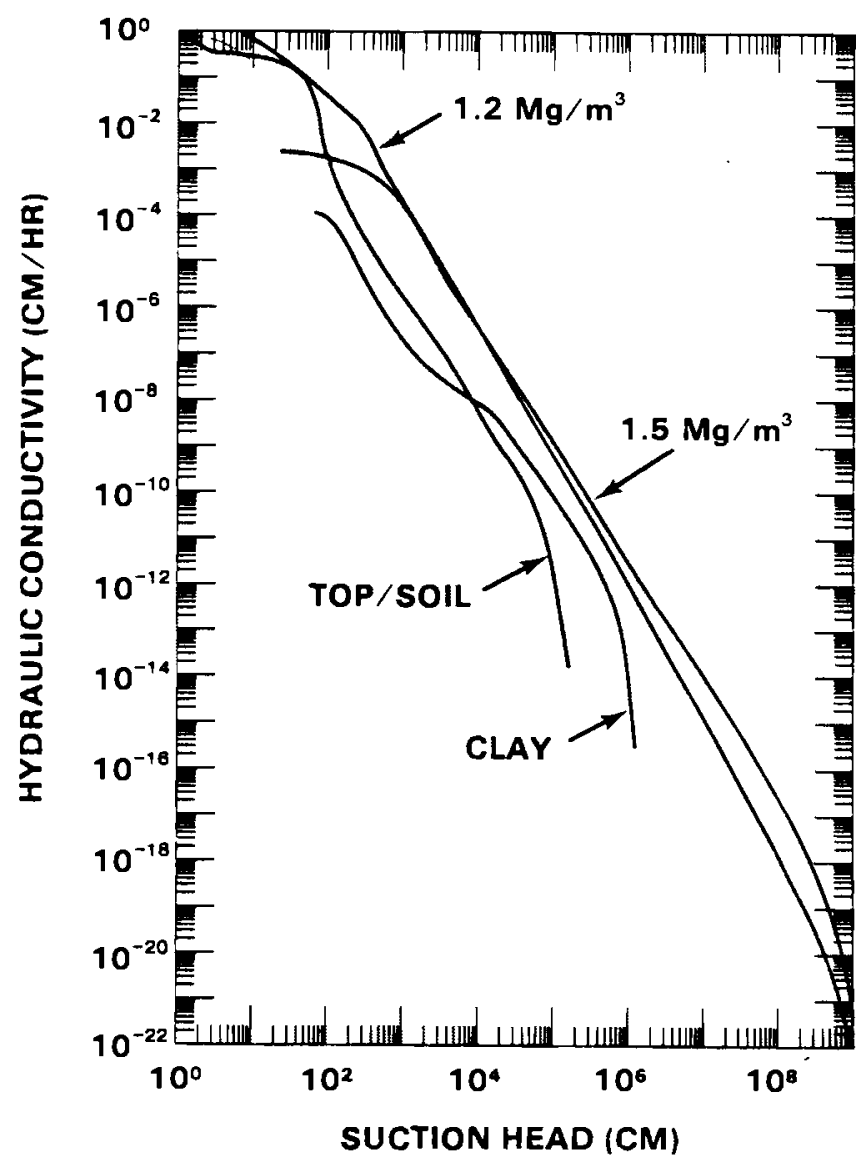

FIGURE 5. Hydraulic Conductivity Relationship for Soil, 1.2 and $1.5 \mathrm{Mg} / \mathrm{m}^{3}$ Shale, Topsoil and Clay

\section{Boundary Conditions}

The boundary conditions were defined as a flux condition at the surface and $a$ held (constant) water table condition at the base of the profile in both test cases. Precipitation and evaporation were the only surface flux conditions considered. Transpiration was not a factor because a plant cover (revegetation) was not simulated in either test case.

\section{Precipitation}

The climate of the Piceance basin is semi-arid-steppe (Wymore et al. 1974). Large climatic variations in short distances and in time are common. Winters are cold with accumulation of snowfall. The summers are hot with low relative humidity. Summer rains occur as scattered showers from thunderstorms. The potential for surface infiltration is greatest in the winter and spring. 
TABLE 2. Summary of Material Properties and Initial Moisture Conditions

$\begin{array}{lcccc}\text { Existing Pile } & \begin{array}{c}\text { Saturated } K \\ (\mathrm{~m} / \mathrm{sec})\end{array} & \begin{array}{c}\text { Initial Moisture } \\ \text { Content }\end{array} & \begin{array}{c}\text { Saturated Mo isture } \\ \text { Content }\left(\mathrm{cm}^{3} / \mathrm{cm}^{3}\right)\end{array} \\ \text { Soil } & 2.00 \times 10^{-6} & \text { Equilibrium } & 0.44 \\ 1.2 \mathrm{Mg} / \mathrm{m}^{3} \text { shale } & \begin{array}{c}1.87 \times 10^{-6} \\ 1.5 \mathrm{Mg} / \mathrm{m}^{3} \text { shale }\end{array} & 7.38 \times 10^{-9} & " & 0.47 \\ \text { Clay } & 2.78 \times 10^{-10} & " & 0.40\end{array}$

Transient Pile

Initial Moisture Content

\begin{tabular}{|c|c|c|c|c|c|c|}
\hline & \multirow[b]{3}{*}{$\begin{array}{c}\text { Saturated K } \\
(\mathrm{m} / \mathrm{sec})\end{array}$} & \\
\hline & & \multicolumn{4}{|c|}{\begin{tabular}{l}
\multicolumn{1}{l}{ Initial Moisture Content } \\
Ist Scenario
\end{tabular}} & \multirow{2}{*}{$\begin{array}{l}\frac{\text { Saturation }}{\text { Vol }} \\
\left(\mathrm{cm}^{3} / \mathrm{cm}^{3}\right) \\
\end{array}$} \\
\hline & & $\begin{array}{l}\text { Dry Wt } \\
(\%)\end{array}$ & $\begin{array}{c}\text { Vol } \\
\left(\mathrm{cm}^{3} / \mathrm{cm}^{3}\right)\end{array}$ & $\begin{array}{l}\text { Dry wt } \\
(\%)\end{array}$ & $\begin{array}{c}\text { Vol } \\
\left(\mathrm{cm}^{3} / \mathrm{cm}^{3}\right)\end{array}$ & \\
\hline Soil Cap & $2.00 \times 10^{-6}$ & - & 0.12 & 一 & 0.12 & 0.44 \\
\hline $1.2 \mathrm{Mg} / \mathrm{m}^{3}$ shale & $1.87 \times 10^{-5}$ & 15 & 0.18 & 30 & 0.36 & 0.47 \\
\hline $1.5 \mathrm{Mg} / \mathrm{m}^{3}$ shale & $7.38 \times 10^{-9}$ & 15 & 0.23 & 26 & 0.40 & 0.40 \\
\hline Soil (bottom) & $2.00 \times 10^{-6}$ & - & equil & - & equil & 0.44 \\
\hline
\end{tabular}

TABLE 3. Polynomial Coefficients for the Soil Moisture Characteristic Curves

\begin{tabular}{|c|c|c|c|c|c|c|c|}
\hline \multirow{2}{*}{$\begin{array}{c}\text { Material/ } \\
\text { Subset } \\
\end{array}$} & \multicolumn{6}{|c|}{ Coefficients } & \multirow[t]{2}{*}{$\begin{array}{c}\text { Subset } \\
\text { Dividing } \\
\text { Point } \\
\text { (Head } \\
\text { in cm) }\end{array}$} \\
\hline & A & $B$ & C & $D$ & $E$ & $F$ & \\
\hline \multicolumn{8}{|c|}{$1.2 \mathrm{Mg} / \mathrm{m}^{3}$ Shale } \\
\hline Subset 1 & 0.455 & 0.062 & -0.081 & 0.033 & -0.007 & & 403 \\
\hline Subset 2 & 1.429 & -0.706 & 0.139 & -0.012 & $-4.25 \times 10^{-4}$ & & \\
\hline \multicolumn{8}{|c|}{$1.5 \mathrm{Mg} / \mathrm{m}^{3}$ Shale } \\
\hline Subset 1 & -0.213 & 1.209 & -1.034 & -0.358 & -0.046 & & 423 \\
\hline Subset 2 & 0.996 & -0.321 & 0.038 & -0.002 & & & \\
\hline \multicolumn{8}{|l|}{ Soil } \\
\hline Subset 1 & 0.461 & -0.217 & 0.705 & -1.065 & 0.728 & -0.184 & 37 \\
\hline Subset 2 & 3.173 & -3.727 & 1.823 & -0.444 & 0.053 & -0.002 & \\
\hline \multicolumn{8}{|l|}{ Clay } \\
\hline Subset 1 & 0.570 & -0.103 & 0 & 0.002 & & & 9,901 \\
\hline Subset 2 & 0.685 & -0.106 & & & & & \\
\hline
\end{tabular}


TABLE 4. Polynomial Coefficients for the Hydraulic Conductivity Curves

\begin{tabular}{|c|c|c|c|c|c|c|c|}
\hline \multirow{2}{*}{$\begin{array}{c}\text { Material/ } \\
\text { Subset }\end{array}$} & \multicolumn{6}{|c|}{ Coefficients } & \multirow{2}{*}{$\begin{array}{l}\text { Subset Divid- } \\
\text { ing Point } \\
\text { (Head in } \mathrm{cm} \text { ) }\end{array}$} \\
\hline & A & $B$ & $C$ & D & $E$ & $F$ & \\
\hline \multicolumn{8}{|c|}{$1.2 \mathrm{Mg} / \mathrm{m}^{3}$ Shale } \\
\hline Subset 1 & 0.461 & -0.995 & 0.384 & -0.293 & -0.048 & -0.002 & - \\
\hline \multicolumn{8}{|c|}{$1.5 \mathrm{Mg} / \mathrm{m}^{3}$ Shale } \\
\hline Subset 1 & -2.700 & 1.346 & -0.194 & & & & \\
\hline Subset 2 & -1.084 & 0.000 & 0.000 & -0.196 & -0.036 & -0.002 & 423 \\
\hline \multicolumn{8}{|l|}{ Soil } \\
\hline Subset 1 & -0.042 & -0.868 & 0.000 & 0.000 & 0.591 & -0.323 & 47 \\
\hline Subset 2 & 38.330 & -60.655 & 37.669 & -12.261 & 1.981 & -0.126 & \\
\hline \multicolumn{8}{|l|}{ Clay } \\
\hline Subset 1 & -33.971 & 43.785 & -21.302 & 3.572 & 0.000 & -0.036 & $1.3 \times 10^{4}$ \\
\hline Subset 2 & 161.10 & -104.40 & 21.622 & -1.518 & & & \\
\hline
\end{tabular}

Precipitation data for two different years, a dry year and a wet year, were applied in the two test case simulations. In both cases the data were simulated over the time period (hours) during which it occurred.

The existing pile case used 1976 data, a dry year, for Rifle, Colorado which is 8 miles east of Anvil Points (the Paraho process site). The transient pile case used 1979 data, a wet year, obtained from Grand Junction, Colorado which is 56 miles southwest and $144 \mathrm{~m}$ lower in elevation than Anvil Points. In both cases these were the best data available for the given year. Both weather observation sites are operated by the National Oceanic and Atmospheric Administration (NOAA). The data reports used were monthly summaries (NOAA 1976 and 1979).

The total precipitation for 1976 and 1979 was $23.1 \mathrm{~cm}$ and $30.6 \mathrm{~cm}$, respectively. When simulating several years, as in the transient pile case, the same data (1979) was used each year.

Potential Evapotranspiration

Potential evapotranspiration (PET) was calculated by an auxiliary program to the UNSAT1D model called FAOPET (Doorenbos and Pruitt 1977) (Appendix E). 
FAOPET provides the option to calculate PET by up to five different methods. The Blaney-Criddle, Radiation, and Penman methods were tested in this study.

Climatological data for the respective dry and wet years, 1976 and 1979, were input to FAOPET. The principal types of information required are daily temperature, net radiation, vapor pressure, and wind velocity. Comparisons of PET as calculated by the Penman method for 1976 and 1979 are shown in Figures 6 and 7 , respectively. PET data from the other two methods compared favorably with the Penman method. Therefore, the PET data as calculated by the Penman method was used for both years.

The total annual PET for 1976 and 1979 was $144.3 \mathrm{~cm}$ and $171.8 \mathrm{~cm}$, respectively. Listings of the PET data for 1976 and 1979 are contained in Appendix $E$.

The model uses hourly factors in order to distribute PET over each day. A distribution experimentally determined at the University of California at Davis (Gupta et al. 1978, page 116) was used to represent the daily PET distribution in both test cases. This distribution, as shown in Figure 8 , assumes that almost 90\% of the evaporation occurs between 6 AM and 6 PM with the peak occurring about 2 PM.

In addition to using the hourly factors, the model further regulates the surface evaporation according to the soil water holding capacity (i.e., suction head) at the soil surface. The function used in the model is (Beese et al. 1977):

$$
F A C=-0.5767 \log h+1.78
$$

where

$h=$ the suction head in centimeters of water

$F A C=$ fraction (between 0.0 and 1.0) of PET that can evaporate at the given suction head.

This function log linearly reduces the fraction of PET that $c$ an evaporate as the suction head increases. 


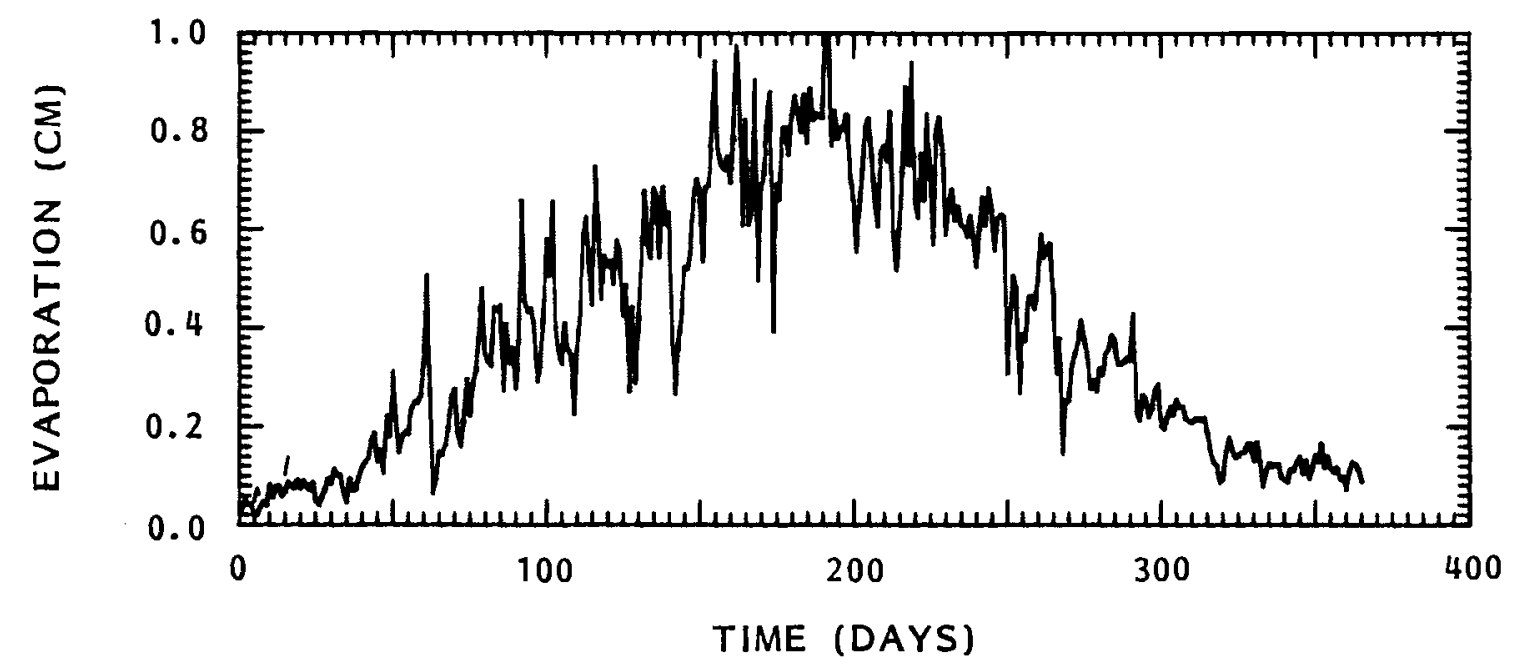

FIGURE 6. 1976 Potential Evapotranspiration as Calculated by the Penman Method

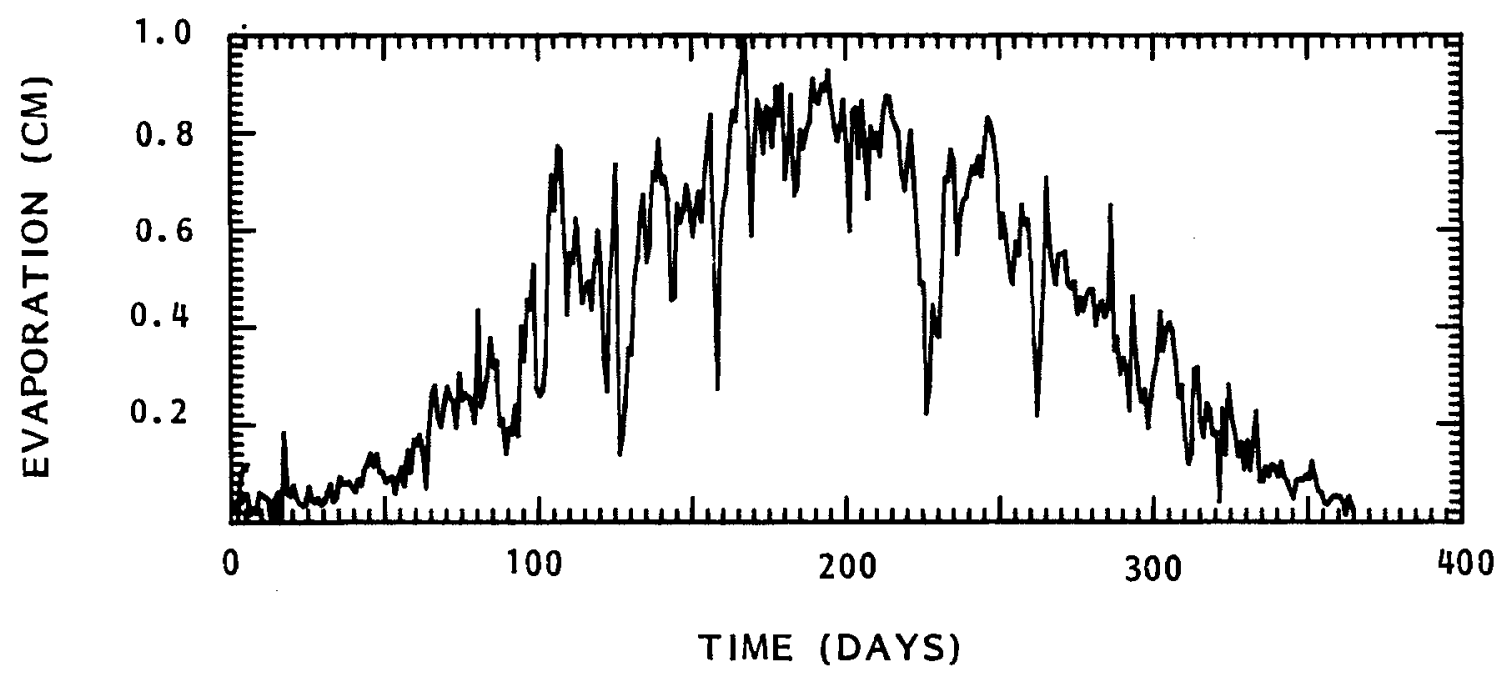

FIGURE 7. 1979 Potential Evapotranspiration as Calculated by the Penman Method 


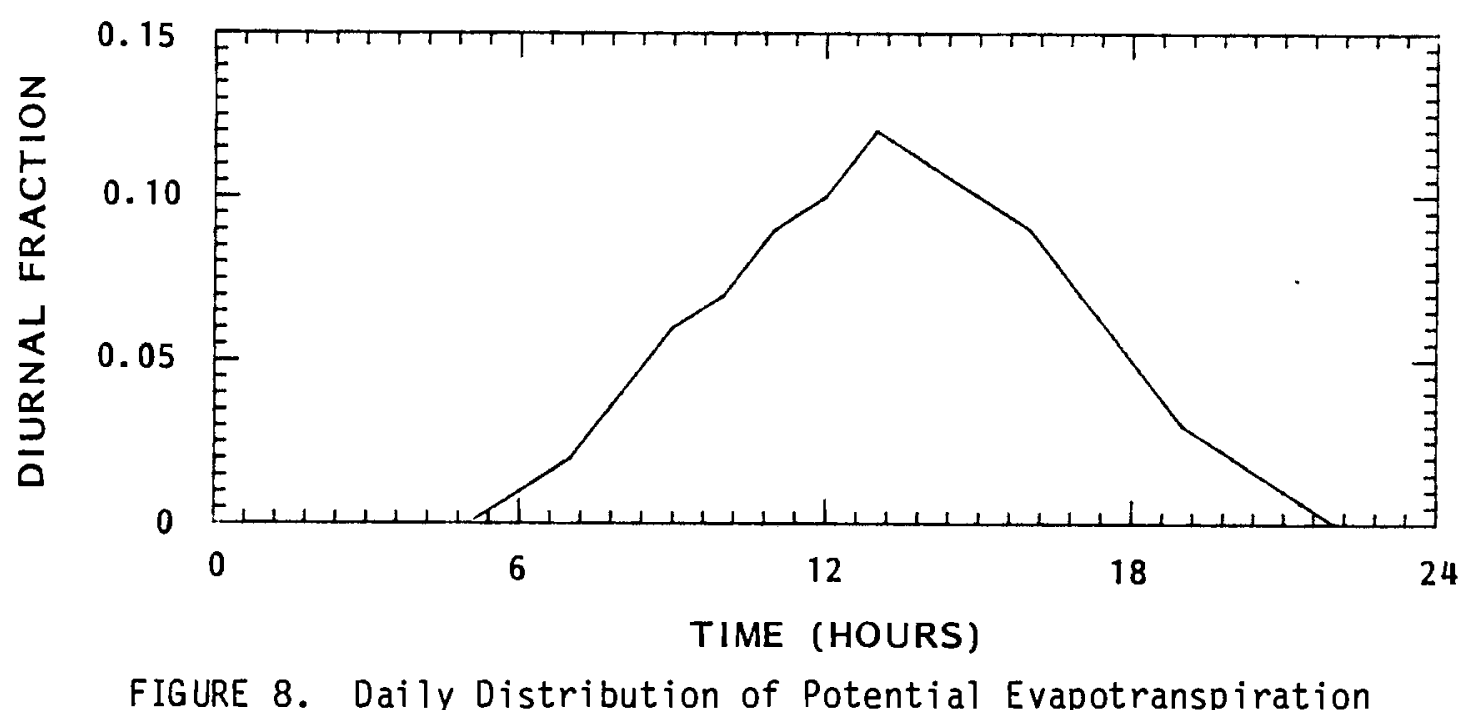

\section{TEST CASE RESULTS}

The results of the two test cases, as discussed below, are primarily presented in the form of soil moisture distributions versus depth and time, and cumulative water flux versus time. In the second test case (multiple year simulation) the results are presented on a yearly basis rather than as 30-year totals.

\section{Existing Pile Case}

A 1 year simulation was run for each of the three scenarios of the existing pile test case. For the given initial and boundary conditions, and for the model input parameters as defined above, the model predicted the suction head distribution (and the corresponding moisture distribution) in the soil profile at each time step (daily) of the simulation period.

Plots of the moisture distribution in the profile for each of the three scenarios are shown in Figures 9 and 10 . Figure 9 shows water content versus the full $30.2 \mathrm{~m}$ profile depth on days $1,90,180,270$, and 365 of the year. Because all the moisture redistribution occurred at the top of the profile, Figure 10 shows the water content versus depth distribution for the top $1.5 \mathrm{~m}$. The break in the plots is due to the change in material type (i.e., soil to shale). 
CASE 1

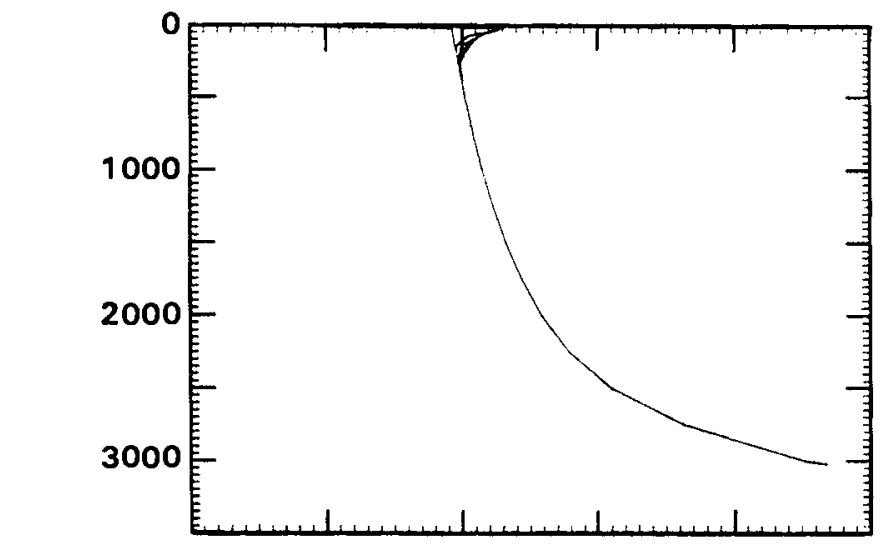

CASE 2

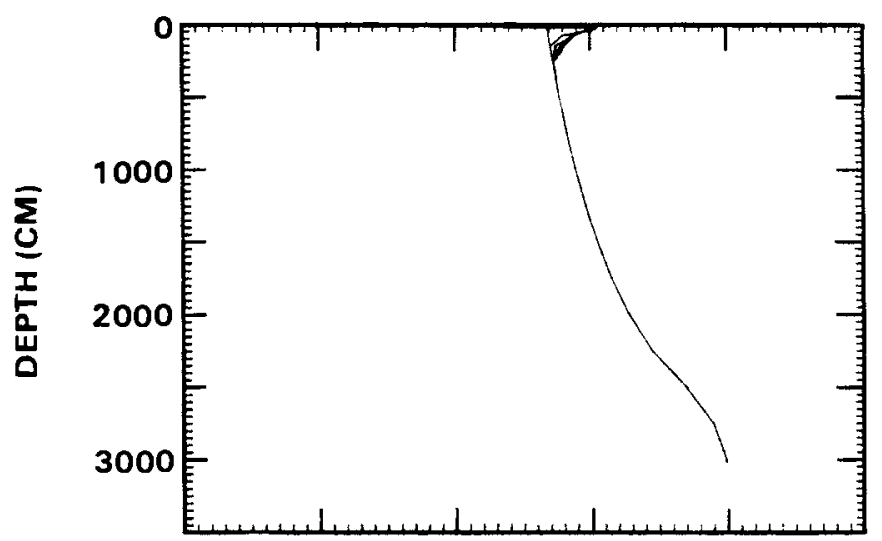

CASE 3

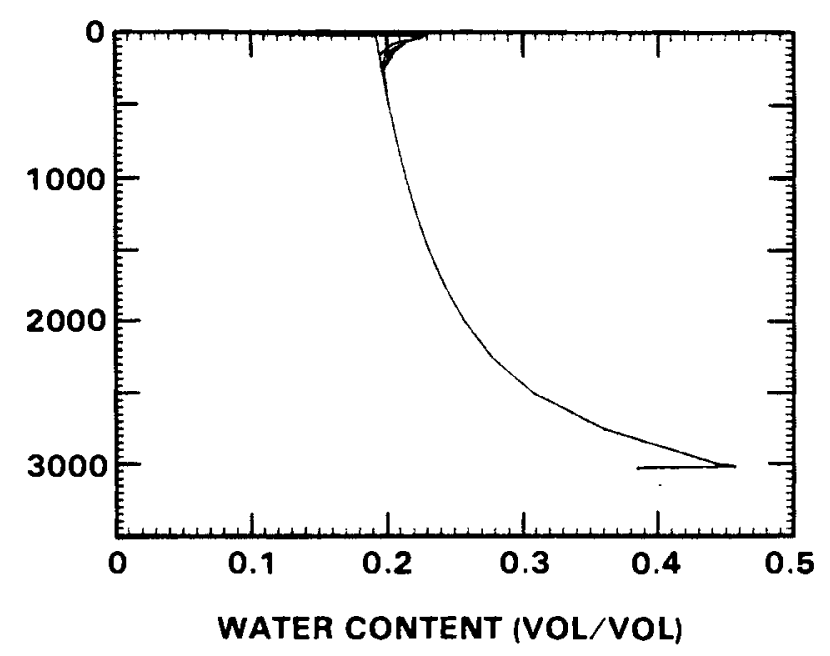

FIGURE 9. Water Content Versus Depth $(30.2 \mathrm{~m})$ on Days 1, 90, 180, 270, and 365 for the Three Scenarios of the Existing Pile Case 


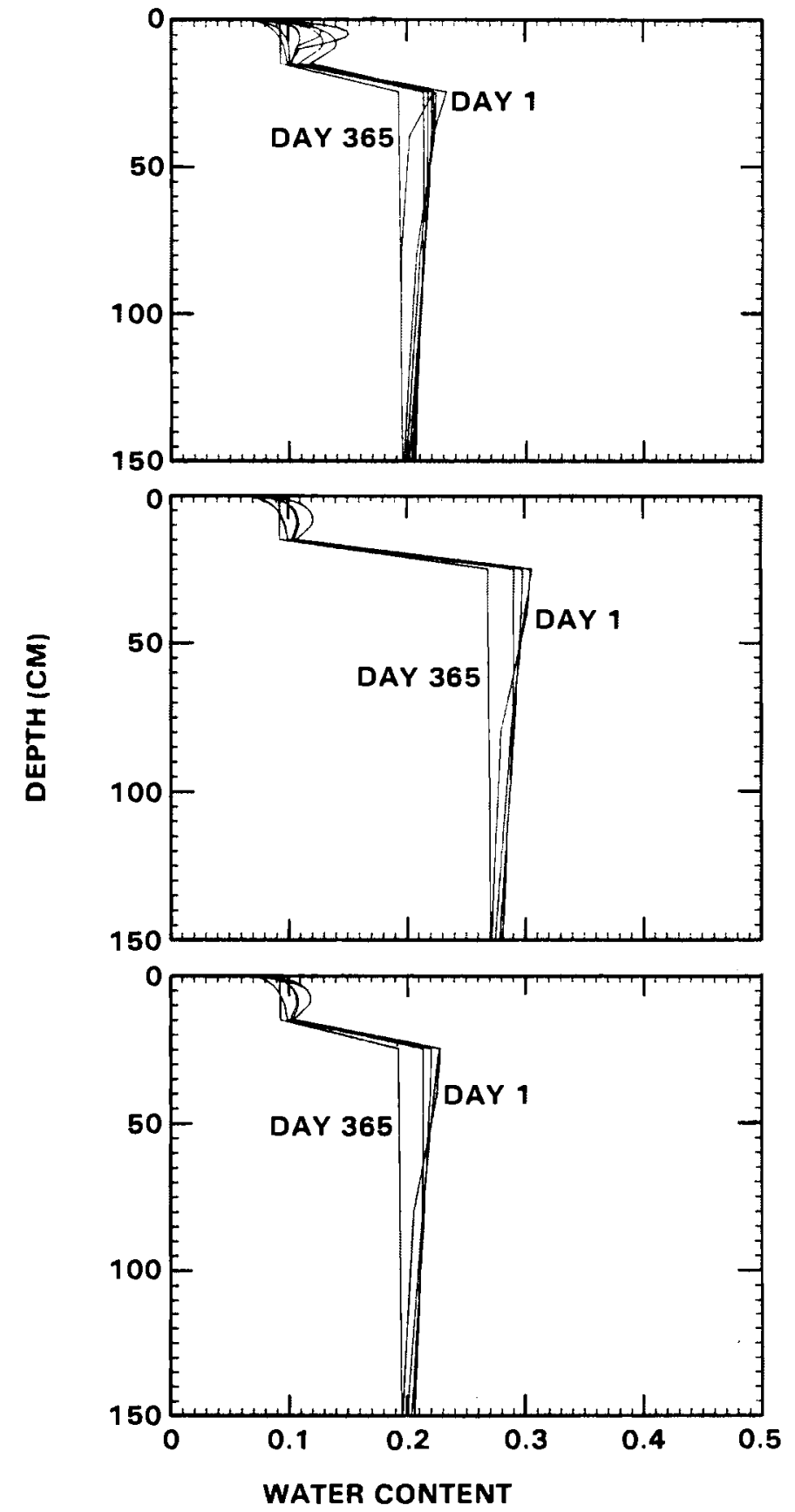

FIGURE 10. Water Content Versus Depth $(1.5 \mathrm{~m})$ on Days $1,90,180,270$, and 365 for the Three Scenarios of the Existing Pile Case 
Plots showing the change in moisture content with time at depths of 5,15 , and $25 \mathrm{~cm}$ for all three scenarios are shown in Figure 11 . The spikes in the 5 and $15 \mathrm{~cm}$ depth lines indicate the effect of precipitation events. The moisture content at $25 \mathrm{~cm}$ depth is higher than at 5 and $15 \mathrm{~cm}$ because the material type has changed from soil to shale. The spikes resulting from rainfall have nearly attenuated at the $25 \mathrm{~cm}$ depth.

The three-dimensional plot shown in Figure 12 helps to visualize the results. This plot of depth versus time versus moisture content for the first scenario shows the sequence and magnitide of rainfall events and the resulting redistribution into the soil profile. The initial moisture content of the soil (top $0.2 \mathrm{~m}$ ) is also contrasted against that in the $1.2 \mathrm{Mg} / \mathrm{m}^{3}$ shale. Threedimensional plots of the top $0.5 \mathrm{~m}$ for the other two scenarios are very similar to Figure 12 except that the $1.5 \mathrm{Mg} / \mathrm{m}^{3}$ shale (second scenario) has a higher water content.

Water balance information was obtained from the model using the equation:

$$
\begin{aligned}
& \underset{\text { Storage }}{\text { Change }}=\text { Precipitation - Evaporation - Drainage - Runoff } \\
& \begin{array}{lllll}
(\triangle S) & (P p t) & (E V A P) & (D r) & (R o)
\end{array}
\end{aligned}
$$

Water balance data for the three scenarios of the existing pile case are summarized below:

$$
\begin{aligned}
& \text { Scenario } 1 \text { Water Balance } \\
& \hline \text { Ppt }=23.06 \mathrm{~cm} \\
& \text { EVAP }=16.30 \mathrm{~cm} \\
& \text { Dr }=0.00 \mathrm{~cm} \\
& \text { Ro }=3.66 \mathrm{~cm} \\
& \Delta S=3.10 \mathrm{~cm}
\end{aligned}
$$

Scenario 2 Water Balance

Ppt $=23.06 \mathrm{~cm}$

EVAP $=16.23 \mathrm{~cm}$

$\mathrm{Dr}=0.00 \mathrm{~cm}$

Ro $=3.77 \mathrm{~cm}$

$\Delta S=3.06 \mathrm{~cm}$

Scenario 3 Water Balance

Ppt $=23.06 \mathrm{~cm}$

EVAP $=16.40 \mathrm{~cm}$

$\mathrm{Dr}=0.00 \mathrm{~cm}$

$R_{0}=3.62 \mathrm{~cm}$

$\Delta S=3.04 \mathrm{~cm}$ 


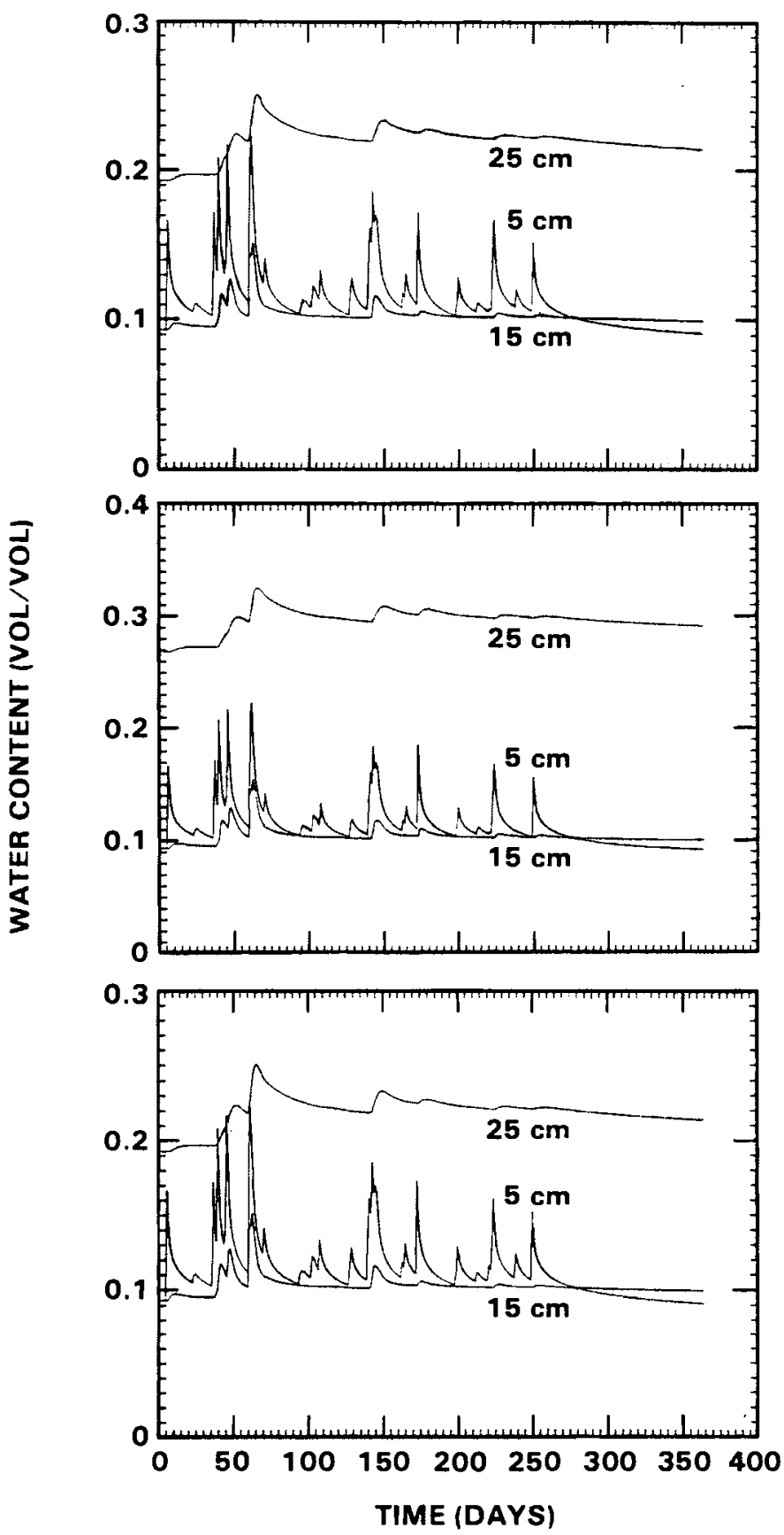

FIGURE 11. Water Content Versus Time at Depths $5,15,25 \mathrm{~cm}$ for the Three Scenarios of the Existing Pile Case 


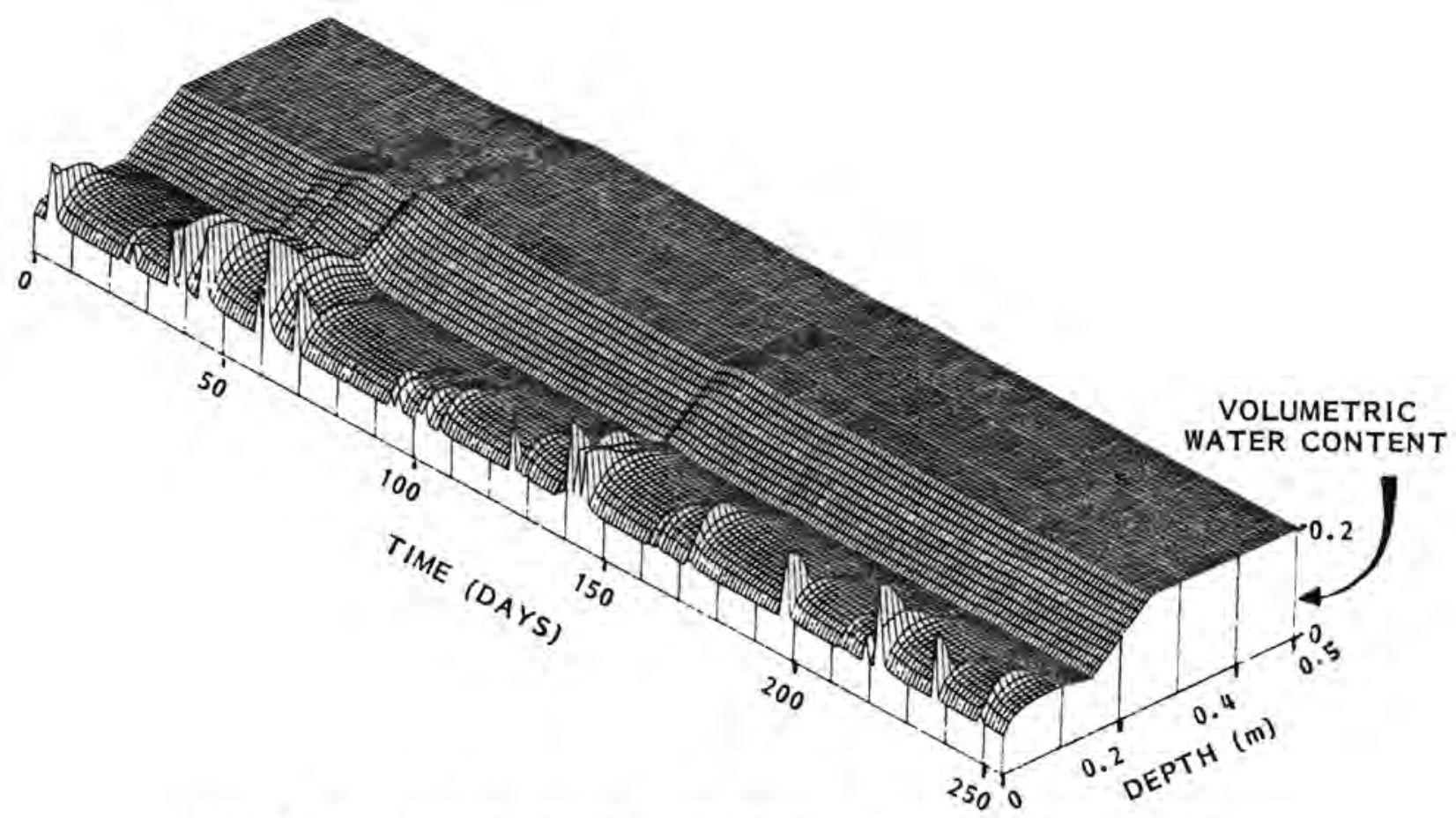

FIGURE 12. Depth Versus Time Versus Moisture Content for the First Scenario of the Existing Pile Case

The results for all three scenarios are very similar, with the difference in moisture content being on the order of tenths of centimeters or less. This similarity occurred because the simulation was only run for one year and it was a low rainfall year. As a result, the moisture front did not penetrate much further than $150 \mathrm{~cm}$ and there was not enough time for a marked difference in results to occur.

In all three scenarios there is no drainage out the bottom of the profile in one year's time; however, moisture storage in the profile does occur.

\section{Transient Pile Case}

In both scenarios of the transient pile case the model was used to evaluate redistribution of moisture during a 5 year pile construction/growth period and a 25 year fixed pile period. The 30 year time period was chosen for this simulation recognizing that longer time periods will be addressed in 
subsequent studies. In both scenarios the model was run with a maximum time step of $1 \mathrm{hr}$ and the results (head, moisture content, and flux) were written out at the end of every day.

Water Content Versus Depth. Plots of the moisture distribution with depth for the first year are shown in Figures 13 and 14 for the two scenarios. These figures show the moisture profile on days 1 (initial conditions), 90, 180, 270, and 365 for the first $10 \mathrm{~m}$ lift of shale material $\left(5 \mathrm{~m}-1.2 \mathrm{Mg} / \mathrm{m}^{3}\right.$ shale, $5 \mathrm{~m}-1.5 \mathrm{Mg} / \mathrm{m}^{3}$ shale, $5 \mathrm{~m}$-soil between the shale and water table). The difference in the initial volumetric moisture content in the shales is easily seen in these figures. In the first scenario (Figure 13) the $1.5 \mathrm{Mg} / \mathrm{m}^{3}$ shale gains water from above and below due to its greater suction head and additional storage capacity, whereas in the second scenario (Figure 14 ) the $1.5 \mathrm{Mg} / \mathrm{m}^{3}$ shale is at saturation and does not accept any additional water. In $f$ act, the water begins to build up on top of the $1.5 \mathrm{Mg} / \mathrm{m}^{3}$ shale (perched water table) at the end of the first year (day 365 in Figure 14). The moisture profiles with depth at the end of the $5 \mathrm{yr}$ pile growth period are shown in Figures 15 and 16. These figures show the moisture profile in the full $50 \mathrm{~m} \mathrm{pile}$ and overlying soil $(5 \mathrm{~m})$ on days $1,90,180,270$, and 365 of the sixth year.

The contrast in the redistribution of water between the two scenarios is quite apparent. In the first scenario (Figure 15) water entering the pile at the surface has only moved to a depth of about $15 \mathrm{~m}$. Additional water has entered the $1.5 \mathrm{Mg} / \mathrm{m}^{3}$ shale layer from above and below, and their is no drainage out the base of the pile. The second scenario (Figure 16) shows that water entering the pile at the surface and the water initially stored in the $1.2 \mathrm{Mg} / \mathrm{m}^{3}$ shale have moved downward to form a perched water table above the $1.5 \mathrm{Mg} / \mathrm{m}^{3}$ shale layer. This perched water table has resulted in drainage out the base of the pile.

The moisture profiles for the two scenarios at the end of $10 \mathrm{yr}$ are shown in Figures 17 and 18, respectively. Figure 17 shows that water has moved to a depth of about $20 \mathrm{~m}$ but below this the water content is at the initial level, $18 \%$ by volume. Figure 18 shows that the perched water table above the 


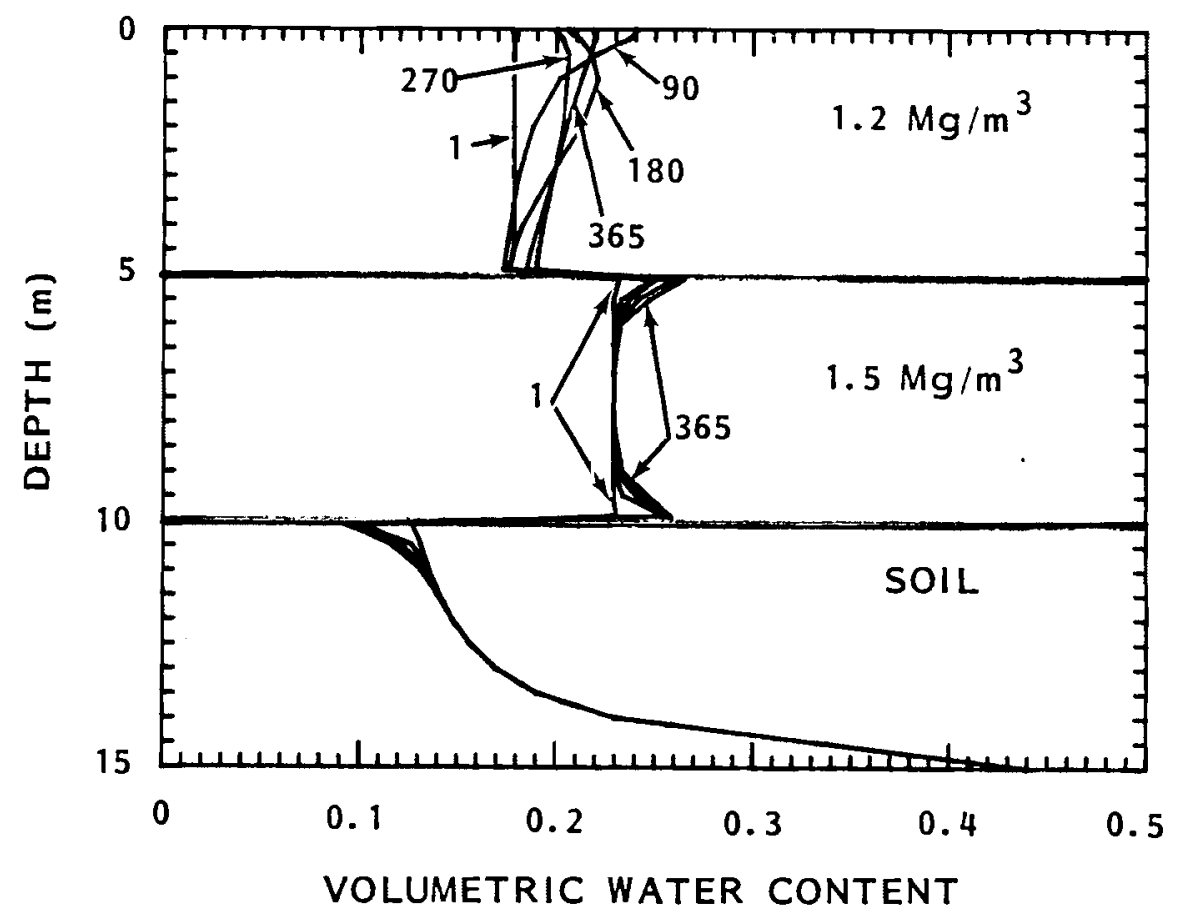

FIGURE 13. Transient Pile 1st Scenario - Moisture Profile on Days 1, $90,180,270$, and 365 of the 1st Year

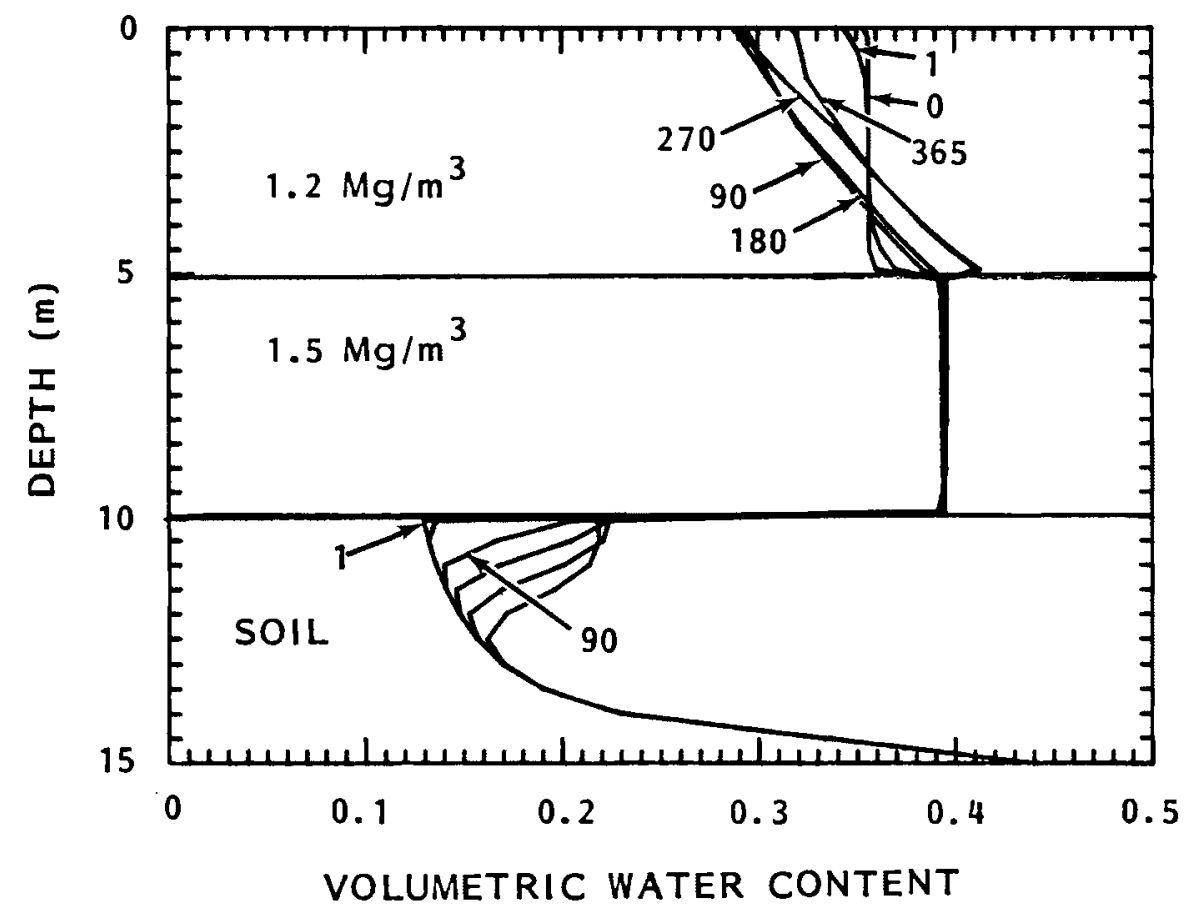

FIGURE 14. Transient Pile 2nd Scenario - Moisture Profile on Days 1, $90,180,270$, and 365 of the 1st Year 


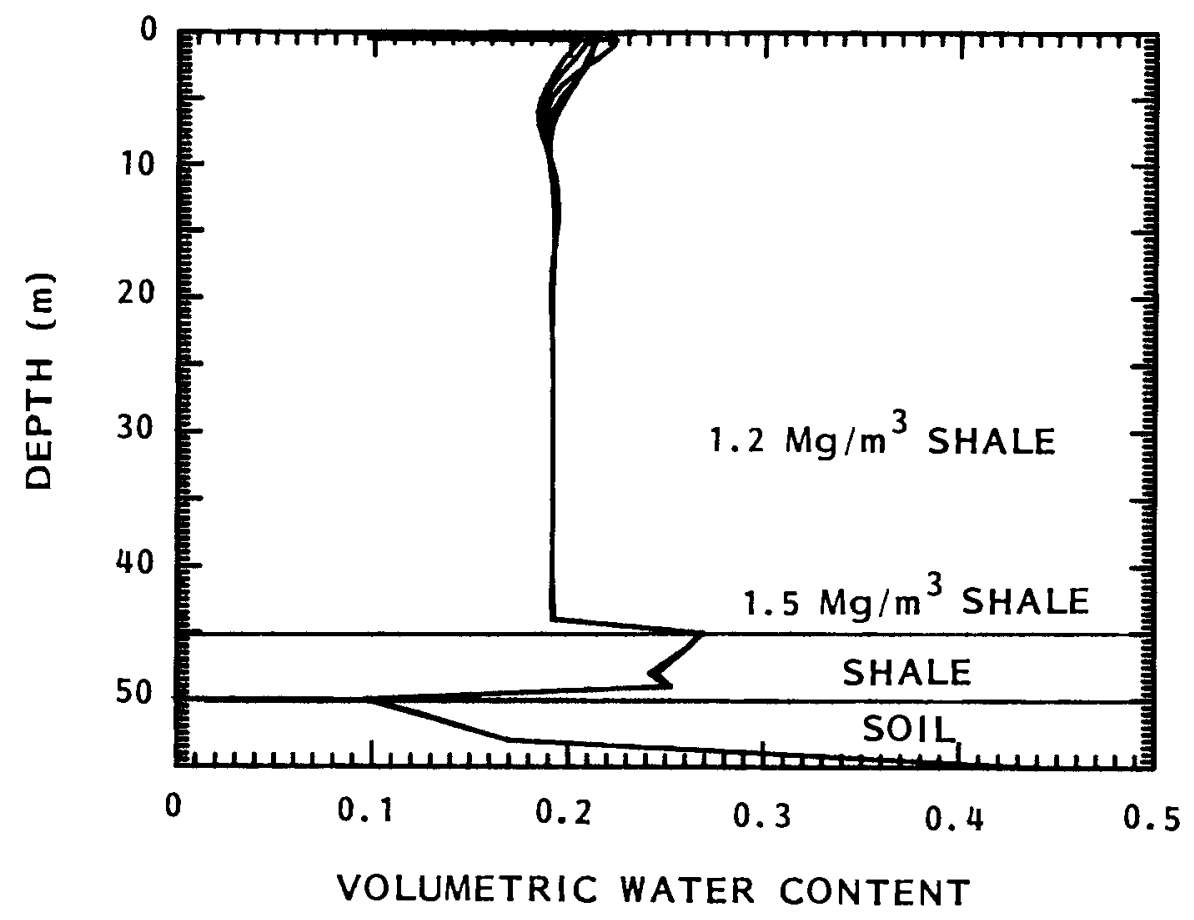

FIGURE 15. Transient Pile 1st Scenario - Moisture Profile on Days 1, $90,180,270$, and 365 of the 6 th Year

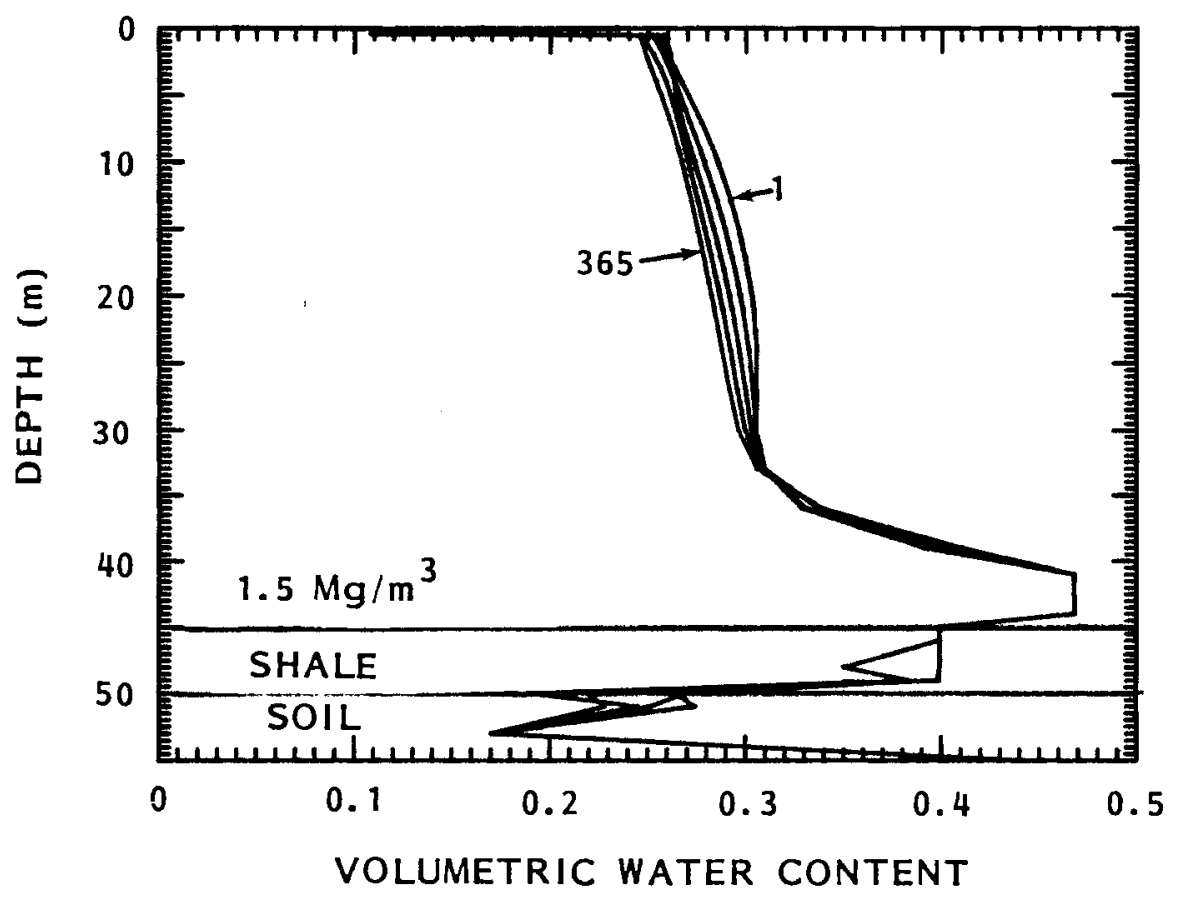

FIGURE 16. Transient Pile 2nd Scenario - Moisture Profile on Days 1, $90,180,270$, and 365 of the 6 th Year 


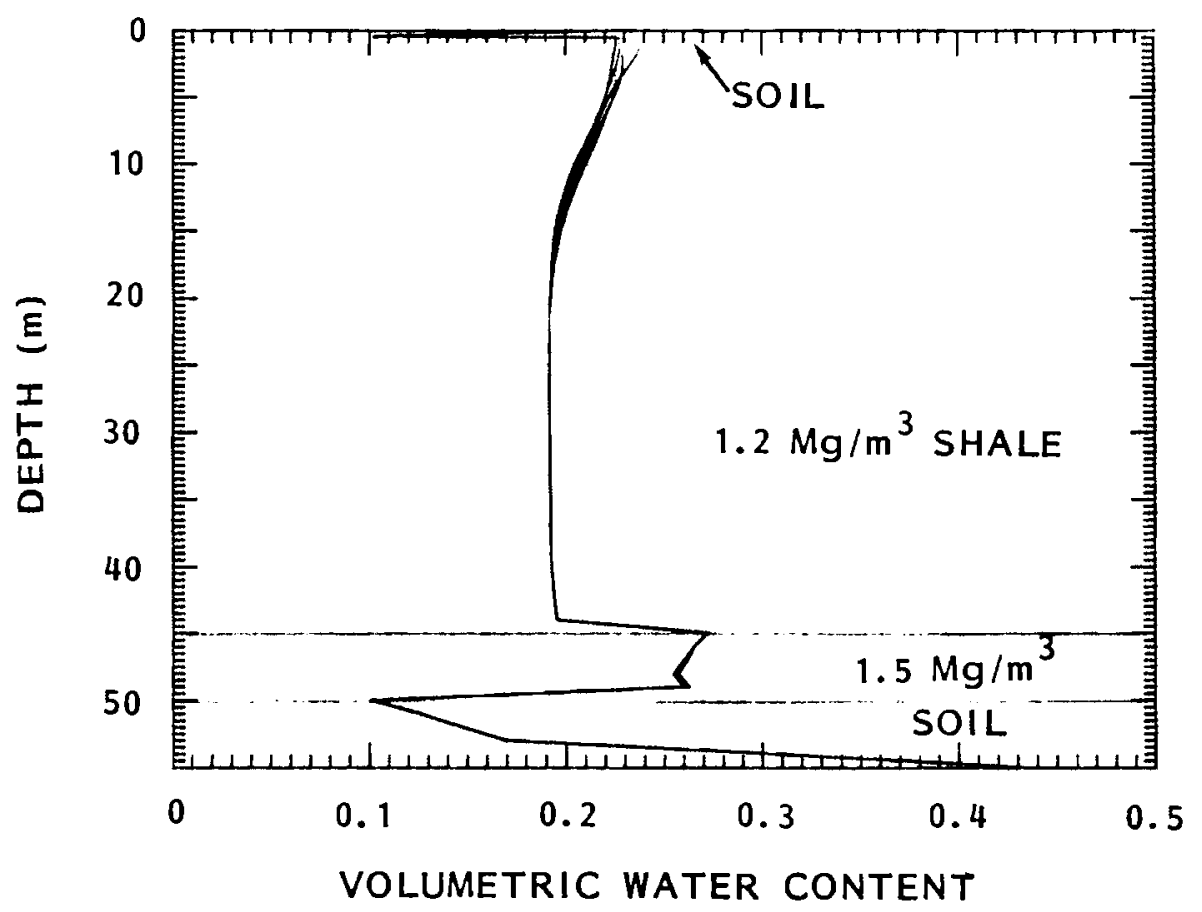

FIGURE 17. Transient Pile 1st Scenario - Moisture Profile on Days 1, $90,180,270$, and 365 of the 10th Year

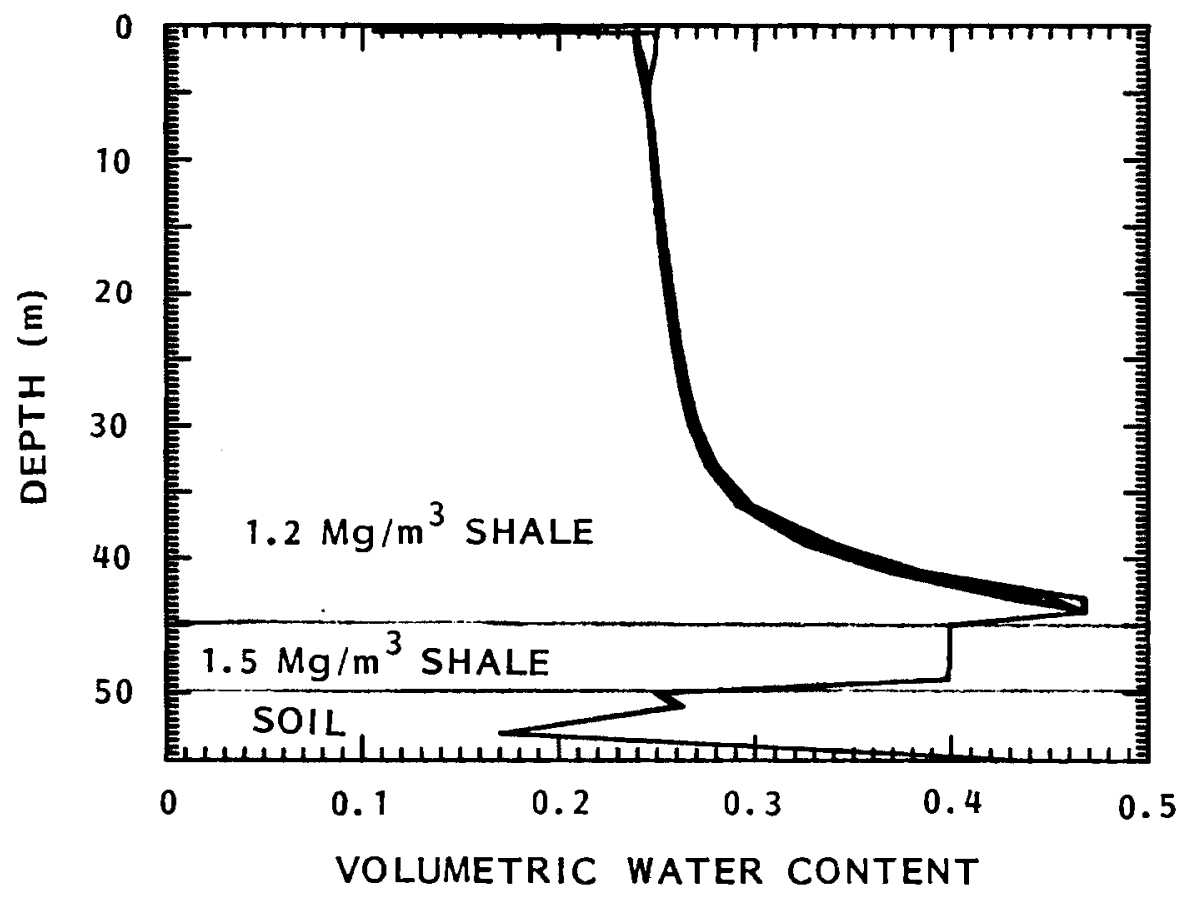

FIGURE 18. Transient Pile 2nd Scenario - Moisture Profile on Days 1, $90,180,270$, and 365 of the 10th Year 
$1.5 \mathrm{Mg} / \mathrm{m}^{3}$ shale still exists, however, there is less water stored in the $1.2 \mathrm{Mg} / \mathrm{m}^{3}$ shale than after 6 years (Figure 16 ) as a result of drainage out the base of the pile. In effect the pile is draining to an equilibrium (steady state) condition for the given amount of rainfall.

Between 10 and 15 years, the perched water table in the second scenario begins to disappear as a result of drainage out the base of the profile. This disappearance of the perched water table can easily be seen in Figures 19, 20, and 21 which show the moisture profile after 12,13 , and 15 years, respectively. After 15 years, much of the water initially stored in the profile has drained and the pile is approaching an equilibrium condition.

Plots of the the moisture profiles after 20 and 30 years for the first scenarios are shown in Figures 22 and 23 , respectively. Figure 22 shows that after 20 years, rainfall entering the profile at the surface has moved to a depth of about $30 \mathrm{~m}$. Figure 23 shows that after 30 years the moisture content in the entire $1.2 \mathrm{Mg} / \mathrm{m}^{3}$ shale profile has increased from an initial value of $18 \%$ by volume to between $21 \%$ and $22 \%$. This higher moisture level is far below saturation and there is still no drainge out the base of the profile.

Plots of the moisture profiles after 20 and 30 years for the second scenario are shown in Figures 24 and 25 , respectively. The moisture profiles after 15 (Figure 21), 20, and 30 years are all nearly identical which indicates that the pile has nearly reached on equilibrium condition after 15 years. After 30 years there is drainage out the base of the profile but it has decreased with time.

Water Content Versus Time. Plots of water content versus time for the first 50 days of the two scenarios are shown in Figures 26 and 27 . In the first scenario where the soil is relatively dry, the rainfall events drastically increase the water content in the surface soils (Figure 26) for short periods of time before redistribution occurs. The magnitude of the changes in water content decreases with depth in the profile due to the time required for water to infiltrate deeper in the soil. At a depth of $6 \mathrm{~m}$, in the $1.5 \mathrm{Mg} / \mathrm{m}^{3}$ shale layer, the water content is not affected by the rainfall and remains constant at the initial water content of about $23 \%$. 


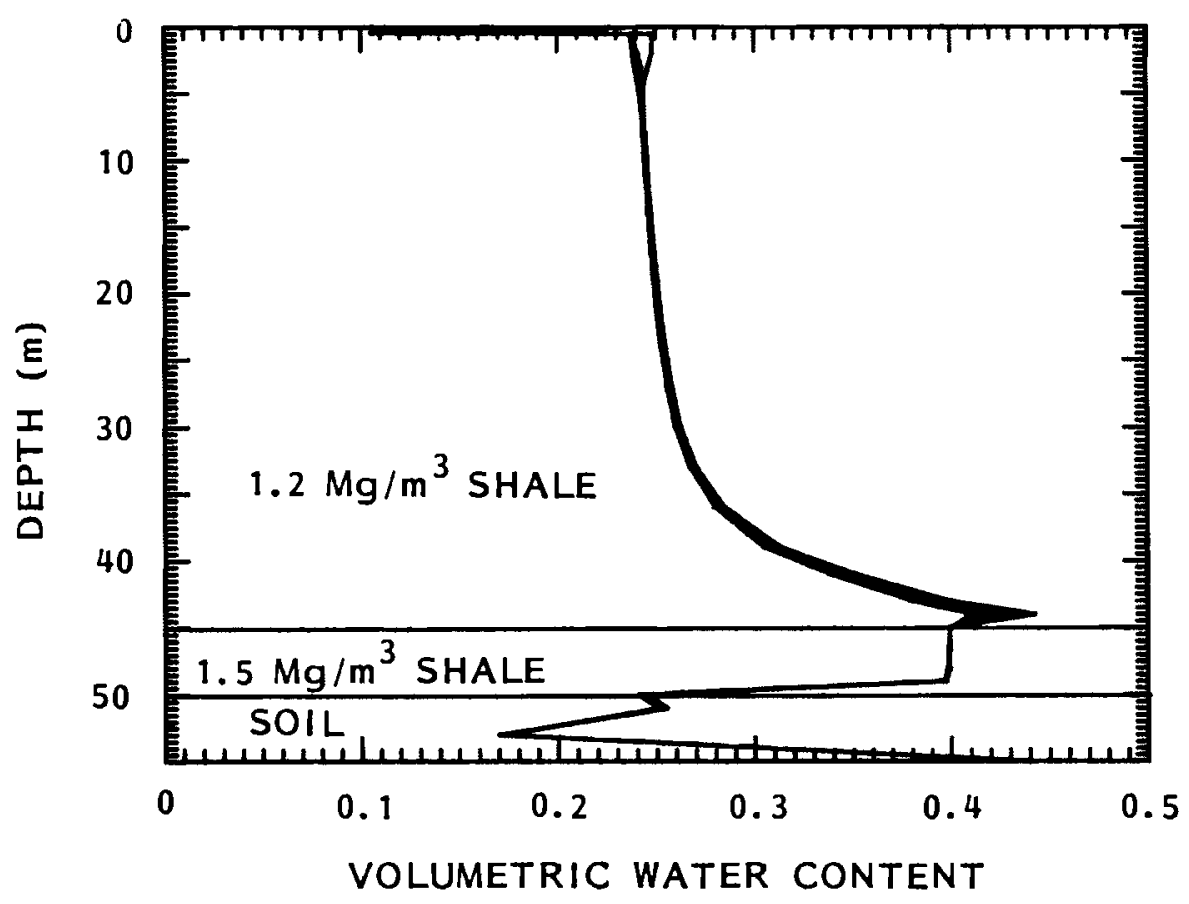

FIGURE 19. Transient Pile 2nd Scenario - Moisture Profile on Days 1, $90,180,270$, and 365 of the 12th Year

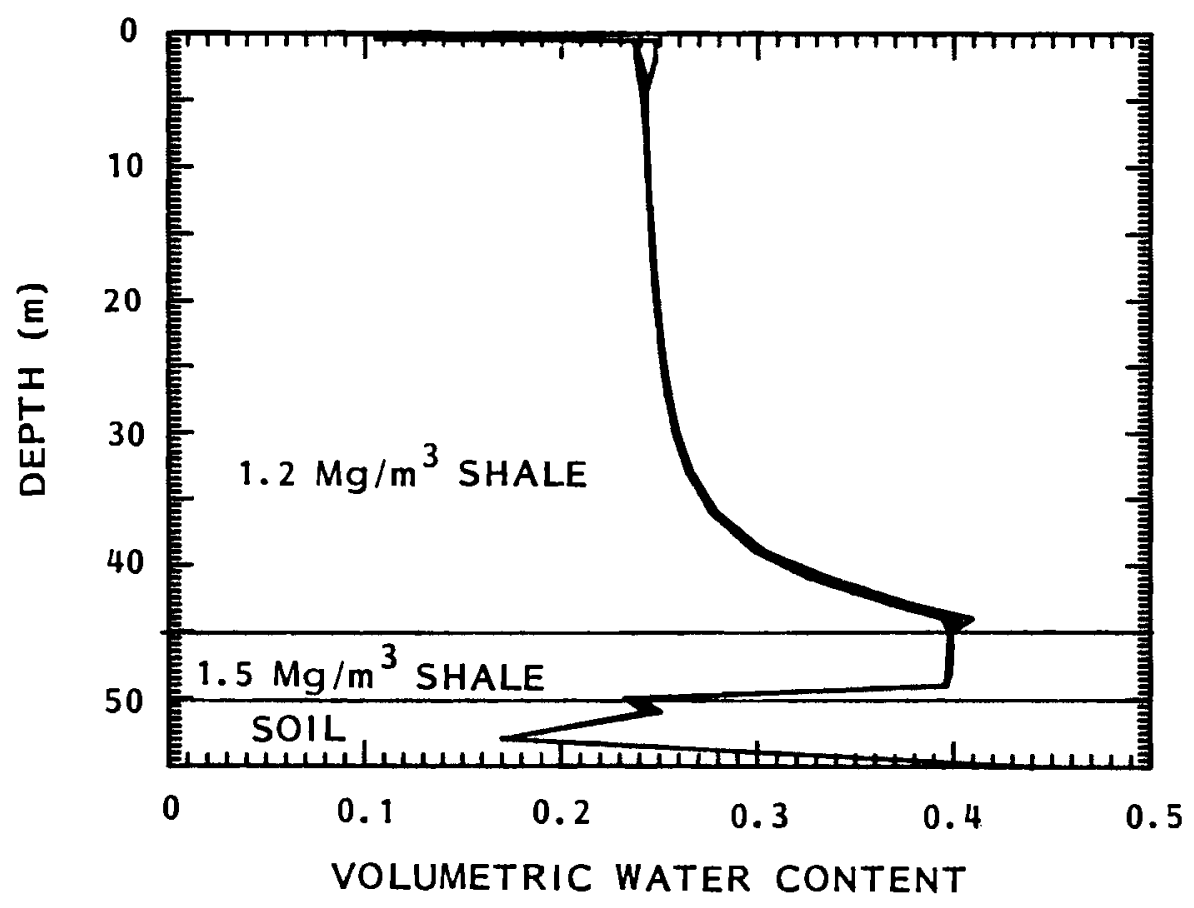

FIGURE 20. Transient Pile 2nd Scenario - Moisture Profile on Days 1, $90,180,270$, and 365 of the 13th Year 


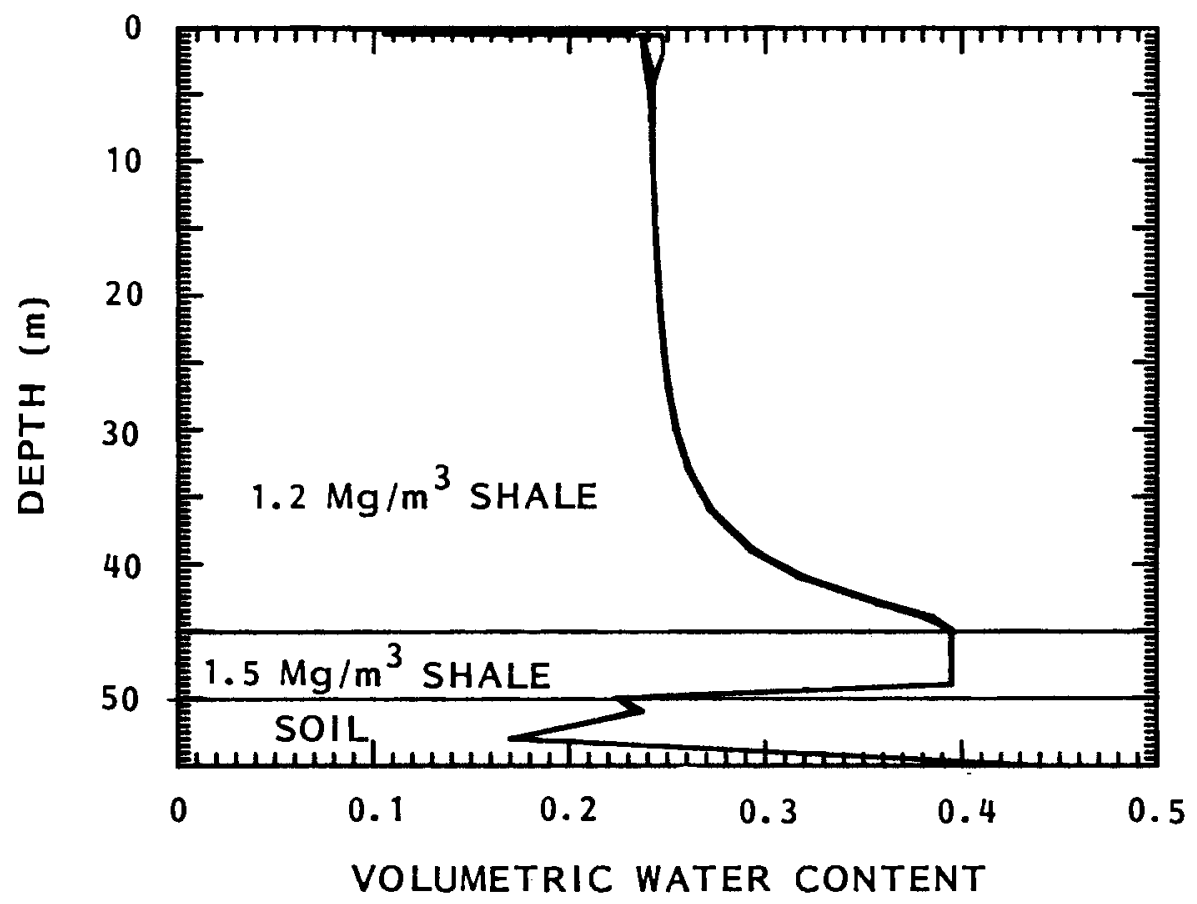

FIGURE 21. Transient Pile 2nd Scenario - Moisture Profile on Days 1, $90,180,270$, and 365 of the 15th Year

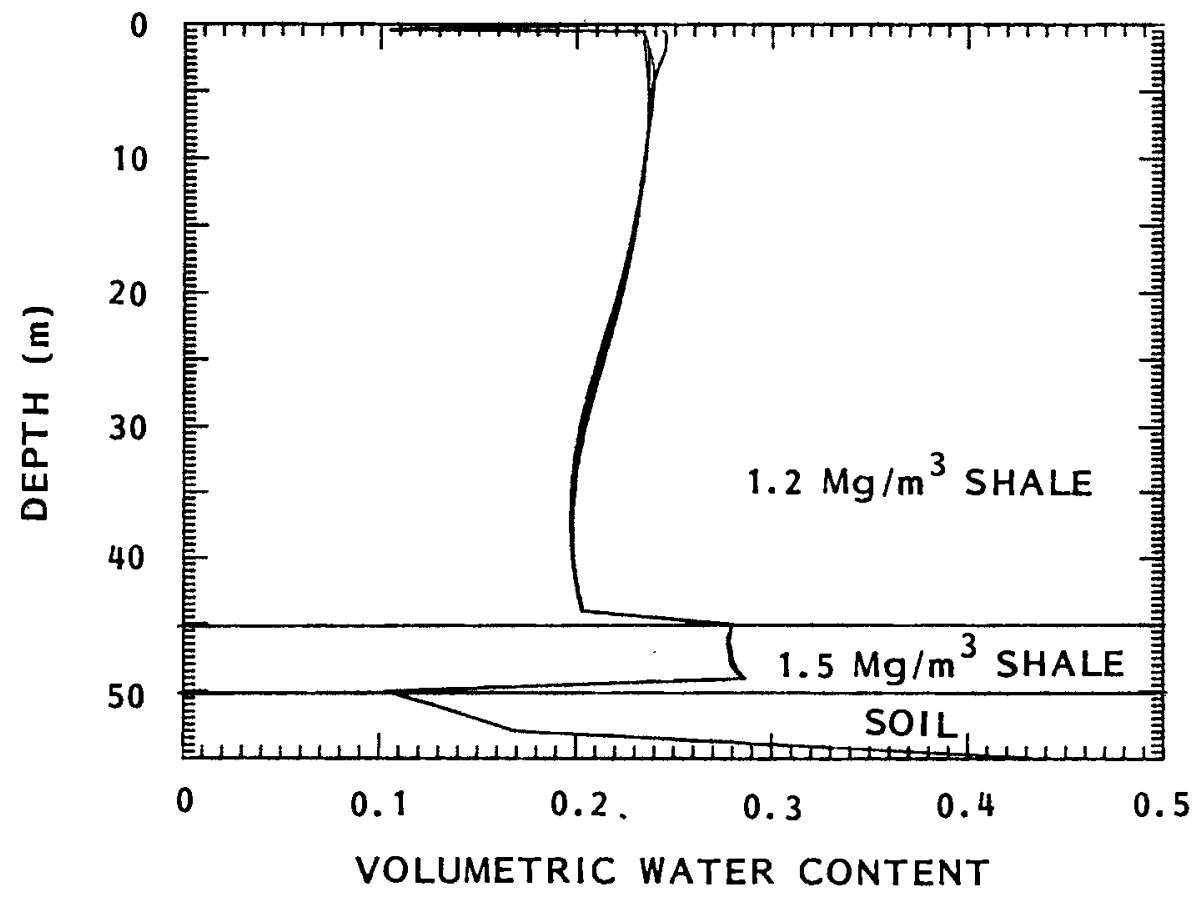

FIGURE 22. Transient Pile 1st Scenario - Moisture Profile on Days 1, $90,180,270$, and 365 of the 20th Year 


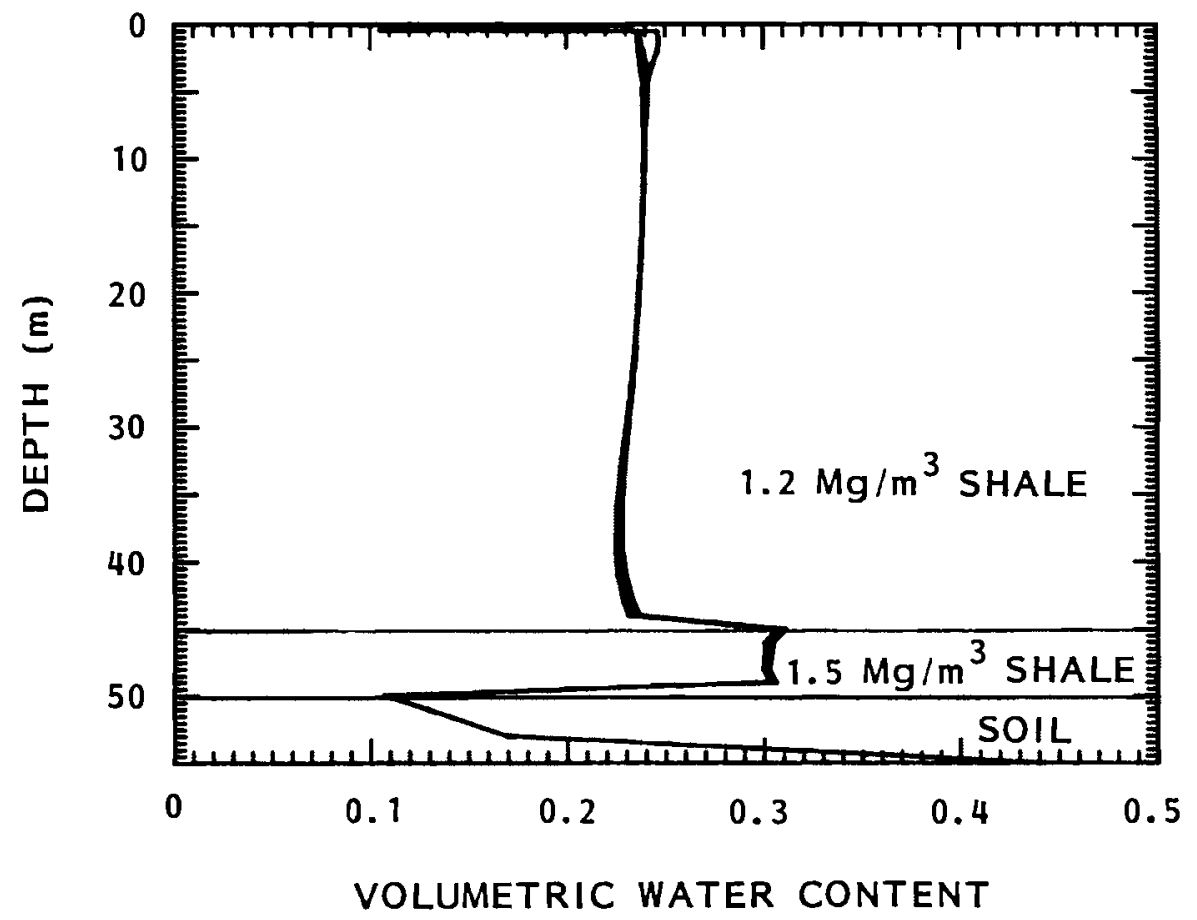

FIGURE 23. Transient Pile 1st Scenario - Moisture Profile on Days 1, $90,180,270$, and 365 of the 30 th Year

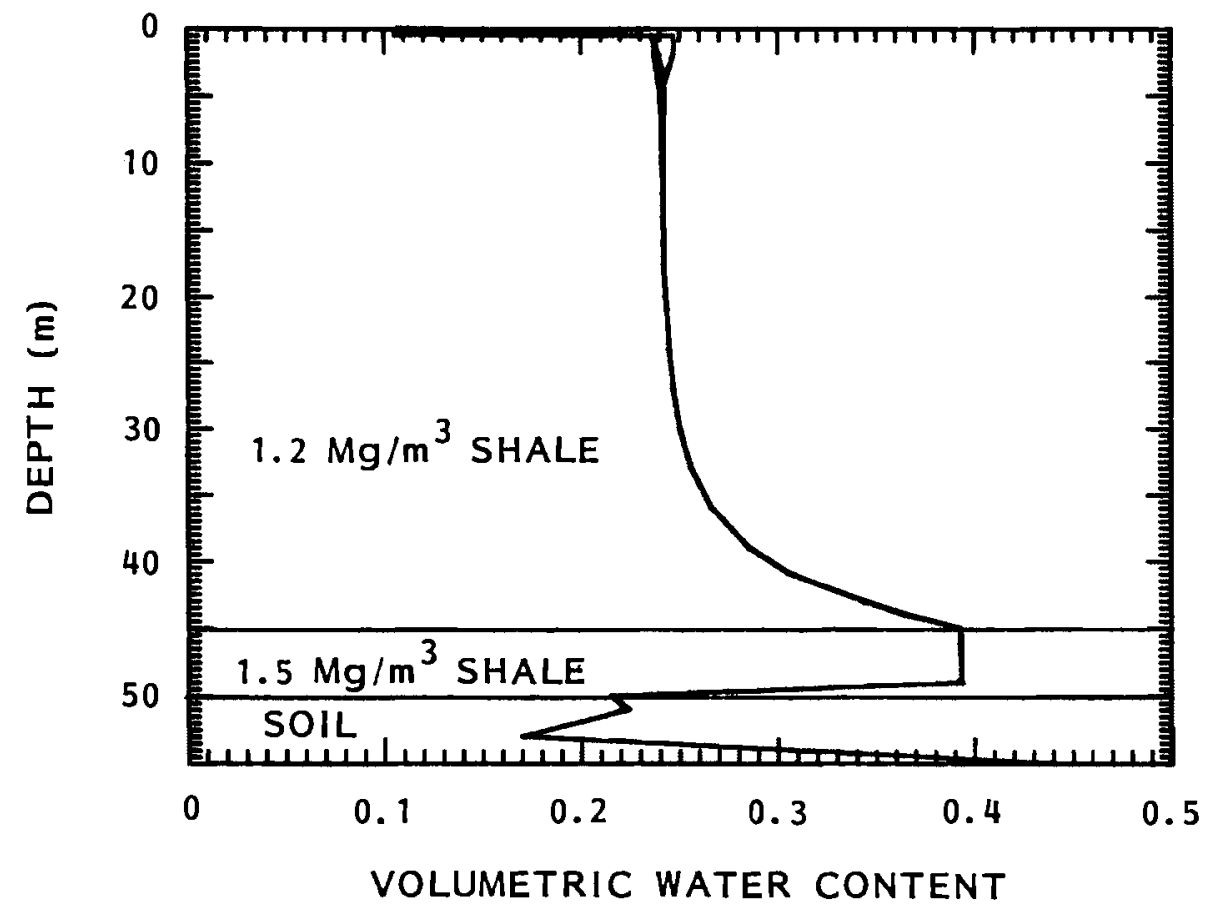

FIGURE 24. Transient Pile 2nd Scenario - Moisture Profile on Days 1, $90,180,270$, and 365 of the 20th Year 


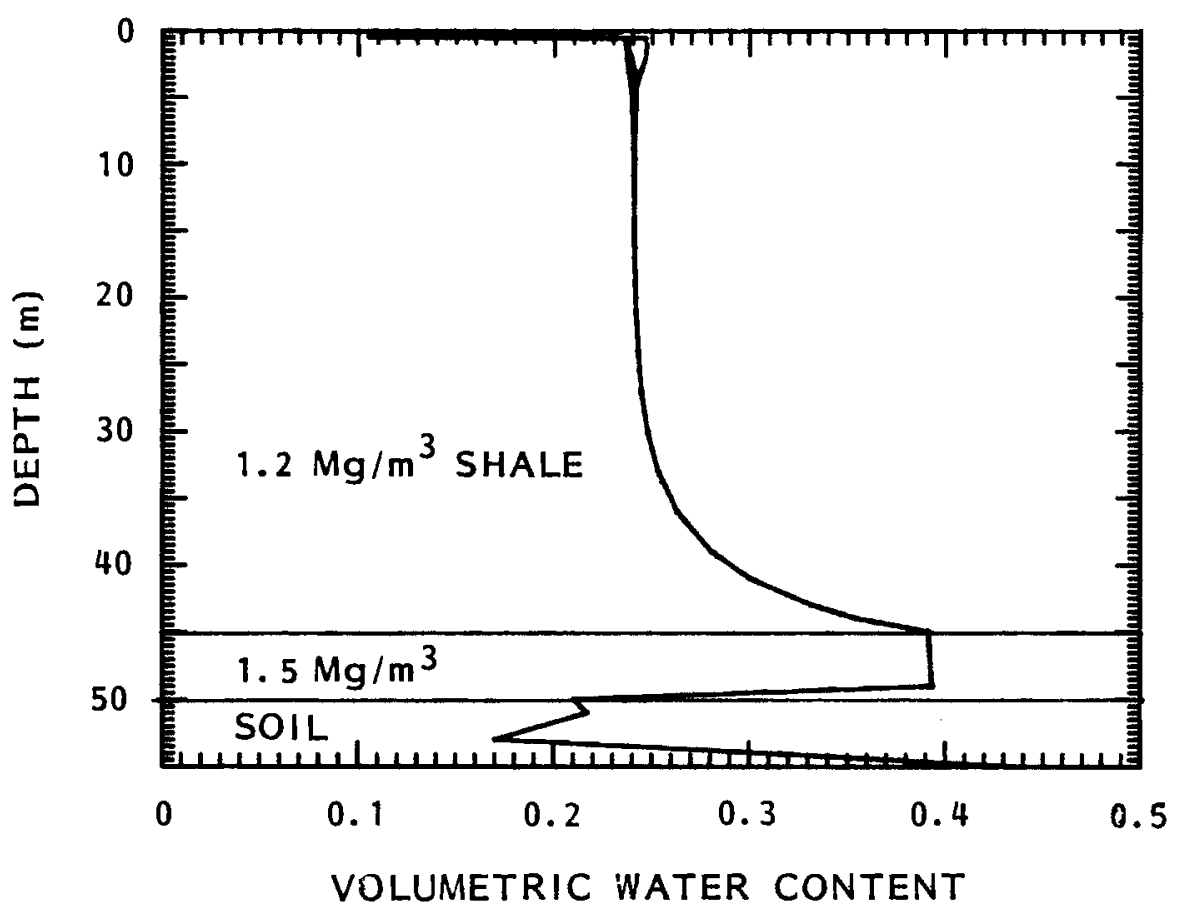

FIGURE 25. Transient Pile 2nd Scenario - Moisture Profile on Days 1, $90,180,270$, and 365 of the 30th Year

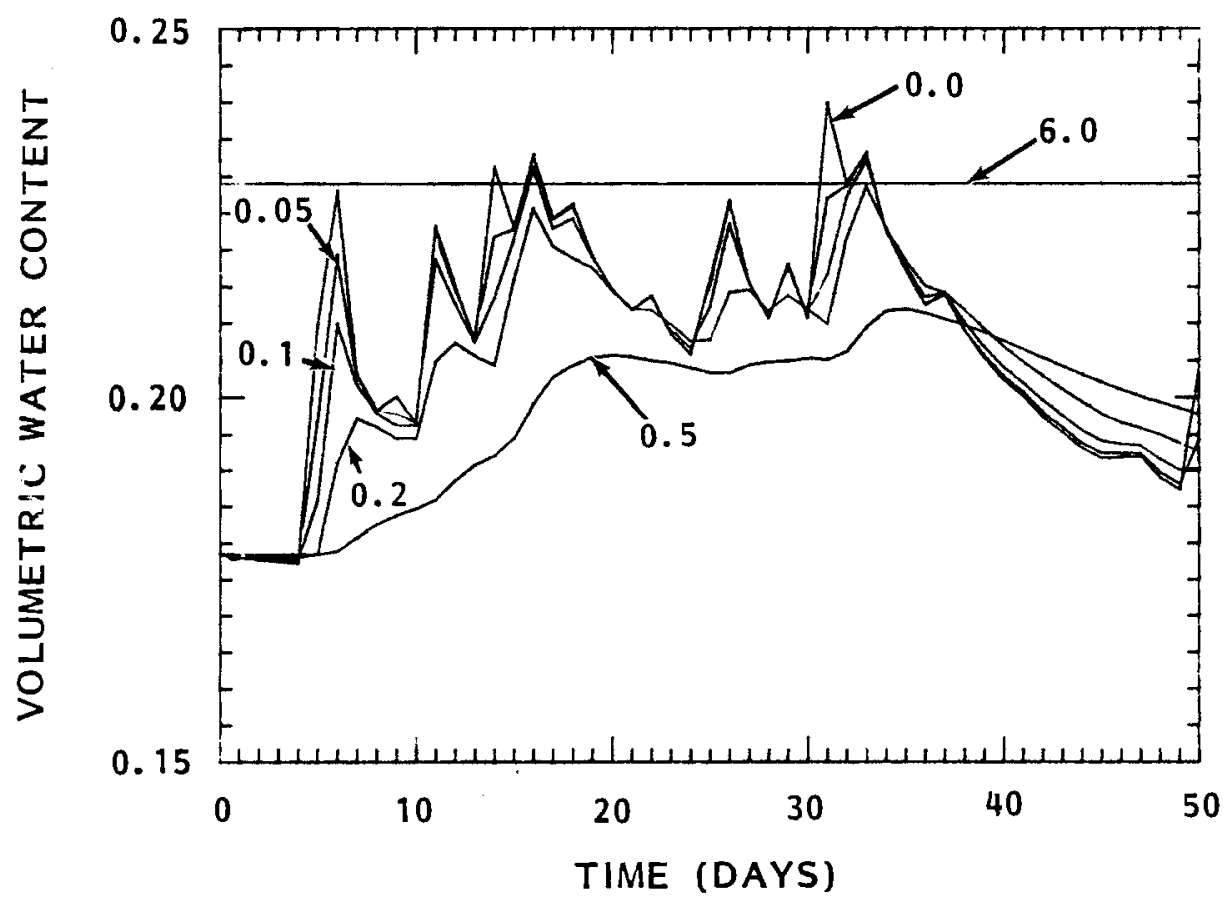

FIGURE 26. Transient Pile 1st Scenario - Moisture Content Versus Time at Depths $0.0,0.5,0.1,0.2,0.5$, and $6.0 \mathrm{~m}$ 


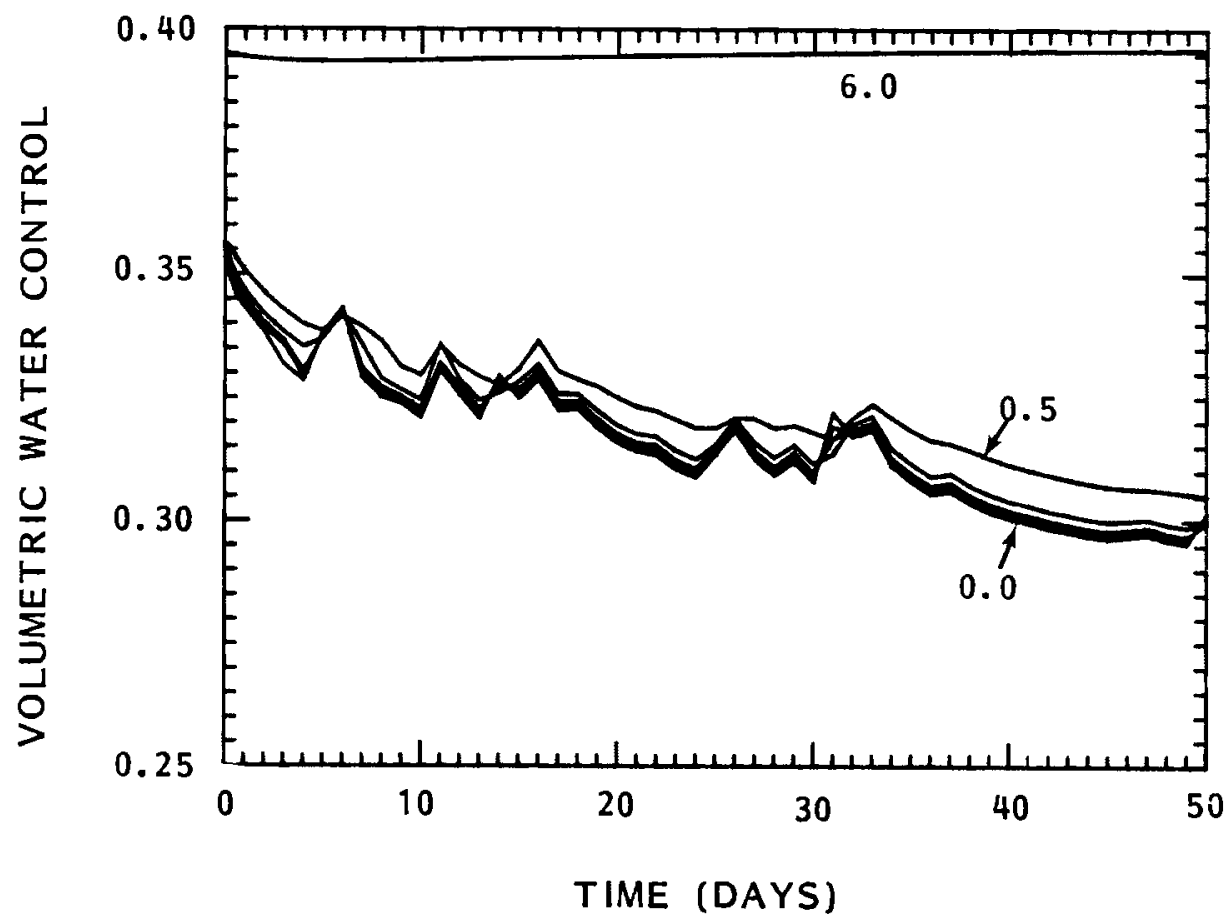

FIGURE 27. Transient Pile 2nd Scenario - Moisture Content Versus Time at Depths $0.0,0.5,0.1,0.2,0.5$, and $6.0 \mathrm{~m}$

The second scenario shows a completely different response over the first 50 days of simulation (Figure 27). In this scenario the initial moisture content in the $1.2 \mathrm{Mg} / \mathrm{m}^{3}$ shale $(36 \%$ ) was much nearer to saturation (47\%) so the rainfall events had a less pronounced effect on the water content. The changes in water content at various depths near the surface of the pile were quite similar because the retorted shale, which was near saturation, responded quickly to infiltration of water at the surface. It is also interesting to note that the water content in the profile decreases with time in contrast to the increase seen in the first scenario. This decrease is due to enhanced drainage at the higher initial water content, whereas in scenario 1 , there is room for increased storage. At a depth of $6 \mathrm{~m}$, in the $1.5 \mathrm{Mg} / \mathrm{m}^{3}$ shale, the water content increases slightly due to drainage from the $1.2 \mathrm{Mg} / \mathrm{m}^{3}$ shale, but again, there is no direct impact from rainfall at the surface.

Water flux Versus Time. Plots of cumulative water flux (drainage) at various depths versus time show how much water $(\mathrm{cm})$ has moved past a given 
point in the profile in a given time period. The plots discussed below are not cumulative over the total 30 years simulation period, but rather they are cumulative on a year by year basis.

Plots of the cumulative drainage at various depths for the tenth year are shown in Figures 28 and 29 for scenarios 1 and 2 , respectively. For scenario 1 it $c$ an be seen that there is some drainage past $10 \mathrm{~m}$ depth but there is no significant drainage below that point. These results agree with the results shown in Figure 17. Scenario 2 shows markedly different results, however, with the maximum drainage occurring at the base of the profile $(55 \mathrm{~m})$ and progressively less water movement approaching the top of the pile. This indicates that most of the water movement in the pile is due to drainage of the initial stored water and not due to the flux of rainfall at the surface.

Plots of cumulative flux after 20 and 30 years for the first scenario are shown in Figures 30 and 31 , respectively. Figure 30 shows that a significant amount of water has begun to move past a depth of $20 \mathrm{~m}$ after 20 years, whereas water has begun to move past $30 \mathrm{~m}$ after 30 years (Figure 31 ). However, after 30 years there is still no drainage out the base of the pile.

Plots of cumulative flux after 20 and 30 years for the second scenario are shown in Figures 32 and 33, respectively. The two figures indicate that about the same amount of flux is passing though the pile after 30 years as after 20 years. Also, in each figure, about the same amount of water is passing each depth. This indicates that the pile is near equilibrium; at which point water entering the surface equals the amount of water draining out the base.

Figure 34 shows the cumulative drainage out the base of the profile over the $30 \mathrm{yr}$ simulation period for the second scenario. It $c$ an be seen that drainage begins after the first year and increases to a maximum amount $(83.2 \mathrm{~cm})$ after 5 years, the end of the pile growth period. During the 6 th year the model predicted a sharp decrease in drainage followed by a smaller but definite decline. The shape of the drainage-time curve reflects the time required for the water perched above the $1.5 \mathrm{Mg} / \mathrm{m}^{3}$ shale layer to move through that denser layer. After 7 years the model predicted a continuous decrease in drainage until a near equilibrium condition $(\sim 10 \mathrm{~cm} / \mathrm{yr})$ is reached at about 20 years. 


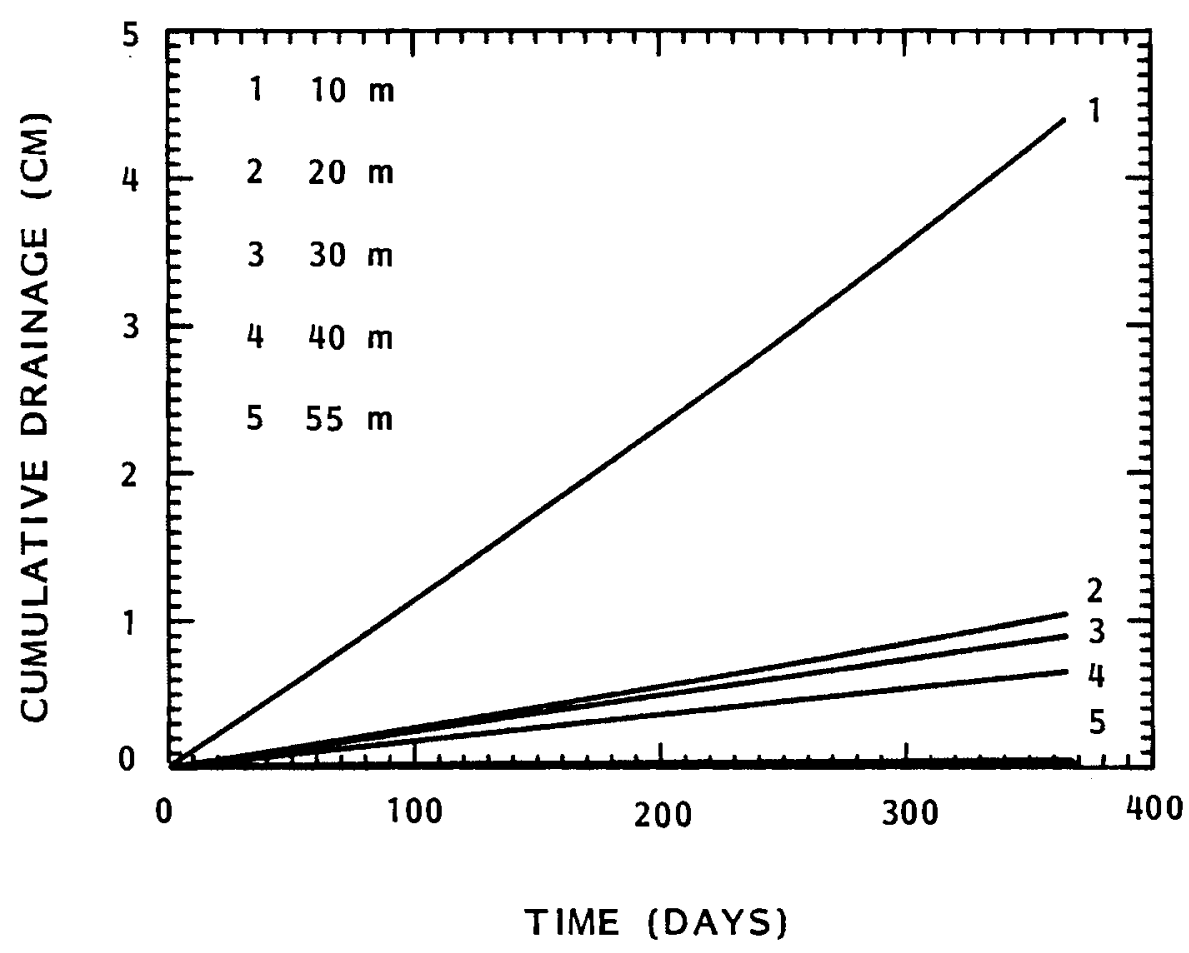

FIGURE 28. Transient Pile 1st Scenario - Cumulative Water Flux Versus Time at Depths $10,20,30,40$, and $55 \mathrm{~m}$ After 10 Years

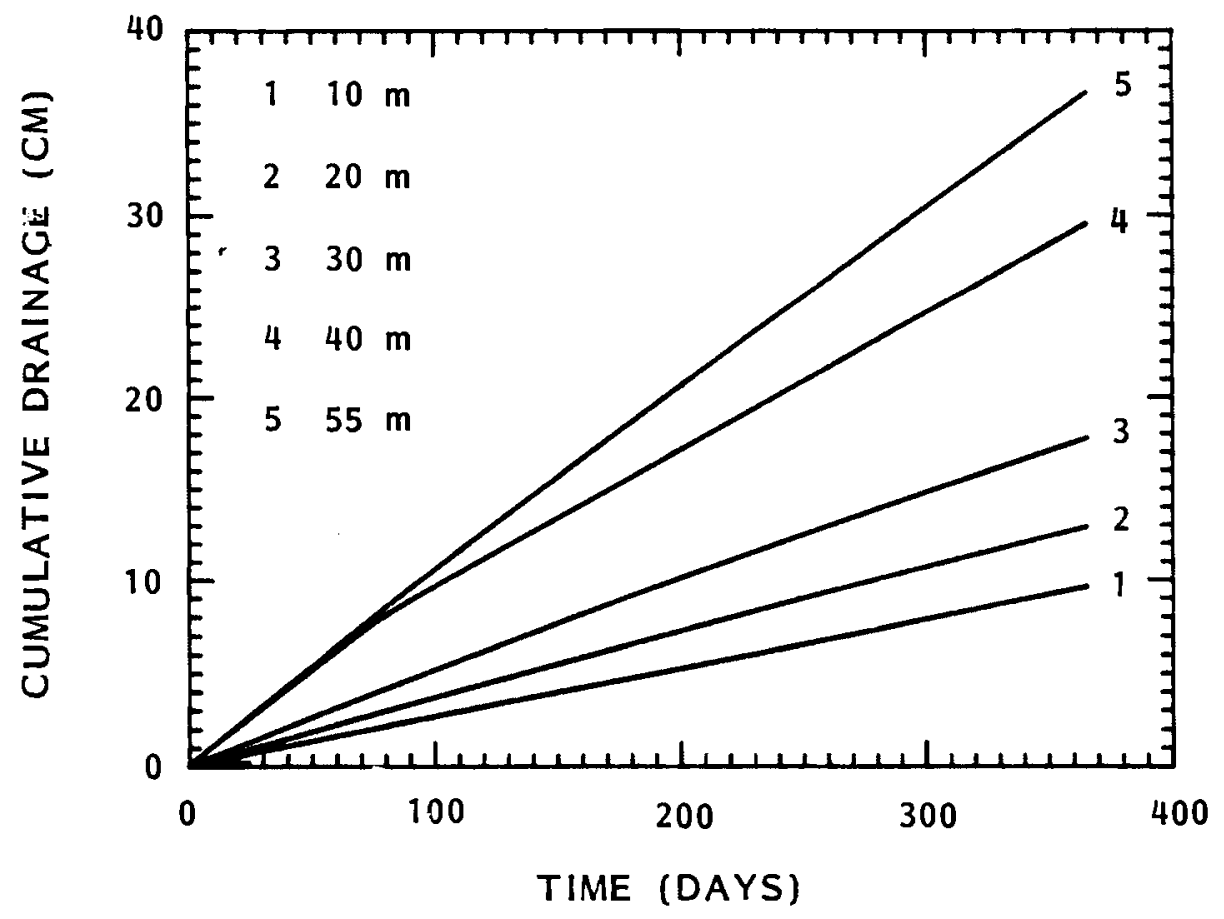

FIGURE 29. Transient Pile 2nd Scenario - Cumulative Water Flux Versus Time at Depths 10, 20, 30, 40, and $55 \mathrm{~m}$ After 10 Years 


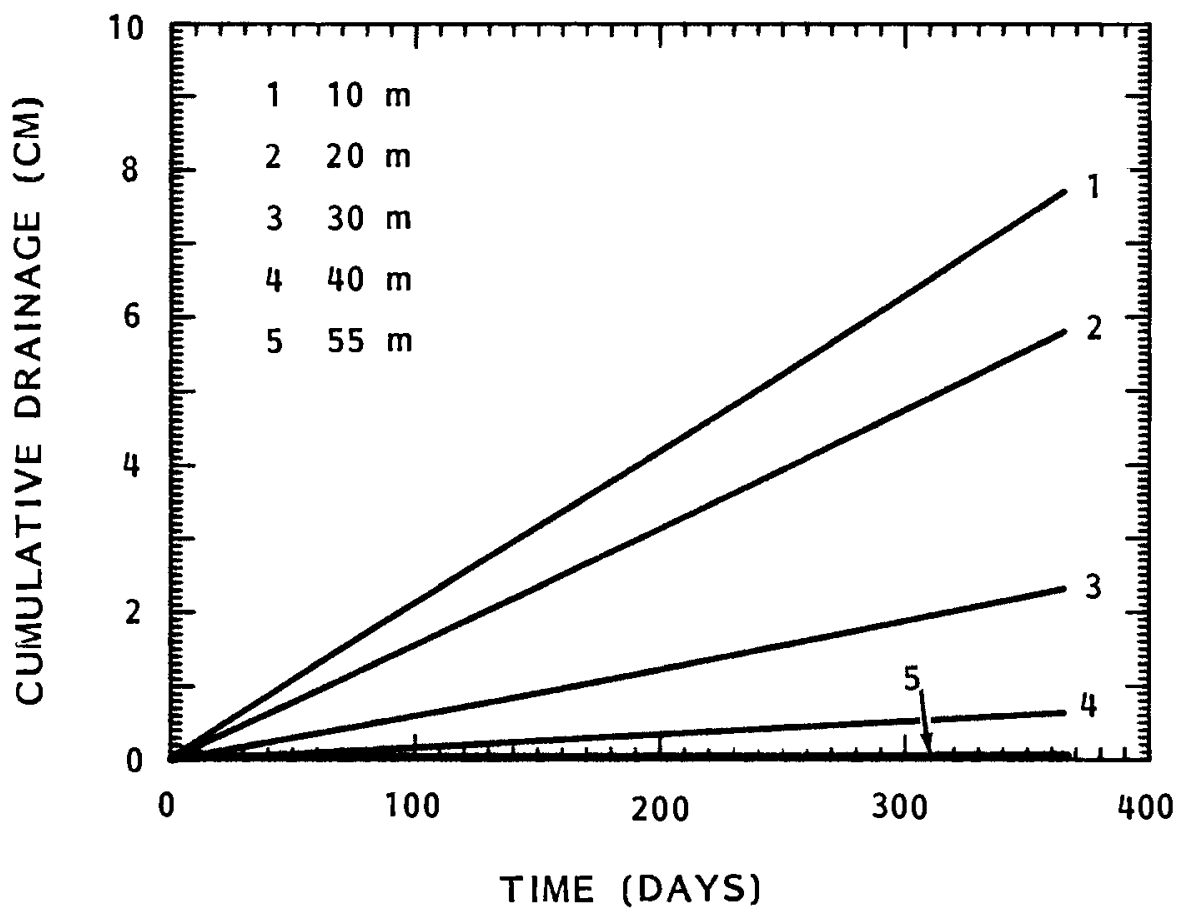

FIGURE 30. Transient Pile 1st Scenario - Cumulative Water Flux Versus Time at Depths $10,20,30,40$, and $55 \mathrm{~m}$ After 20 Years

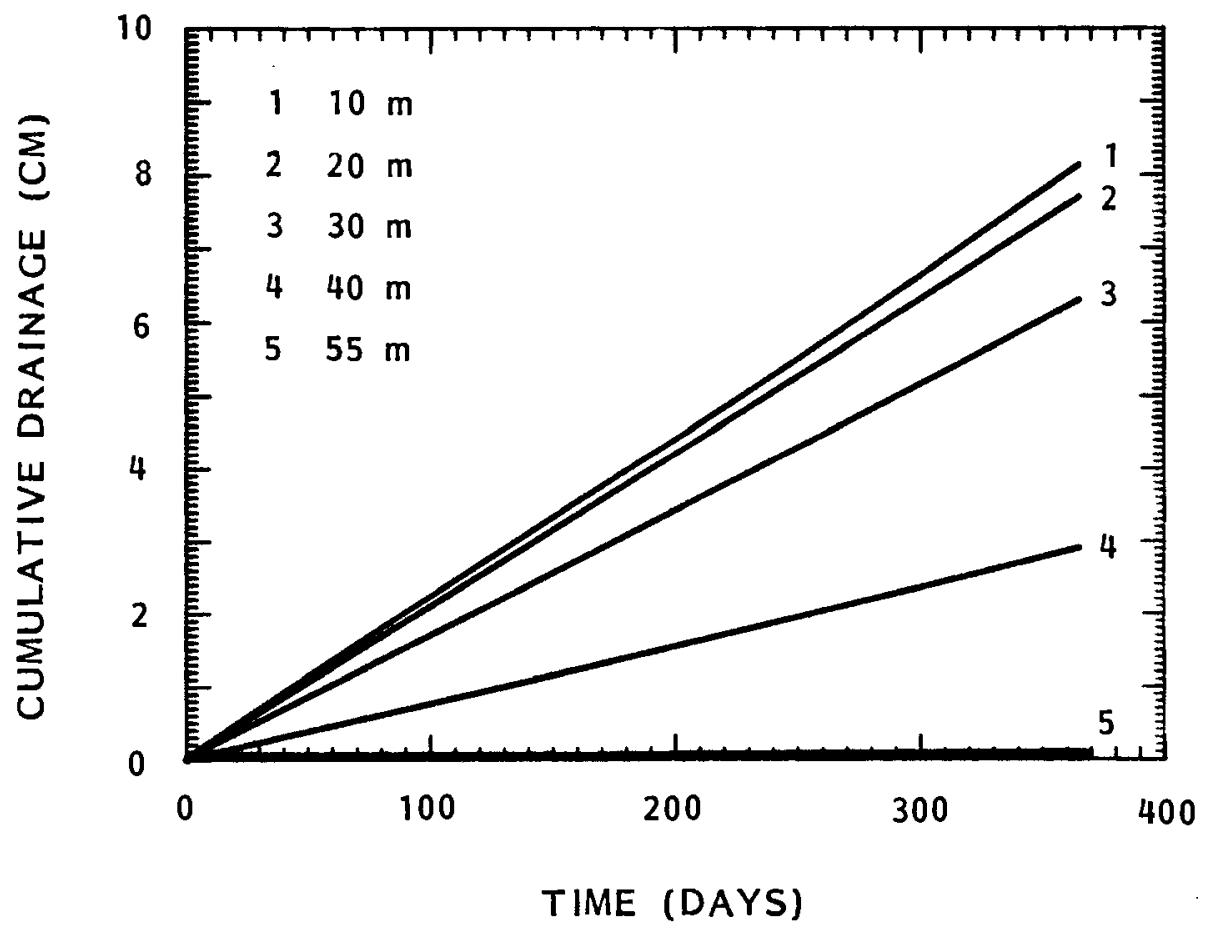

FIGURE 31. Transient Pile 1st Scenario - Cumulative Water Flux Versus Time at Depths $10,20,30,40$, and $55 \mathrm{~m}$ After 30 Years 


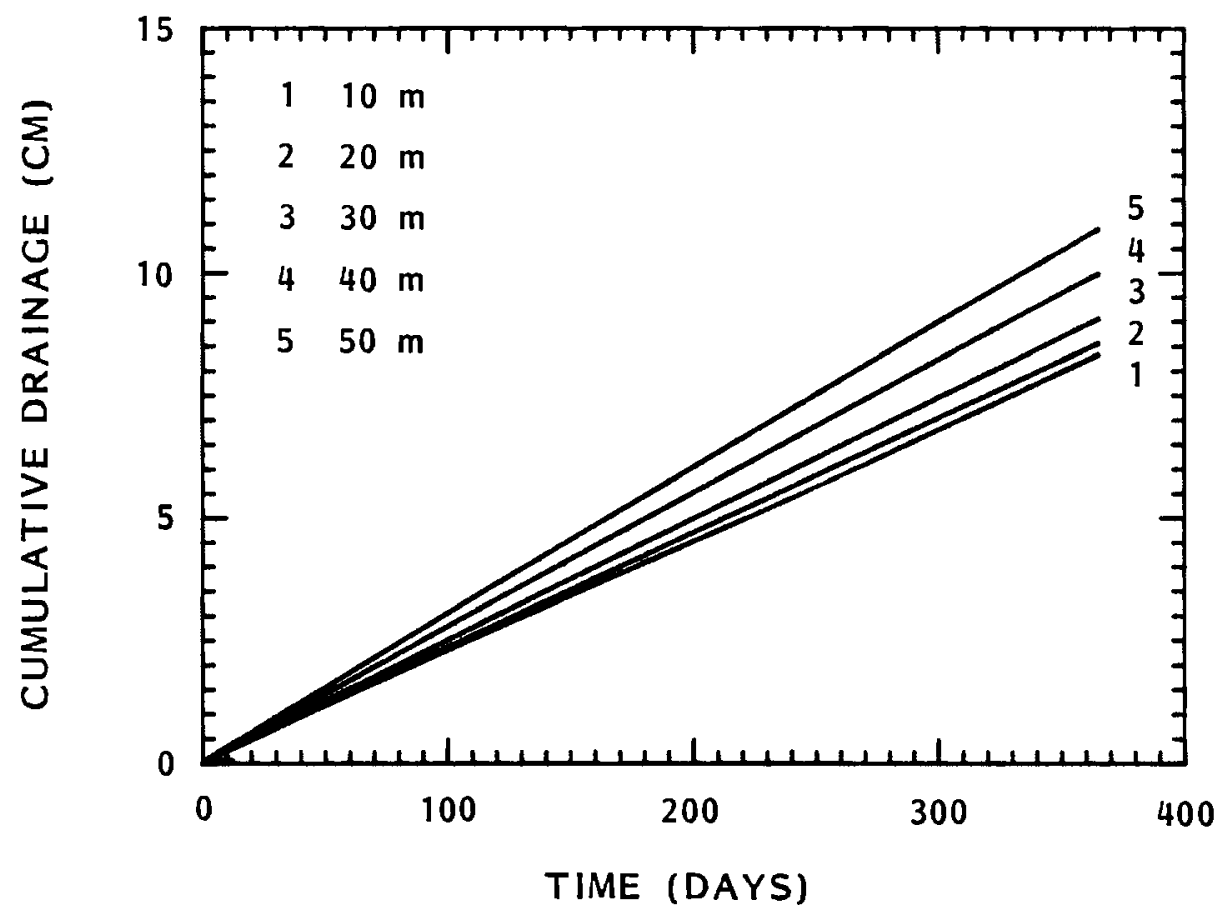

FIGURE 32. Transient Pile 2nd Scenario - Cumulative Water Flux Versus Time at Depths 10, 20, 30, 40, and $55 \mathrm{~m}$ After 20 Years

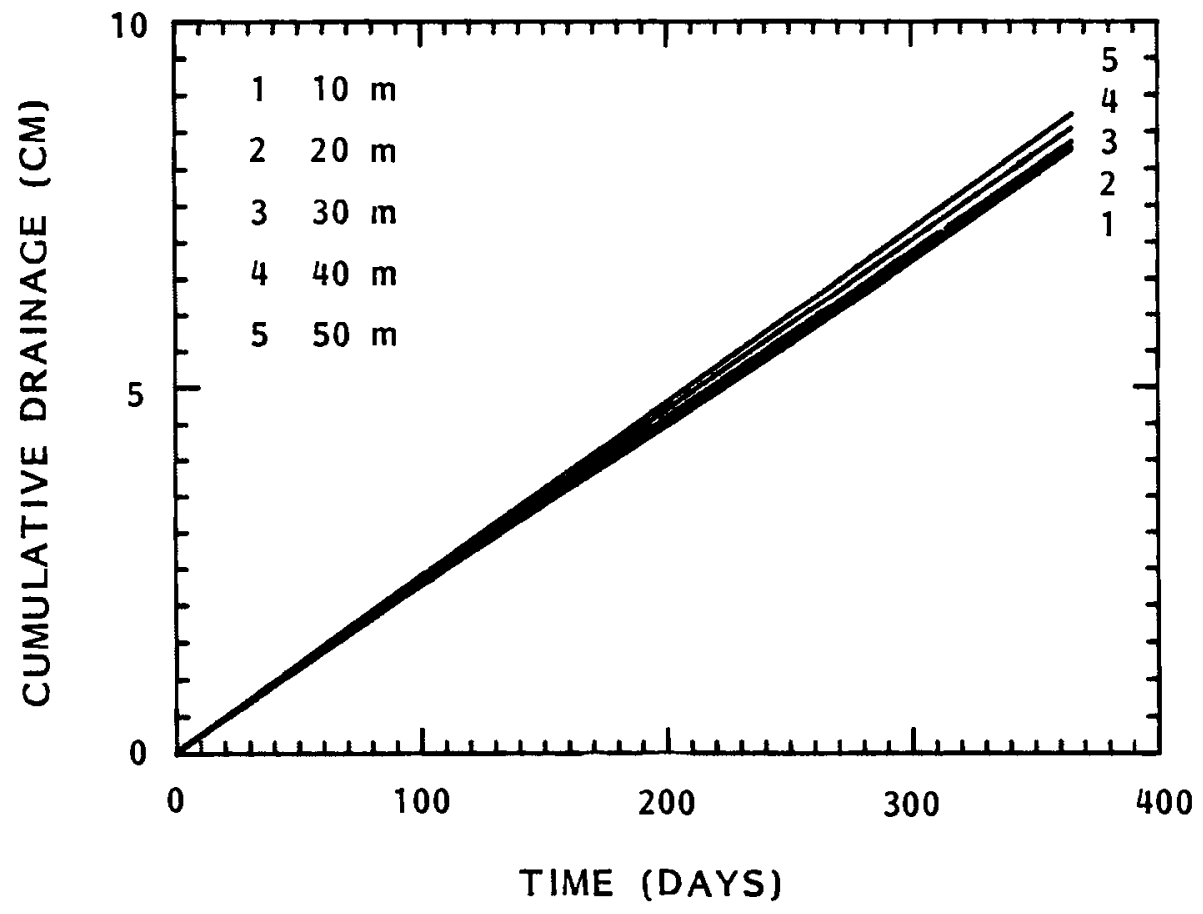

FIGURE 33. Transient Pile 2nd Scenario - Cumulative Water Flux Versus Time at Depths $10,20,30,40$, and $55 \mathrm{~m}$ After 30 Years 


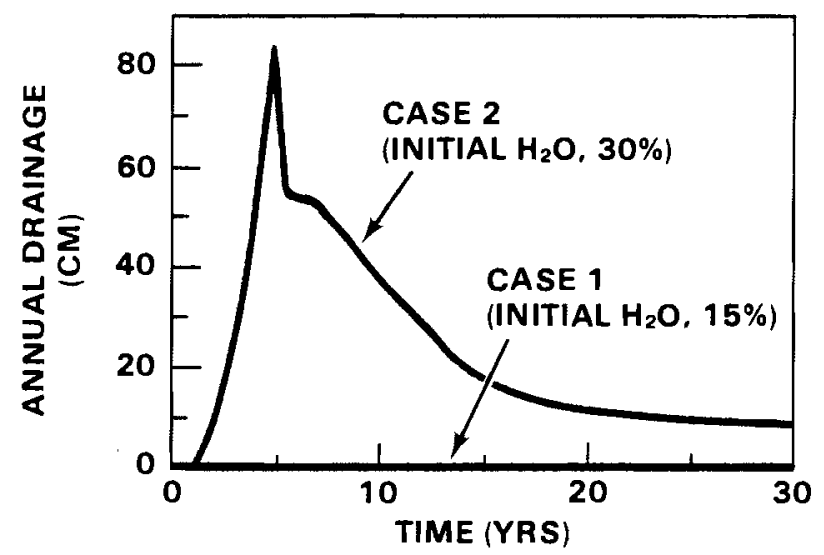

FIGURE 34. Transient Pile - Annual Water Flux (Drainage) Out the Base of the Spent Shale Pile Over the 30-yr Simulation Period

\section{Water Balance}

Water balance data for the two scenarios of the transient pile growth case for the 30 th year are given below. Equation 4 defines the water balance equation.

Scenario 1 (Low Initial Water Content) Water Balance

$$
\begin{aligned}
& \text { Ppt }=30.56 \mathrm{~cm} \\
& \text { Evap }=20.55 \mathrm{~cm} \\
& \text { Dr }=0.00 \mathrm{~cm} \\
& \text { Ro }=0.83 \mathrm{~cm} \\
& \mathrm{~S}=9.18 \mathrm{~cm}
\end{aligned}
$$

Scenario 2 (High Initial Water Content) Water Balance

$$
\begin{aligned}
& \text { Ppt }=30.56 \mathrm{~cm} \\
& \text { Evap }=21.75 \mathrm{~cm} \\
& \text { Dr }=8.71 \mathrm{~cm} \\
& \text { Ro }=3.21 \mathrm{~cm} \\
& \mathrm{~S}=-3.11 \mathrm{~cm}
\end{aligned}
$$

As discussed earlier, there was no drainage from the pile in the first scenario and there was an increase in storage of $9.18 \mathrm{~cm}$ in the 30 th year. In contrast to this, $8.71 \mathrm{~cm}$ drained from the pile in the 30 th year of the second 
scenario and there was a decrease in storage of $3.11 \mathrm{~cm}$. In the second scenario there was more surface runoff than in the first scenario $13.21 \mathrm{~cm}$ versus $0.83 \mathrm{~cm}$ ) due to the increased water content resulting in less space for storage in the soil. 


\section{REFERENCES}

Argall, J. R. (ed). 1978. "Tailings Disposal Today," Proceedings of the Second International Tailing Symposium. Denver, Colorado, Vol. 2, pp. 244-249.

Bond, F. W., C. R. Cole and P. J. Gutknecht. 1982. Unsaturated Flow Model (UNSAT1D) Computer Code Manual. EPRI CS-2423.

Beese, F., R. R. van der Ploeg and W. Richter. 1977. Test of a Soil-Water Model Under Field Conditions. Soil. Sci. Soc. Am. J. 41:979-984.

B loomsburg, G. L., and R. D. Wells. 1978. Seepage Through Partially Saturated Shale Wastes. U.S. Bureau of Mines.

Cloninger, J. S. 1978. Revegetation of Retorted Shale. Presented at American Nuc lear Soc iety, Denver, Colorado, September 26, 1978. Union 0il Co. of California, Grand Junction, Colorado.

DOI (U.S. Department of the Interior). 1977. Final Environmental Impact Statement. Proposed Development of the $0 i 1$ Shale Resources. Colony Development Operation, Atlantic Richfield, Co., Denver, CoTorado.

Doorenbos, J., and W. 0. Pruitt. 1975. "Guidelines for Predicting Crop Water Requirements," Irrigation and Drainage Paper 24:1-179. First Edition. Food and Agricultural Organization of the United Nations, Rome.

Feddes, R. A., P. J. Kowalik and H. Zaradny. 1978. Simulation of Field Water Use and Crop Yield. John Wiley and Sons, New York, New York.

Gupta, S. K., K. Tanji, D. Nielsen, J. Biggar, C. Simmons and J. Macintyre. 1978. Field Simulation of Soil-Water Movement with Crop Water Extraction. Water Science and Engineering Paper No. 4013. Dept. of Land, Air, and Water Resour., Univ. of Calif., Davis.

IMSL, Inc. 1980. IMSL Library Refrence Manual. Edition 8, Vol. 3 Houston, Texas.

Kilkelly, M. K., H. P. Harbert and W. A. Berg. 1981. Field Studies on Paraho Retorted 0il Shale Lysimeters: Leachate, Vegetation, Moisture, Salinity, and Runoff, 1977-1980. U.S. Environmental Protection Agency. EPA-600/57-81-131.

Merino, J. M., and R. B. Crookston. 1977. Reclamation of Spent $0 i 1$ Shale. Mining Congress Journal, 10:31-36.

Molz, F. J., J. M. Davidson and E. W. Tollner. 1979. Unsaturated Zone Water. Amer. Geophysical Union, 17:1221-1239. 
Mualem, Y. 1976a. A Catalog of the Hydraulic Properties of Unsaturated Soils. Hydrodynamics and HydrauTic Laboratory, Technion Israel Institute of Technology, Haifa, Israel. Research Project 442.

Mualem, Y. 1976b. A New Model for Predicting the Hydraulic Conductivity of Unsaturated Porous Media. Water Resour. Res. 12:513-522.

NOAA (National Oceanic and Atmospheric Administration). 1976, 1979. Local Climatological Data, Monthly Summary for Grand Junction, Colorado. Department of Commerce.

Nelson, R. W., A. E. Reisenauer and G.W. Gee. 1980. Model Assessment of Alternatives for Reducing Seepage from Buried Uranium Mill Tailings at the Morton Ranch Site in Central Wyoming. NUREG/CR-1495 Nuc lear Regulatory Commission.

Rio Blanco Oil Shale Project. 1981. Modification to the Detailed Development Plan: Lurgi Demonstration Project. Gulf Oil Corp. and Standard Oil Co. (Ind), Denver, Colorado, February 1981.

Wildung, R. E., and J. M. Zachara. 1980. Geochemistry of 0il Shale Solid Waste Disposal. In: Proc. of Symposium: 0 il Shale-The Environmental Challenges, Vail, Colorado. Colorado School of Mines Press, Golden, Colorado.

Wildung, R. E., and J. M. Zachara. 1981. Effects of 0il Shale Solid Waste Disposal on Water Quality: Current Knowledge, Information Requirements, and Research Strategy. In: Proc. of Symposium: 0iा Shale-The Environmental Challenges II, Vail, Colorado.

Wymore, I. F., W. D. Striffler and W. A. Berg. 1974. "Water Requirements for Stabilizing and Vegetating Spent Shale in the Piceance Basin." in Surface Rehabilitation of Land Disturbances Resulting From 0 il Shale Development. Environmental Resources Center, Colorado State University, Fort Collins, Colorado. Tech. Rept. Series No. 1. 
APPENDIX A

PROGRAM HYDRAK 
PROGRAM HYDRAK

Because of the complication encountered in measurements of hydraulic conductivity in the laboratory, a considerable effort has been made to develop theoretical capillary flow models of hydraulic conductivity $(K)$. The computer program HYDRAK was developed which uses three such models (Millington-Quirk, Mualem and Burdine) to estimate the hydraulic conductivity versus suction head relationship from the moisture content versus suction head relationship for a particular soil. Mualem (1976b) discusses each of these methods.

Mualem's model is the most recent and is based on the relationship between the pore size distribution and the soil moisture characteristics. The model calculates the relative hydraulic conductivity $K_{r}(\theta)$ :

$$
K_{r}(\theta)=S_{e}^{n}\left[\int_{0}^{\theta} d \theta / h \int_{0}^{\theta} \operatorname{sat} d \theta / h\right]^{2}
$$

where

$K_{r}(\theta)=$ relative hydraulic conductivity as a function of water content

$\theta=$ water content of the soil

$\mathrm{S}_{\mathrm{e}}=$ effective saturation

$h=$ capillary head (or suction, negative pressure head)

$\mathbf{n}=0.5$ is the best $f$ it value as determined by Mualem for 45 soils.

The effective saturation is given by:

$$
S_{e}=\frac{\theta-\theta_{r}}{\theta_{\text {sat }}-\theta_{r}}
$$

where

$$
\begin{aligned}
\theta_{r} & =\text { residual water content, measured after substantial drying } \\
\theta_{\text {sat }} & =\text { saturated water content. }
\end{aligned}
$$


Once the relative hydraulic conductivities are calculated, the curve is matched with one or more measured hydraulic conductivities. Most often, this matching factor is the saturated hydraulic conductivity, but HYDRAK is capable of using more than one point. The saturated hydraulic conductivity is used most often because it is the least difficult and most accurate to measure.

Inspection of the test cases given by Mualem shows the results are sensitive to both the choice of the hydraulic conductivity model and the soil type. Generally, Mualem's model seems to be the most reliable since agreement with most of the measured cases is best.

A few difficulties are typically encountered when applying these capillary conductivity models. The computed results are affected by the presence or absence of a capillary fringe and depend strongly on the residual water content.

The capillary fringe is a region on the soil moisture characteristic curve where the soil is saturated, or nearly so. The air entry pressure head must be reached before any substantial reduction in water content will occur. In a field situation, the capillary fringe occurs above the phreatic surface. HYDRAK checks for fringe conditions. To enable the computer program to recognize a capillary fringe, zero slope must be observed. HYDRAK then discards the fringe for calculation of the relative hydraulic conductivity by setting the matching factor at the fringe turning point.

Difficulties arise in calculating the relative hydraulic conductivities when the fringe region has a slight slope. Physically, this is not unreasonable because most fringes are likely never saturated throughout. However, when this occurs, HYDRAK has computational difficulties. The matching factor for the saturated hydraulic conductivity is assigned to the saturated water content and the sloped fringe region is included in the computation. This produces a large drop in head over a small change in water content. Because the relative hydraulic conductivity varies as the inverse of suction, the result is a large drop in the hydraulic conductivity curve in the same water content region. 
The capillary fringe must therefore be included. Most measured soils will show a fringe, but to enable HYDRAK to compute the correct relative hydraulic conductivities, the fringe region must have no change in water content with a change in suction.

The second problem encountered is that the relative hydraulic conductivity calculations depend strongly on the residual water content $\theta_{r}$. Residual water content represents the smallest pore size involved in liquid capillary flow, but is reached only after extensive drying. Measurements become increasingly difficult in the upper range of suction, so often the residual water content is far from the other points and a dummy value of suction head may be assigned to that water content. When this is the case, a computer program called EXTEND is used to extrapolate the curve. Program EXTEND is discussed in Appendix $B$. 


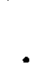


APPENDIX B

PROGRAM EXTEND 


\section{PROGRAM EXTEND}

Measurement of water retention characteristics at high suction is often limited by the laboratory apparatus. Therefore, Mualem (1976) discusses a need for an objective analytic procedure for extrapolating measured soil moisture characteristic curves to the residual water content. Often, only a portion of the characteristic is measured and it is unclear how to extrapolate the curve to the residual water content.

Two conditions must be fulfilled by the extended soil moisture characteristic curve. As the water content approaches the residual value, de/dh must approach zero. Secondly, the curve extension must pass through the last measured point $\left(h_{\max }, \theta_{\min }\right)$. The derivative de/dh must approach zero to fulfill the additional requirement that $K\left(\theta_{r}\right)=0$.

The algorithm presented by Mualem is:

$$
\frac{\theta-\theta_{r}}{\theta_{\min }-\theta_{r}}=\left(\frac{h_{\min }}{h}\right)^{\lambda}
$$

where

$\theta, \theta_{r}=$ the actual and residual water contents

$\theta_{\min }=$ the minimum measured water content

$h_{\max }=$ the minimum measured capillary head

$\mathrm{h}=$ the capillary or suction head

$\lambda=$ an exponent based on a specified number of the measured points.

This relationship is solved for the actual water content to complete the curve once the parameter $\lambda$ is fixed. The exponent $\lambda$ is computed with the aid of a minimum square deviation regression of measured soil moisture characteristic points. The relationship for calculating $\lambda$ is: 


$$
\lambda=\frac{\sum_{1}^{N}\left[\ln \left(\frac{\theta_{i}-\theta_{r}}{\theta_{\min }-\theta_{r}}\right)\right]^{2}}{\sum_{1}^{N} \ln \left(\frac{h_{\min }}{h_{i}}\right) \ln \left(\frac{\theta_{i}-\theta_{r}}{\theta_{\min }-\theta_{r}}\right)}
$$

where $N$ is the number of points $\lambda$ is based on. A requirement is that the sum of the square deviation of the measured data from the analytic curve is a minimum. Mualem assumes a series for $\theta_{r}$ (up to $\theta_{\text {min }}$ ) and selects the $\theta_{r}$ which gives the minimum square deviation.

Program EXTEND uses a measured $\theta_{r}$. It is assumed that this value of $\theta_{r}$ would give a minimum square deviation. The exponent $\lambda$ is sensitive to the number of points used to calculate the value. The user interactively sets the number of measured points on which $\lambda$ is based. The maximum value of $\lambda$ should be selected to best obtain a curve extension where $d \theta / d h \rightarrow 0$ as $\theta \rightarrow \theta_{r}$. The number of measured points maximum $\lambda$ is based on will vary with the soil type and the measured data set.

The relationship for calculating the actual water content asymptotically approaches the residual water content. Stating that $h \rightarrow \infty$ for $\theta \rightarrow \theta_{r}$ is another way to describe this. The suction must be large to reach the residual water content. This creates numerical difficulties when the extended curve is input to HYDRAK. HYDRAK attempts to calculate relative hydraulic conductivities which are too small for the computer to handle and the program stops. Inasmuch as unsaturated water flow becomes dominated by vapor phase movement at large suction, program EXTEND overrides the user's interactive selection of suction at $10^{9}$ and recalculates the residual water content at that value. This recalculation does not greatly affect the hydraulic conductivity estimates.

A serious limitation to the use of program EXTEND is that the measured data set must include the capillary fringe turning point. If measurements do not express the turning point of the characteristic curve, $\lambda$ will not be large enough to permit an adequate extension. 
APPENDIX C

PROGRAM POLYFIT 
APPENDIX C

PROGRAM POLYFIT

Program POLYFIT was developed to fit the soil water characteristic curve [water content $(\theta)$ versus suction head] and the hydraulic conductivity $(K)$ versus suction head $(h)$ relationship with polynomial expressions. The polynomials developed are used directly in UNSAT1D to provide the relationships between $\theta, h$, and $K$. Polynomial expressions are used to avoid large data storage requirements associated with many material layers and provide a convenient method for interpolating between data points.

POLYFIT has the capability to fit an entire data set (curve) with a single polynomial, or to divide the curve into a maximum of four subsets and fit each one with a separate polynomial. The maximum degree of the polynomial expression is 6 .

For each subset, the polynomial expressions are of the form

Soil water characteristic:

$$
\theta(h)=A+B(\log h)+C(\log h)^{2}+\ldots
$$

Hydraulic conductivity:

$$
\log K(h)=A+B(\log h)+C(\log h)^{2}+\ldots
$$

where $\theta$ is moisture content, $h$ is suction head, $K$ is hydraulic conductivity and $A, B, C, .$. are the polynomial coefficients which POLYFIT solves for.

The polynomial fitting portion of the program is performed in a subroutine called RLSEP of the IMSL Library (1980). RLSEP uses a regression model with a forward stepwise algorithm and computes entries for a standard analysis of variance table. 

APPENDIX D

PROGRAM FAOPET 
APPENDIX D

\section{PROGRAM FAOPET}

Program FAOPET was designed to use several theoretical methods for calculating potential evapotranspiration (PET) based on climatic data. PET is defined as "the rate of evapotranspiration from an extensive surface of 8 to $15 \mathrm{~cm}$ tall, green grass cover of uniform height, actively growing, completely shading the ground and not short of water" (Doorenbos and Pruitt 1975). The program can calculate on a routine basis the daily, weekly, or monthly PET for several locations, and provide a table or map of the data distribution.

There are five subroutines to the main program, each of which corresponds to one of the methods available for calculating PET: Blaney-Criddle, Radiation, Penman, Penman with Correction, and Pan Evaporation. The choice of method(s) is based on the type of climatic data available and on the accuracy required in determining water loss. The types of data required by the different methods are temperature, humidity, wind speed, sunshine, and radiation.

For a complete description of the theory and application of the various methods the reader is referred to Guidelines for Predicting Crop Water Requirements (Doorenbos and Pruitt 1975).

In this study, the Penman Radiation, and Blaney Criddle methods were tested using historical climate data available from NOAA (1976, 1979). The Penman method was selected as the preferred method and was used in the modeling test cases. The following data sets were used as input for PET and precipitation for 1976 and 1979 for the modeling test cases: 
1976 Potential Evaporation Precipitation (PET) and PET Data Calculated by the Penman method (Doorenbos and Pruitt 1975)

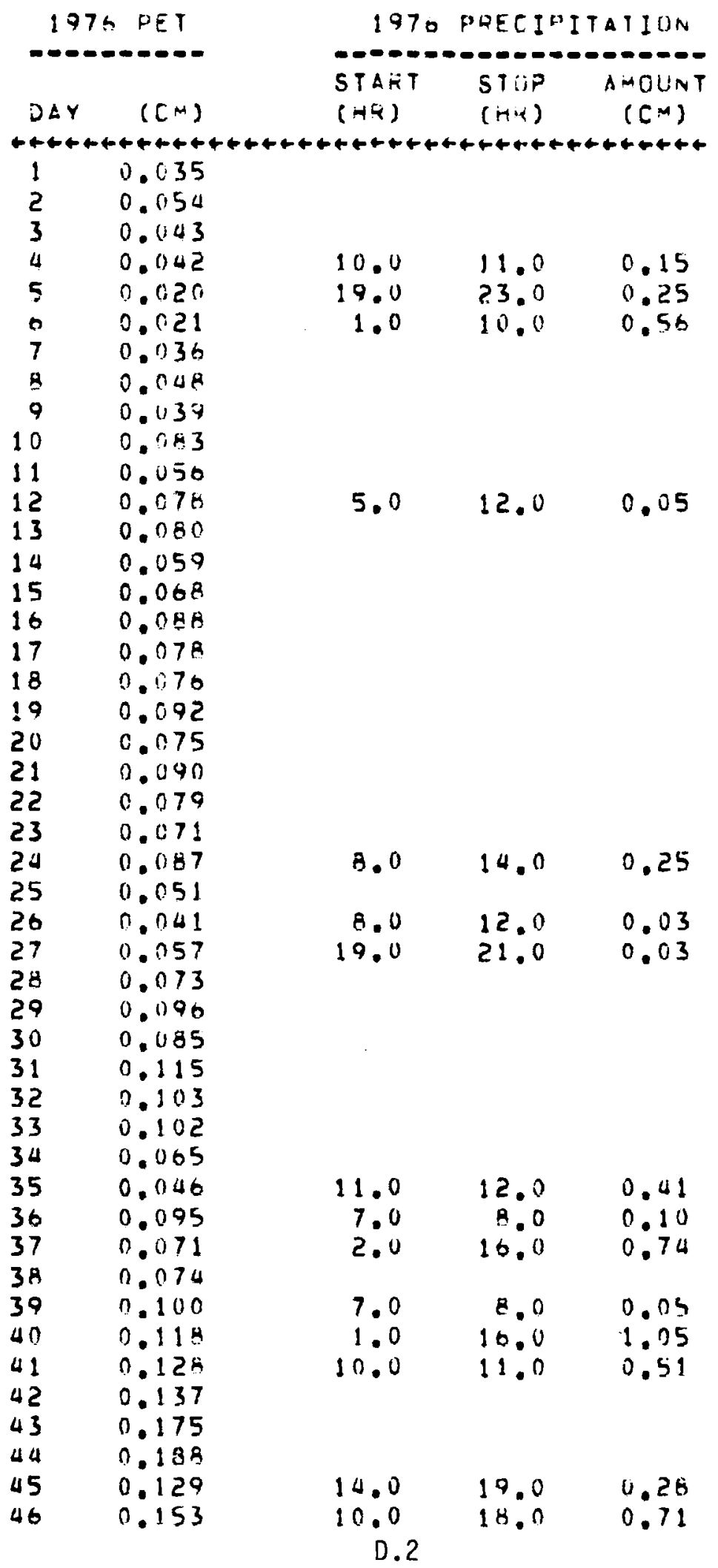


1976 Potential Evaporation Precipitation (PET) and PET Data Calculated by the Penman method (Doorenbos and Pruitt 1975)

\begin{tabular}{|c|c|c|c|c|}
\hline 47 & 0.106 & 1.0 & 4.0 & 0.41 \\
\hline 48 & 0.222 & 1.0 & 6.0 & 0.05 \\
\hline 40 & 0.181 & & & \\
\hline $\begin{array}{l}50 \\
51\end{array}$ & $0.31 ?$ & & & \\
\hline $\begin{array}{l}51 \\
52\end{array}$ & $\begin{array}{l}0.212 \\
0.149\end{array}$ & & & \\
\hline 53 & 0.179 & & & \\
\hline $\begin{array}{l}54 \\
55\end{array}$ & 0.190 & & & \\
\hline $\begin{array}{l}55 \\
56\end{array}$ & 0.187 & & & \\
\hline $\begin{array}{l}56 \\
57\end{array}$ & $\begin{array}{l}0.236 \\
0.240\end{array}$ & & & \\
\hline 58 & $\begin{array}{l}0.24 \pi \\
0.24 \pi\end{array}$ & & & \\
\hline 59 & 0.263 & & & \\
\hline 60 & 0.329 & 19.0 & 24.0 & \\
\hline 61 & 0.507 & 1.0 & 13.0 & $\begin{array}{r}0.10 \\
2.18\end{array}$ \\
\hline $6 ?$ & 0.275 & 12.0 & 24.0 & .10 \\
\hline 63 & 0.004 & 1.0 & 4.0 & 0.33 \\
\hline 64 & 0.094 & 7.0 & 9.0 & 0.15 \\
\hline 65 & 0.151 & & & \\
\hline 66 & 0.144 & & & \\
\hline $\begin{array}{l}67 \\
68\end{array}$ & $0.16 \mathrm{~J}$ & & & \\
\hline $\begin{array}{l}68 \\
69\end{array}$ & 0.199 & & & \\
\hline $\begin{array}{l}69 \\
70\end{array}$ & 0.259 & & & \\
\hline $\begin{array}{l}70 \\
71\end{array}$ & 0.275 & 15.0 & 24.0 & 0.2 \\
\hline $\begin{array}{l}71 \\
72\end{array}$ & 0.180 & 1.0 & 5.0 & 0.1 \\
\hline $\begin{array}{l}72 \\
73\end{array}$ & 0.161 & & & \\
\hline 74 & 0.210 & & & \\
\hline 75 & 0.221 & & & \\
\hline 76 & 0.254 & & & \\
\hline 77 & 0.314 & & & \\
\hline $\begin{array}{l}78 \\
79\end{array}$ & 0.378 & & & \\
\hline $\begin{array}{l}79 \\
80\end{array}$ & 0.430 & & & \\
\hline $\begin{array}{l}80 \\
81\end{array}$ & 0.340 & & & \\
\hline $\begin{array}{l}81 \\
82\end{array}$ & 0.329 & & & \\
\hline 83 & 0.322 & & & \\
\hline & 0.01 & & & \\
\hline 85 & 0.437 & 14.0 & 20.0 & 0.03 \\
\hline 86 & $\begin{array}{l}0.446 \\
0.271\end{array}$ & & & \\
\hline 87 & 0.407 & & & \\
\hline 88 & 0.327 & & & \\
\hline 89 & 0.359 & & & \\
\hline 90 & 0.277 & & & \\
\hline 91 & 0.374 & & & \\
\hline 92 & 0.657 & & & \\
\hline $\begin{array}{l}93 \\
94\end{array}$ & 0.454 & & & \\
\hline $\begin{array}{l}94 \\
95\end{array}$ & 0.431 & & & \\
\hline $\begin{array}{l}95 \\
96\end{array}$ & 0.438 & 1.0 & 19.0 & 0.25 \\
\hline $\begin{array}{l}96 \\
97\end{array}$ & 0.407 & & & \\
\hline \multirow{2}{*}{97} & 0.290 & 16.0 & 19.0 & \\
\hline & & $D .3$ & & \\
\hline
\end{tabular}


1976 Potential Evaporation Precipitation (PET) and PET Data

Calculated by the Penman method (Doorenbos and Pruitt 1975)

\begin{tabular}{|c|c|c|c|c|}
\hline 98 & 0.322 & & & \\
\hline 99 & 0.411 & & & \\
\hline 100 & 0.578 & & & \\
\hline 101 & 0.505 & & & \\
\hline 102 & 0.657 & 15.0 & 19.0 & 0.58 \\
\hline 103 & 0.401 & 13.0 & 17.0 & 0.28 \\
\hline 104 & 0.351 & 15.0 & 19.0 & 0.13 \\
\hline $\begin{array}{l}105 \\
106\end{array}$ & $\begin{array}{l}0.326 \\
0.409\end{array}$ & & & \\
\hline 107 & 0.357 & & & \\
\hline 108 & 0.340 & 2.0 & 13.0 & 0.41 \\
\hline 109 & 0.220 & 1.0 & 2.0 & 0.05 \\
\hline 110 & 0.355 & & & \\
\hline 111 & 0.418 & & & \\
\hline 112 & 0.562 & & & \\
\hline 113 & 0.526 & 10.0 & 11.0 & 0.10 \\
\hline 114 & 0.515 & & & \\
\hline 115 & 0.446 & & & \\
\hline 116 & 0.726 & & & \\
\hline 117 & 0.609 & & & \\
\hline 118 & 0.457 & & & \\
\hline 119 & 0.547 & & & \\
\hline 120 & 0.525 & & & \\
\hline 121 & 0.537 & & & \\
\hline 122 & 0.480 & & & \\
\hline $\begin{array}{l}123 \\
124\end{array}$ & 0.578 & & & \\
\hline $\begin{array}{l}124 \\
125\end{array}$ & $\begin{array}{l}0.556 \\
0.425\end{array}$ & & & \\
\hline $\begin{array}{l}125 \\
126\end{array}$ & $0.4 \pi 0$ & & & \\
\hline 127 & 0.271 & 22.0 & 24.0 & 0,20 \\
\hline 128 & 0.442 & 1.0 & 7.0 & 0.05 \\
\hline 129 & 0.287 & 2.0 & 7.0 & 0.43 \\
\hline 130 & 0.392 & & & \\
\hline 131 & 0.534 & 18.0 & 19.0 & 0.05 \\
\hline $\begin{array}{l}132 \\
133\end{array}$ & $\begin{array}{l}0.077 \\
0.580\end{array}$ & & & \\
\hline $\begin{array}{l}133 \\
134\end{array}$ & $\begin{array}{l}0.580 \\
0.542\end{array}$ & & & \\
\hline $\begin{array}{l}134 \\
135\end{array}$ & $\begin{array}{l}0.542 \\
0.684\end{array}$ & & & \\
\hline $\begin{array}{l}135 \\
136\end{array}$ & 0.6802 & & & \\
\hline $\begin{array}{l}136 \\
137\end{array}$ & 0.542 & & & \\
\hline 138 & 0.085 & & & \\
\hline 139 & 0.609 & 17.0 & 19.0 & 0.25 \\
\hline 140 & 0.633 & 6.0 & 12.0 & 0.71 \\
\hline 141 & 0.396 & 3.0 & 14.0 & 0.66 \\
\hline 142 & 0.265 & 15.0 & 24.0 & 0.30 \\
\hline 143 & 0.357 & 5.0 & 14.0 & 0.56 \\
\hline 144 & 0.415 & 18.0 & 20.0 & 0.18 \\
\hline 145 & 0.523 & 14.0 & 17.0 & 0.25 \\
\hline 146 & 0.519 & 17.0 & 20.0 & 0.25 \\
\hline 147 & 0.553 & & & \\
\hline 148 & & & & \\
\hline
\end{tabular}


1976 Potential Evaporation Precipitation (PET) and PET Data Calculated by the Penman method (Doorenbos and Pruitt 1975)

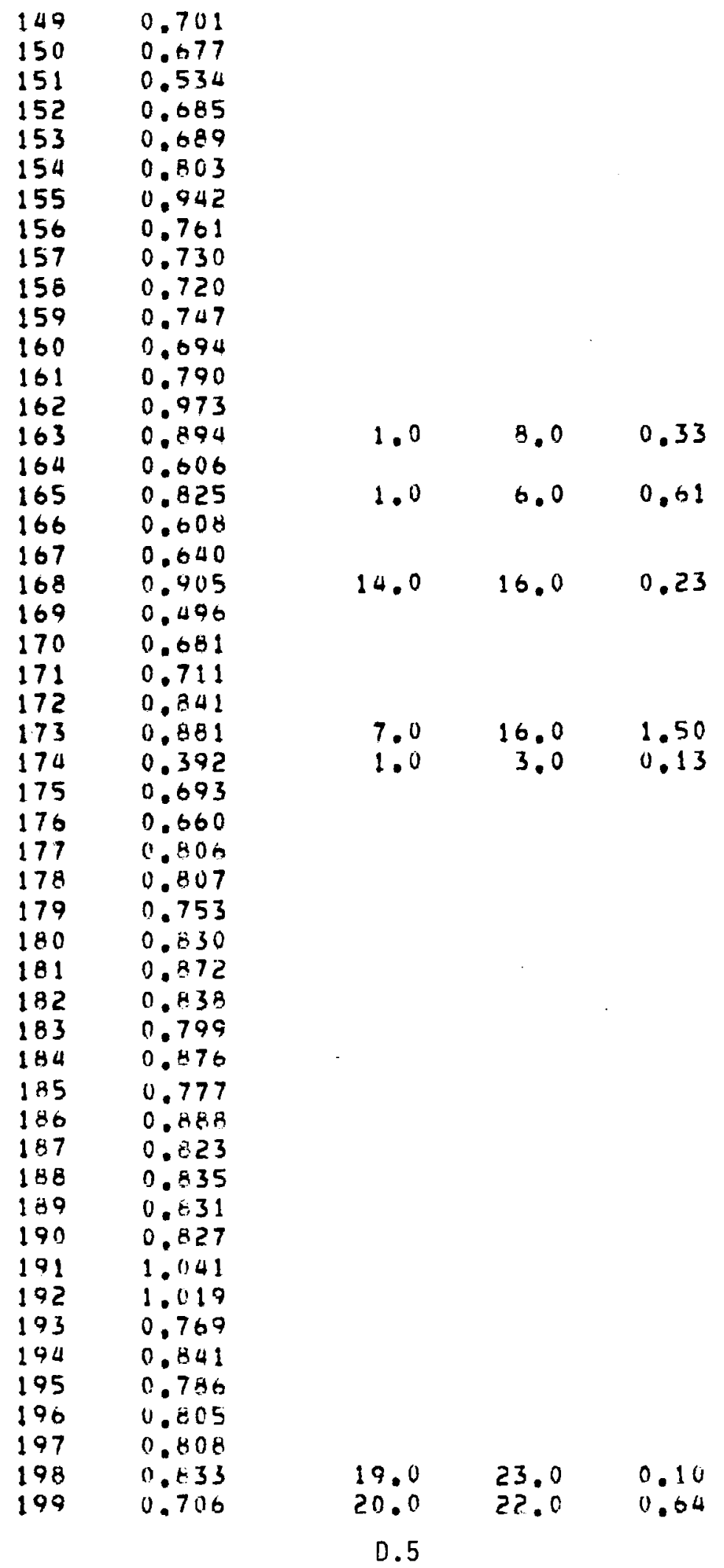


1976 Potential Evaporation Precipitation (PET) and PET Data Calculated by the Penman method (Doorenbos and Pruitt 1975)

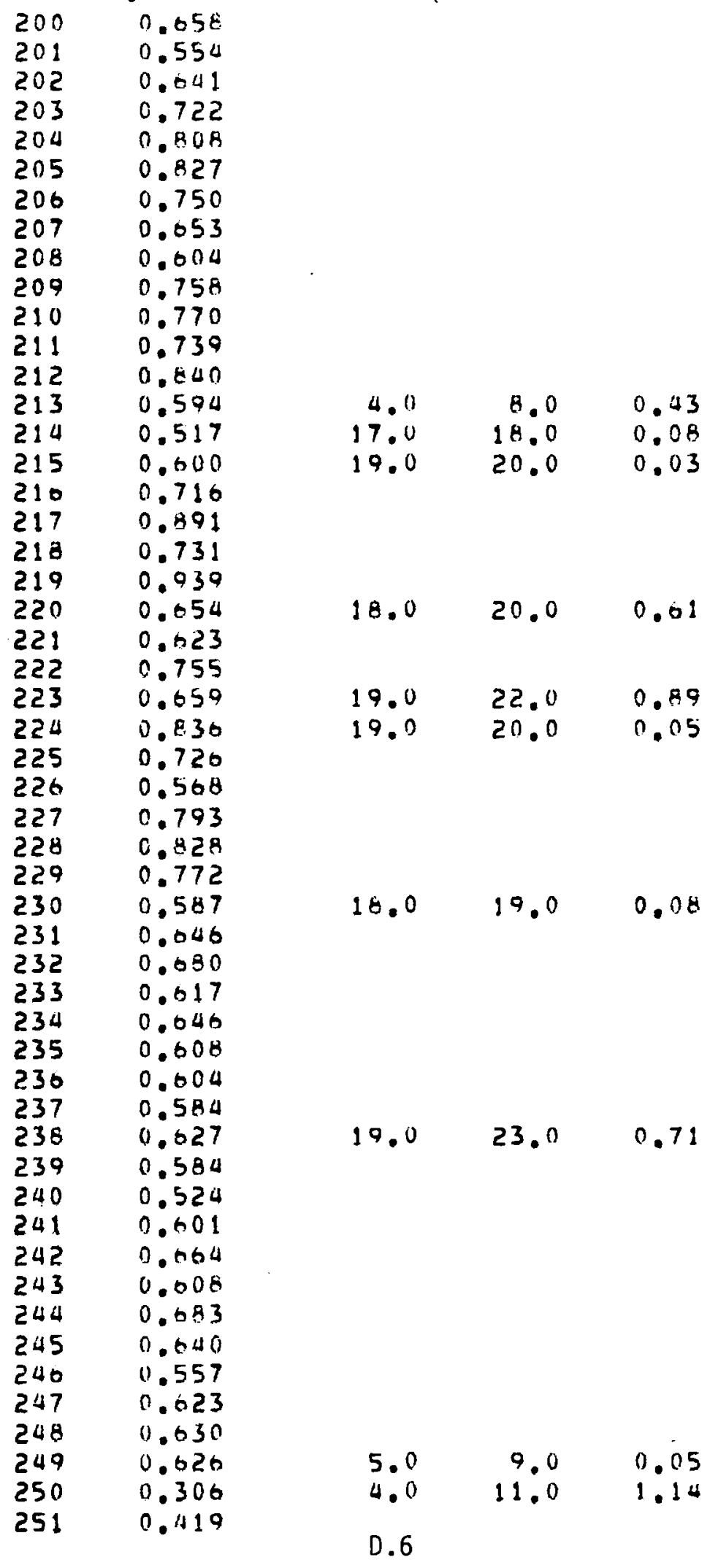


1976 Potential Evaporation Precipitation (PET) and PET Data Calculated by the Penman method (Doorenbos and Pruitt 1975)

$\begin{array}{ll}252 & 0.506 \\ 253 & 0.480 \\ 254 & 0.266 \\ 255 & 0.387 \\ 256 & 0.374 \\ 257 & 0.463 \\ 258 & 0.465 \\ 259 & 0.436 \\ 260 & 0.495 \\ 261 & 0.589 \\ 262 & 0.542 \\ 263 & 0.562 \\ 264 & 0.569 \\ 265 & 0.409 \\ 260 & 0.307 \\ 267 & 0.378 \\ 268 & 0.146 \\ 269 & 0.252 \\ 270 & 0.251 \\ 271 & 0.323 \\ 272 & 0.345 \\ 273 & 0.369 \\ 274 & 0.416 \\ 275 & 0.380 \\ 276 & 0.351 \\ 277 & 0.276 \\ 278 & 0.294 \\ 279 & 0.271 \\ 280 & 0.317 \\ 281 & 0.305 \\ 282 & 0.340 \\ 283 & 0.356 \\ 284 & 0.385 \\ 285 & 0.376 \\ 286 & 0.327 \\ 287 & 0.327 \\ 288 & 0.331 \\ 289 & 0.339 \\ 290 & 0.335 \\ 291 & 0.430 \\ 292 & 0.230 \\ 293 & 0.213 \\ 294 & 0.264 \\ 295 & 0.256 \\ 296 & 0.220 \\ 297 & 0.237 \\ 298 & 0.273 \\ 299 & 0.286 \\ 300 & 0.202 \\ 301 & 0.196 \\ 302 & 0.220\end{array}$

0.7 
1976 Potential Evaporation Precipitation (PET) and PET Data Calculated by the Penman method (Doorenbos and Pruitt 1975)

$\begin{array}{ll}303 & 0.241 \\ 304 & 0.223 \\ 305 & 0.255 \\ 306 & 0.240 \\ 307 & 0.211 \\ 308 & 0.210 \\ 309 & 0.211 \\ 310 & 0.209 \\ 311 & 0.216 \\ 312 & 0.218 \\ 313 & 0.213 \\ 314 & 0.219 \\ 315 & 0.187 \\ 316 & 0.150 \\ 317 & 0.128 \\ 318 & 0.121 \\ 319 & 0.085 \\ 320 & 0.093 \\ 321 & 0.150 \\ 322 & 0.179 \\ 323 & 0.155 \\ 324 & 0.136 \\ 325 & 0.142 \\ 326 & 0.144 \\ 327 & 0.150 \\ 328 & 0.107 \\ 329 & 0.160 \\ 330 & 0.130 \\ 331 & 0.170 \\ 332 & 0.130 \\ 333 & 0.078 \\ 334 & 0.109 \\ 335 & 0.126 \\ 336 & 0.119 \\ 337 & 0.123 \\ 338 & 0.125 \\ 339 & 0.095 \\ 340 & 0.092 \\ 341 & 0.087 \\ 342 & 0.115 \\ 343 & 0.111 \\ 344 & 0.129 \\ 345 & 0.140 \\ 346 & 0.103 \\ 347 & 0.133 \\ 348 & 0.093 \\ 349 & 0.110 \\ 350 & 0.144 \\ 351 & 0.130 \\ 352 & 0.167 \\ 353 & 0.116 \\ & \end{array}$


1976 Potential Evaporation Precipitation (PET) and PET Data Calculated by the Penman method (Doorenbos and Pruitt 1975)

$\begin{array}{ll}354 & 0.140 \\ 355 & 0.113 \\ 356 & 0.107 \\ 357 & 0.117 \\ 358 & 0.093 \\ 359 & 0.098 \\ 360 & 0.073 \\ 361 & 0.111 \\ 302 & 0.128 \\ 363 & 0.123 \\ 364 & 0.113 \\ 365 & 0.089\end{array}$

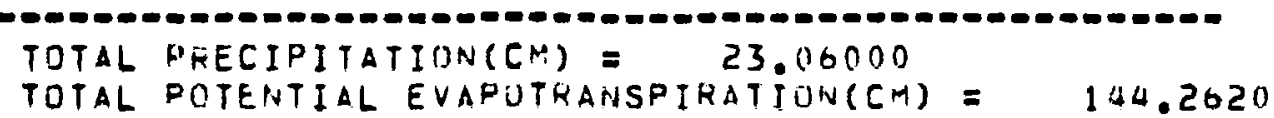


1979 Potential Evaporation Precipitation (PET) and PET Data Calculated by the Penman Method (Doorenbos and Pruitt 1975)

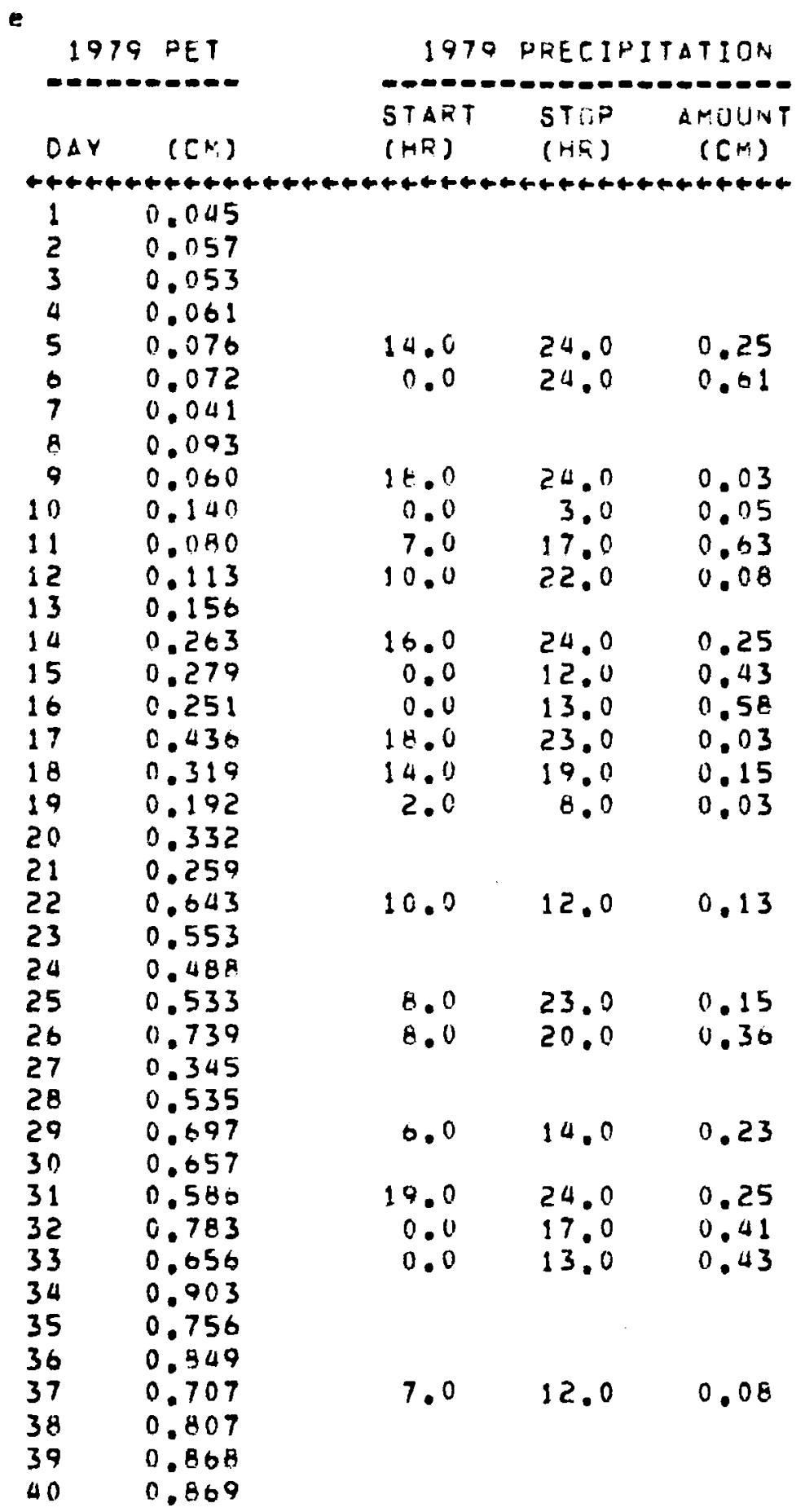


1979 Potential Evaporation Precipitation (PET) and PET Data Calculated by the Penman Method (Doorenbos and Pruitt 1975)

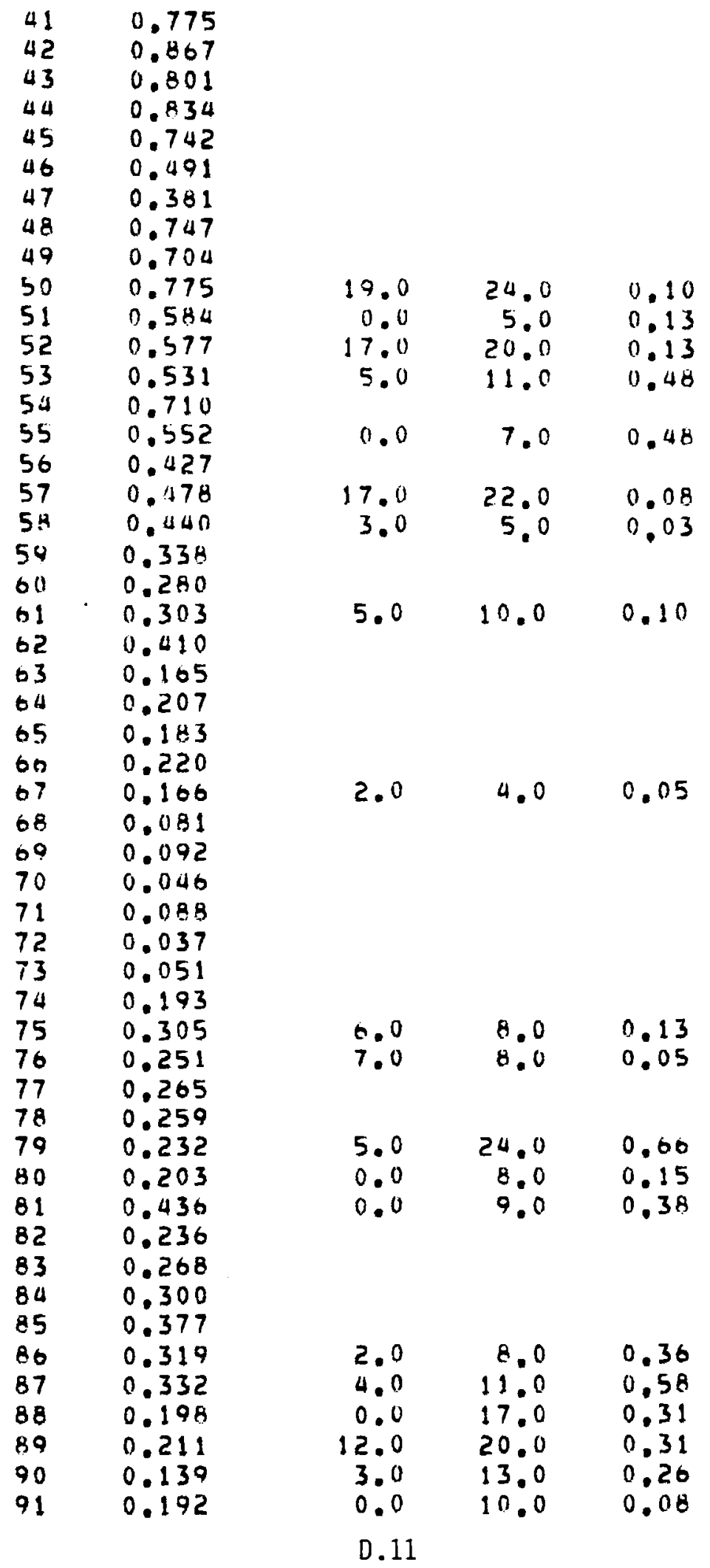


1979 Potential Evaporation Precipitation (PET) and PET Data Calculated by the Penman Method (Doorenbos and Pruitt 1975)

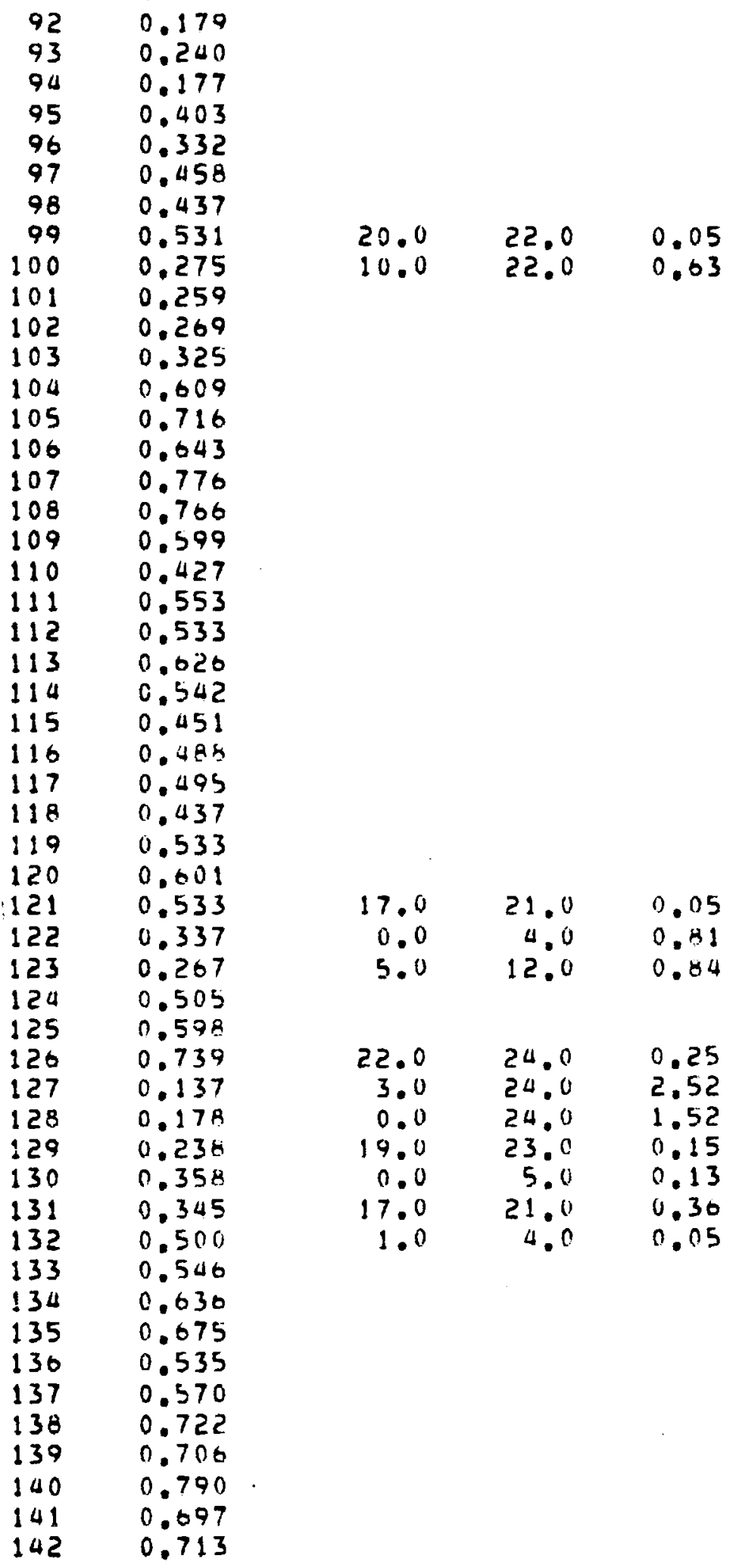


1979 Potential Evaporation Precipitation (PET) and PET Data Calculated by the Penman Method (Doorenbos and Pruitt 1975)

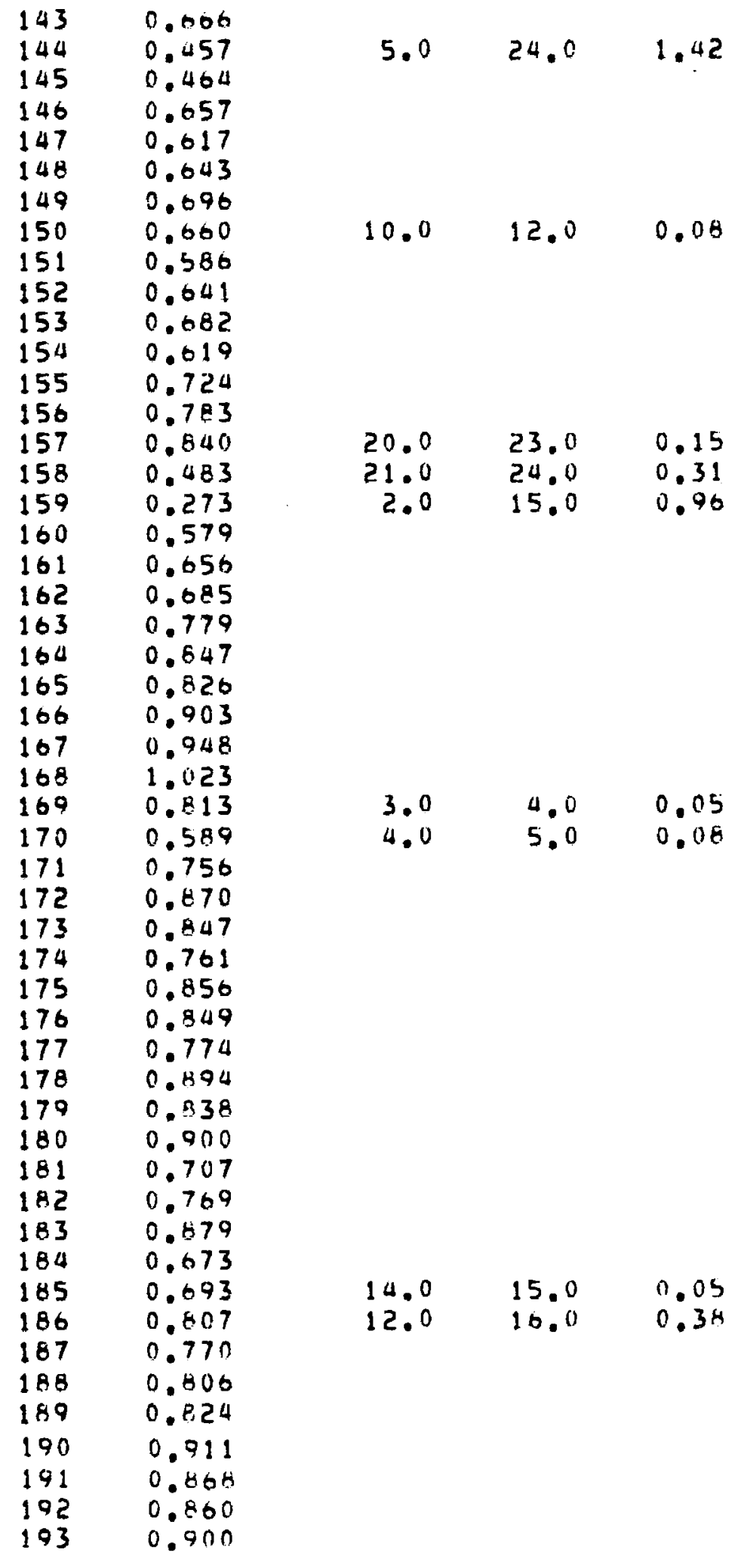


1979 Potential Evaporation Precipitation (PET) and PET Data Calculated by the Penman Method (Doorenbos and Pruitt 1975)

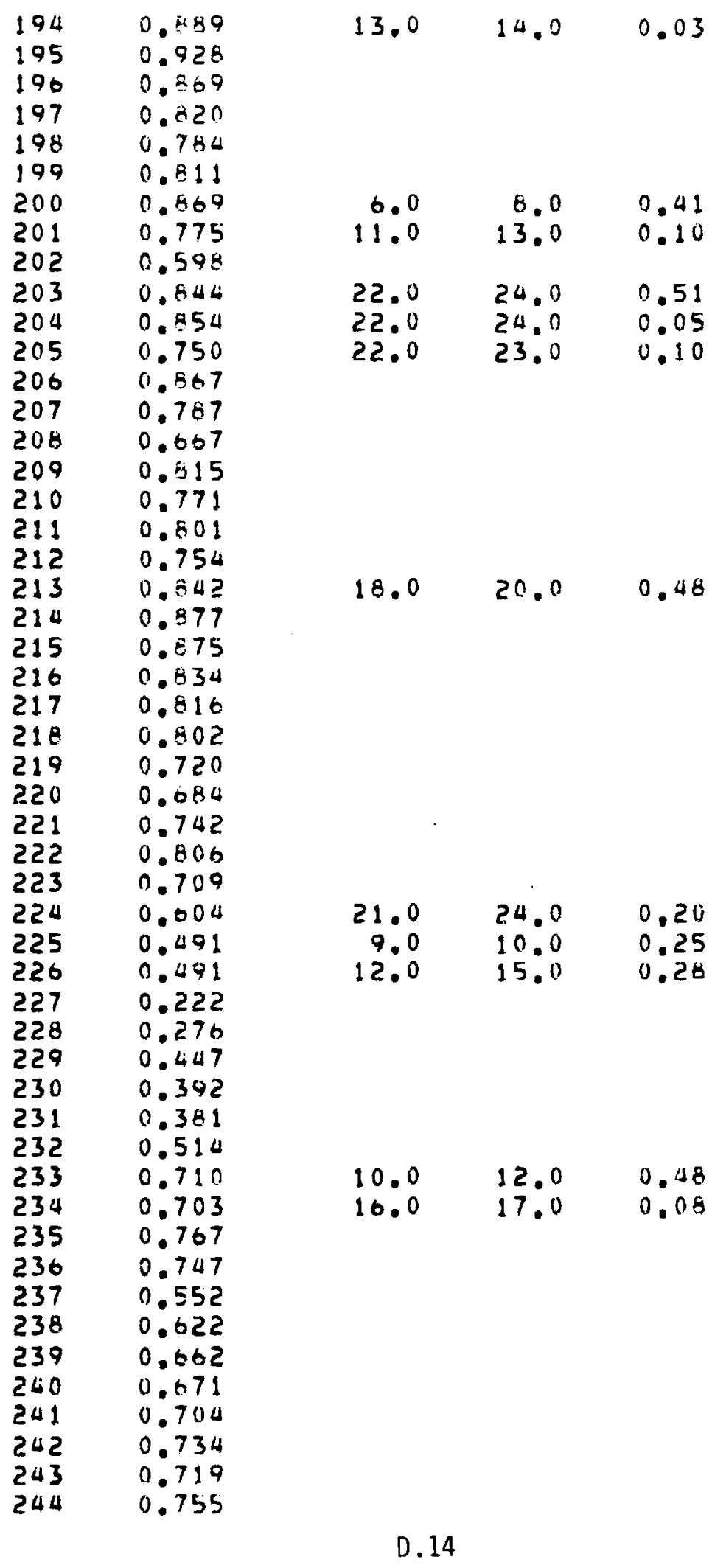


1979 Potential Evaporation Precipitation (PET) and PET Data Calculated by the Penman Method (Doorenbos and Pruitt 1975)

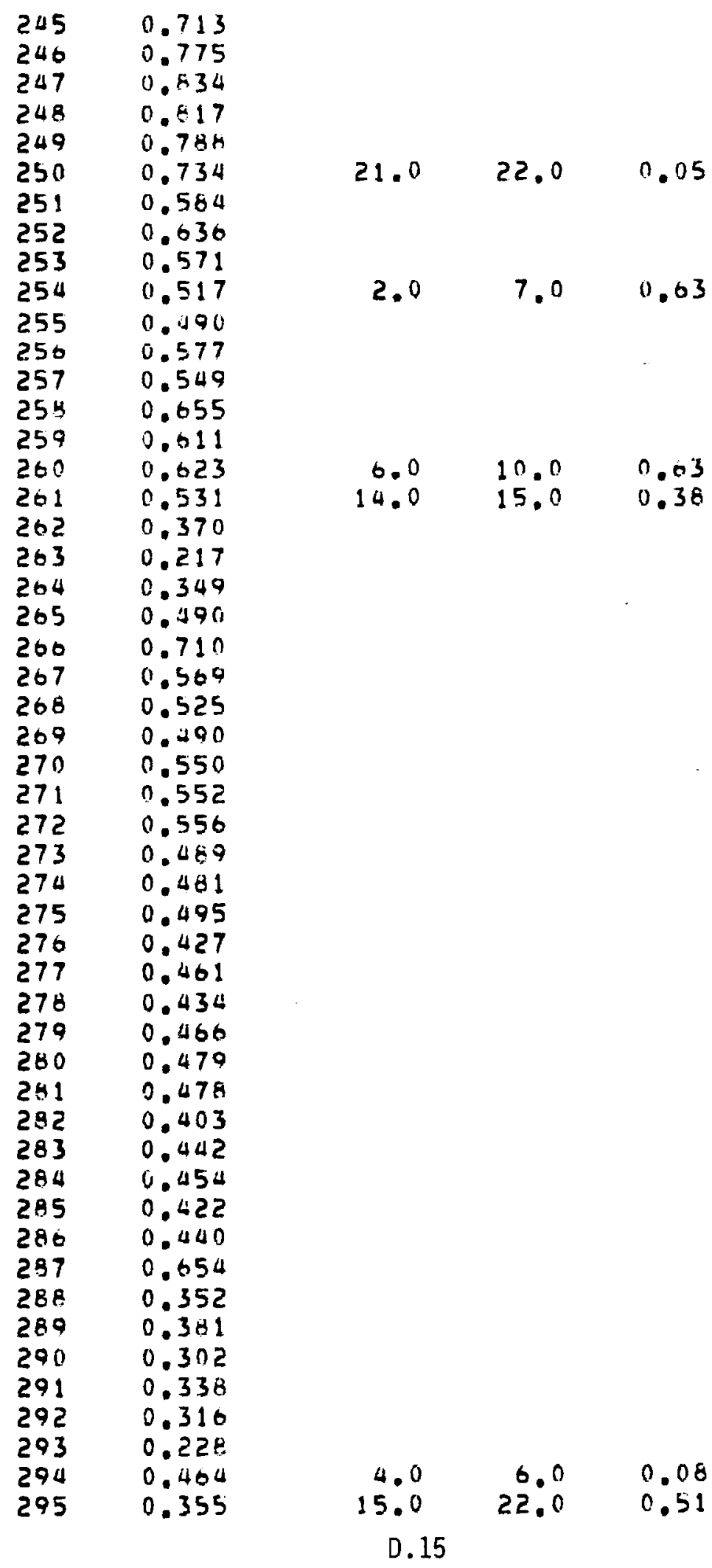


1979 Potential Evaporation Precipitation (PET) and PET Data Calculated by the Penman Method (Doorenbos and Pruitt 1975)

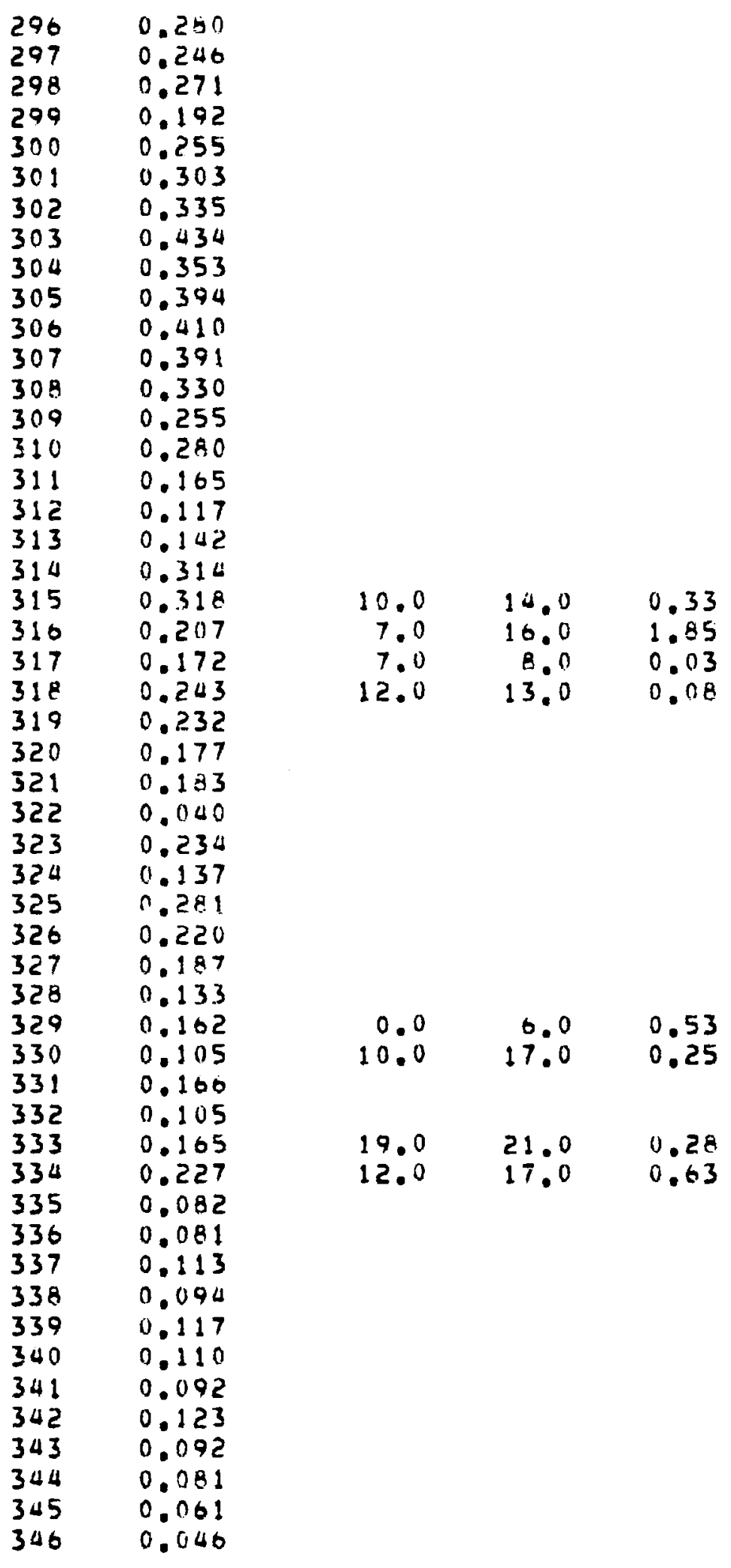


1979 Potential Evaporation Precipitation (PET) and PET Data Calculated by the Penman Method (Doorenbos and Pruitt 1975)

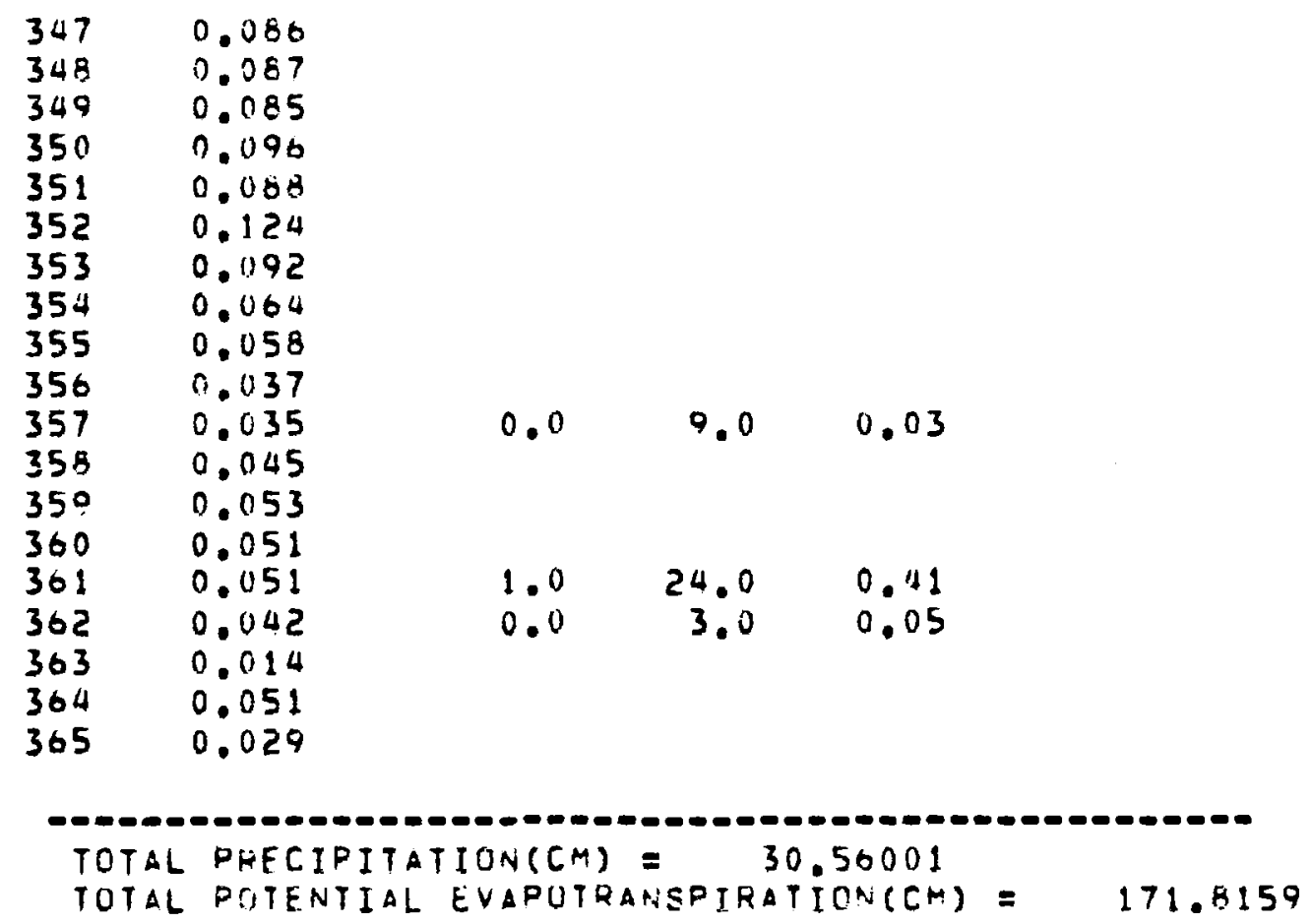


$+$ 


\section{APPENDIX E}

MOISTURE FLOW EQUATION IN FINITE DIFFERENCE FORM 


\section{APPENDIX E}

\section{MOISTURE FLOW EQUATION IN FINITE DIFFERENCE FORM}

In the UNSAT1D program, the unsaturated flow Equation (2) with sink term is represented by a $\mathrm{Crank}-\mathrm{Nicolson}$ implicit finite difference scheme. The total hydraulic head is defined as

$$
H=h+G Z
$$

where $G$ is a gravitational flow angle factor (i.e., $G=1$ for vertical flow and 0 for horizontal flow). The finite difference equation is

$$
c_{i}^{j-1 / 2}\left(\frac{h_{i}^{j}-h_{i}^{j-1}}{\Delta t_{j}}\right)=\frac{2}{Z_{j+1}-Z_{i-1}}\left(q_{j+1 / 2}^{j-1 / 2}-q_{j-1 / 2}^{j-1 / 2}\right)+s_{i}^{j-1 / 2}
$$

where

$$
\begin{aligned}
& c_{i}^{j-1 / 2}=\frac{c_{i}^{j}+c_{i}^{j-1}}{2} \\
& s_{i}^{j-1 / 2}=\frac{s_{i}^{j}+s_{i}^{j-1}}{2} \\
& q_{j}^{j-1 / 2}=\frac{q_{j}^{j}+q_{i}^{j-1}}{2}
\end{aligned}
$$

with

$$
\begin{aligned}
& q_{j+1 / 2}^{j}=k_{i+1 / 2}^{j}\left(\frac{h_{j+1}^{j}-h_{j}^{j}}{\Delta Z i+1}+G\right) \\
& q_{j-1 / 2}^{j}=k_{j-1 / 2}^{j}\left(\frac{h_{j}^{j}-h_{i-1}^{j}}{\Delta Z}+G\right)
\end{aligned}
$$


and with increments

$$
\Delta Z_{i}=z_{i}-z_{i-1}\left(z_{0}=0\right) \text { and } \Delta t_{j}=t_{j}-t_{j-1}\left(t_{0}=0\right)
$$

where $i$ denotes the node of depth, $z_{i}$, and $j$ denotes the $j$ 'th time step, $t_{j}$, with increment $\Delta t_{j}$. Hydraulic conductivity between nodes is calculated as either

$$
k_{j+1 / 2}^{j}=\frac{k_{i}^{j}+k_{j+1}^{j}}{2} \quad \text { (arithmetic mean) }
$$

or

$$
k_{j+1 / 2}^{j}=\left(k_{j}^{j}\right)^{1-w}\left(k_{j+1}^{j}\right)^{w} \quad \text { (geometric mean) }
$$

where $0 \leq w \leq 1$ and $k_{i}^{j}=k\left(h_{j}^{j}\right)$. The weighted mean conductivity (E.4) is a program option useful when the conductivity changes greatly between nodes, as during movement of a wetting front. Without weighting, internodal fluxes (E.2) are determined by the largest conductivity value.

Equation (E.1) is a non-linear equation to be solved for $h_{i}^{j}(i=1, \ldots, N)$ at each time step $j$, based on the head values from the previous time step $j-1$. To begin the solution, the initial head values and boundary condition must be specified. The difference equation for ( $E .1)$ at interior nodes $(i=2, \ldots, N-1)$ is

$$
A_{i}^{\star} h_{i-1}^{*}+B_{i}^{*} h_{i}^{j}+C_{i}^{*} h_{i+1}^{j}=D_{i}^{*}
$$

where

$$
\begin{aligned}
& A_{i}^{\star}=-K_{i-1 / 2}^{j} / \Delta Z^{\star} \Delta Z_{i} \\
& B_{i}^{\star}=C_{i}^{j-1 / 2} / \Delta t_{j}+\left(K_{i+1 / 2}^{j} / \Delta Z_{i+1}+k_{i-1 / 2}^{j} / \Delta Z_{i}\right) / \Delta Z^{*} \\
& C_{i}^{\star}=-K_{i+1 / 2}^{j} / \Delta Z^{\star} \Delta Z_{i+1}
\end{aligned}
$$




$$
\begin{aligned}
D_{i}^{\star} & =c_{i}^{j-1 / 2} h_{i}^{j-1} / \Delta t_{j}+\frac{1}{\Delta Z^{\star}}\left[k_{j+1 / 2}^{j-1}\left(\frac{h_{j+1}^{j-1}-h_{j}^{j-1}}{\Delta Z_{i+1}}+G\right)\right. \\
& \left.-k_{i-1 / 2}^{j-1}\left(\frac{h_{i}^{j-1}-h_{i-1}^{j-1}}{\Delta Z_{i}}+G\right)\right]+\left(k_{i+1 / 2}^{j}-k_{i-1 / 2}^{j}\right) G / \Delta Z^{\star}
\end{aligned}
$$

with $\Delta z^{\star}=z_{1+1}-z_{i-1}$ for $(i=2, \ldots, N-1)$. The tri-diagonal system of Equations (E.5) is solved subject to various boundary condition options listed below.

The fixed surface-head boundary condition is

$$
B_{2}^{\star} h_{2}^{j}+C_{2}^{\star} h_{3}^{j}=D_{2}^{*}-A_{2}^{\star} h_{1}^{j}
$$

for a given $h_{1}^{j}$, [and the system (E.5) begins with $i=2$ ].

The surface flux boundary condition is

$$
B_{1}^{\star} h_{1}^{j}+C_{1}^{*} h_{2}^{j}=D_{1}^{*}
$$

where

$$
\begin{aligned}
A_{1}^{\star} & =0 \\
B_{1}^{\star} & =C_{1}^{j-1 / 2} / \Delta t_{j}+K_{3 / 2}^{j} / \Delta Z^{\star} \Delta Z_{2} \\
C_{1}^{\star} & =-K_{3 / 2}^{j} / \Delta Z^{\star} \Delta Z_{2} \\
D_{1}^{\star} & =C_{1}^{j-1 / 2} h_{1}^{j-1} / \Delta t_{j}+\frac{1}{\Delta Z^{\star}}\left[K_{3 / 2}^{j-1}\left(\frac{h_{2}^{j-1}-h_{1}^{j-1}}{\Delta Z_{2}}+G\right)\right. \\
& \left.+G K_{3 / 2}^{j}-2 q_{1 / 2}^{j-1 / 2}\right]^{-}
\end{aligned}
$$


with $\Delta z^{*}=z_{2}-z_{1}$. The time averaged surface flux $q_{1 / 2}^{j-1 / 2}$ is specified, and the system (E.5) begins with $i=1$.

The fixed head lower boundary condition is

$$
A_{N-1}^{\star} h_{N-2}^{j}+B_{N-1}^{\star} h_{N-1}^{j}=D_{N-1}^{\star}-C_{N-1}^{*} h_{N}^{j}
$$

where $h_{N}^{j}$ is specified, and the system (E.5) ends with $i=N-1$.

The unit gradient lower boundary condition is

$$
A_{N}^{\star} h_{N-1}^{j}+B_{N}^{*} h_{N}^{j}=D_{N}^{*}
$$

where

$$
\begin{aligned}
A_{N}^{\star} & =-K_{N-1}^{j} / \Delta Z^{\star} \Delta Z_{N} \\
B_{N}^{\star} & =C_{N}^{j-1 / 2} / \Delta t j+K_{N-1 / 2}^{j} / \Delta Z^{\star} \Delta Z_{N} \\
C_{N}^{*} & =0 \\
D_{N}^{\star} & =C_{N}^{j-1 / 2} h_{N}^{j-1} / \Delta t_{j}+\frac{1}{\Delta Z^{\star}}\left[2 q_{N+1 / 2}^{j-1 / 2}\right. \\
& \left.-K_{N-1 / 2}^{j-1 / 2}\left(\frac{h_{N}^{j-1}-h_{N-1}^{j-1}}{\Delta Z_{N}}+G\right)-G K_{N-1 / 2}^{j}\right]
\end{aligned}
$$

with $\Delta Z^{\star}=Z_{N}-Z_{N-1}$. The unit gradient drainage flux is

$$
q_{N+1 / 2}^{j-1 / 2}=\frac{1}{2}\left(K_{N}^{j-1}+k_{N}^{j}\right)
$$

A dynamic water table is defined by a specified flux for $q_{N+1 / 2}^{j}$. 
An iterative procedure is used to solve the non-linear system of Equations (E.5). The coefficients $A_{j}^{*}, B_{j}^{*}, C_{j}^{*}$, and $D_{j}^{*}$ are evaluated for the $h_{j}^{j-1}$ of the previous time step, and (E.5) is solved for the $h_{j}^{j}$. These values are then used to re-evaluate the coefficients and solve for a corrected set of head values. The accuracy of the iterative solution is controlled by reducing the time step $\Delta t_{j}$ so that the water mass balance is held within specified error limits.

A special tri-diagonal sequential solution routine is employed to solve (E.5) subject to the given boundary conditions at the profile surface and base. The program proceeds with a surface flux boundary condition whenever evaporation or rainfall is taking place and uses a fixed surface head condition when ponding occurs. If the surface head falls outside specified wet or dry limits during application of surface flux conditions, the program automatically switches to a fixed surface head condition so that a limiting maximum infiltration rate or evaporation rate is imposed by the soil surface.

Soil-Water Mass Balance

Soil-water storage at each time step $j$ is calculated as

$$
w_{j}=\sum_{i=1}^{n}\left(\theta_{i}^{j}+\theta_{j-1}^{j}\right) \Delta z_{j} / 2
$$

Letting $\Delta I_{j}, \Delta E_{j}$, and $\Delta D_{j}$ denote infiltration, evaporation, and drainage, respectively, during each time step, the water mass balance error is calculated as

$$
\text { error }=\left|\Delta I_{j}-\Delta E_{j}-\Delta D_{j}-\Delta W_{j}\right|
$$

Cumulative surface flux $\left(\Delta Q_{j}\right)$ during the time step $\Delta t_{j}$ is

$$
\Delta Q_{j}=\Delta I_{j}-\Delta E_{j}
$$


The program maintains computational accuracy by adjusting the time step so that the mass balance error Equation (E.11) remains less than a prescribed limit. The continuously changing time step is restricted to specified limits, however. Those limits are provided by the user as minimum and maximum time steps in hours. An option to use a reduced time step during water application is also provided. Model computations proceed with the maximum time step and use a reduced time step as required to maintain the prescribed mass balance error.

The water contents $\theta_{j}$ over the nodes are calculated at each time step from the soil-water characteristic curves associated with each soil type, by using the calculated heads. These curves are represented by polynomials (Appendix C). Internodal fluxes from either hourly or daily periods are reported in the program as integrals over time of

$$
q_{j+1 / 2}^{j-1 / 2}
$$

defined by (E.2). Flux is defined as positive in the downward direction. 


\section{DISTRIBUTION}

No. of

Copies

OFFSITE

27 DOE Technical Information Center

Edward Bates

Industrial Environ. Research Lab

Extraction Tech. Branch

U.S. Environ. Protection Agency

Cincinnati, $\mathrm{OH} 45268$

Willard R. Chappell

Campus Box 136

University of Colorado

110014 th Street

Denver, CO 80202

R. Merril Coomes

TOSCO Corporation

10100 Santa Monica Blvd.

Los Angeles, CA 90067

J. Phyllis Fox

J. Phyllis Fox Consulting Serv.

1988 California

Berke ley, CA 94703

Ralph E. Franklin

U.S. Department of Energy

ER-75 GTN

Washington, DC 20545

James God love

White River Shale 0 il Corp.

115 South Main Street

Suite 500 Prudential Bldg.

Salt Lake City, UT 84111

Lawrence B. Gratt

IWG Corp.

975 Hornblend Street

Suite C

San Diego, CA 92109
No. of

Copies

Arthur Hartstein

U.S. Department of Energy

Office of Fossil Energy

FE-34, GTN

Washington, DC 20545

Robert N. Heistand

Anvil Points, Box $A$

Rifle, Co 81650

Jane King

American Petroleum Institute

2101 L Street, N.W.

Washington, DC 20037

Helen M. McCammon

Ecological Research Division

EV-34

E-201 GTN

Office of Energy Research

Washington, DC 20545

Dennis Miller

National Research Council

2101 Constitution Ave., N.W.

Room JH 734

Washington, DC 20418

Glenn Miller

Area 0il Shale Supervisor's Office

131 North 6th Street

Suite 300

Grand Junction, CO 81501

Kathy Petersen

Center for Environ. Sciences

University of Colorado

110014 th Street

Campus Box 136

Denver, CO 80202 
No. of

Copies

Edward Redente

Colorado State University

Department of Range Sciences

Ft. Collins, CO 80523

Cariton B. Scott

Union 0 il Company

461 S. Boylston Street

Los Angeles, CA 90017

Dave Shelton, Director

Colorado Mined Land

Rec lamat ion

1313 Sherman Street

Room 423

Denver, C0 80203

G. C. Slawson

Rio Blanco 0il Shale Company

2851 South Parker Road

Suite 500

Aurora, CO 80014

Russel Tait

ESSO, Australia Limited

70 Goondoon Street

Gl adstone, Queens l and

Australia

Allen Verstuyft

Chevron Shale $0 i l$ Company

Great West Plaza, Tower 2

1625 Broadway

Suite 2150

Denver, CO 80202

Jim Westhoff

Laramie Energy Technical Center

University Station

P. 0. Box 3395

Laramie, WY 82071
No. of

Copies

ONSITE

DOE Richland Operations Office

H. E. Ransom

Marine Research Laboratory (Sequim)

R. L. Schmidt

56 Pacific Northwest Laboratory

F. W. Bond (15)

C. R. Cole

M. E. Dod son

A. R. Felmy

M. D. Freshley

J. S. Fruchter

T. R. Garland

T. E. Gates

G. W. Gee (10)

D. C. Girvin

A. J. Haverfield

P. R. Heller

E. A. Jenne

K. M. Krupka

K. E. Myers

D. E. Oleson

A. E. Reisenauer

R. G. Riley

J. E. Rogers

J. A. Stott lemyre

N. M. Sherer

W. L. Temp leton

R. E. Wildung

W. R. Wiley

B. E. Vaughan

Z. M. Zachara

Technical Information (5)

Publishing Coordination BE(2) 